\title{
Ion Channels in Genetic Epilepsy: From Genes and Mechanisms to Disease-Targeted Therapies
}

Julia Oyrer, Snezana Maljevic, Ingrid E. Scheffer, Samuel F. Berkovic, Steven Petrou, and Christopher A. Reid

The Florey Institute of Neuroscience and Mental Health, University of Melbourne, Parkville, Melbourne, Australia (J.O., S.M., I.E.S., S.P., C.A.R.); Department of Medicine, Austin Health, University of Melbourne, Heidelberg West, Melbourne, Australia (I.E.S., S.F.B.); and Department of Paediatrics, University of Melbourne, Royal Children's Hospital, Melbourne, Australia (I.E.S.)

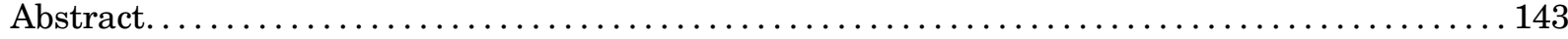

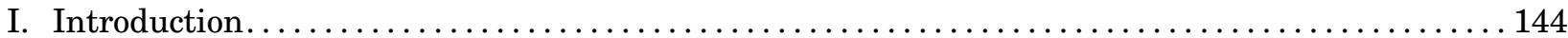

A. General Clinical Principles in Epilepsy.................................. 144

B. Genetic Architecture of Epilepsy .................................... 144

C. A Path for Translational Research in Genetic Epilepsy Caused by Mutations in Ion

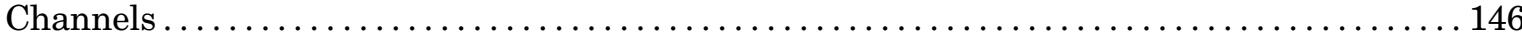

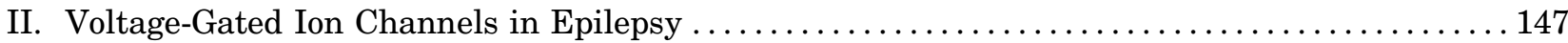

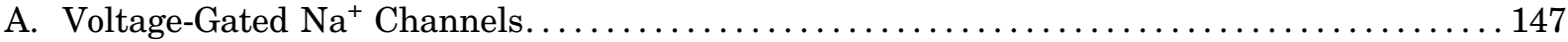

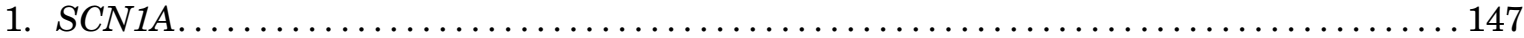

a. Clinical syndrome and molecular findings $\ldots \ldots \ldots \ldots \ldots \ldots \ldots \ldots \ldots \ldots \ldots \ldots \ldots \ldots \ldots$

b. Mechanisms and potential targeted therapies.......................... 149

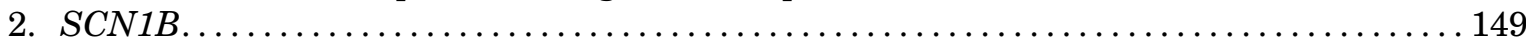

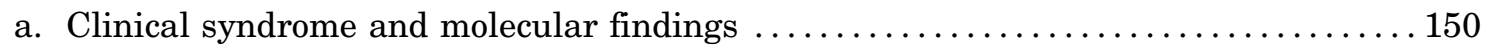

b. Mechanisms and potential targeted therapies............................ 150

3. SCN2A..................................................... 150

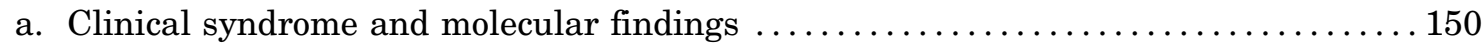

b. Mechanisms and potential targeted therapies........................... 151

4. SCN8A...................................................... 151

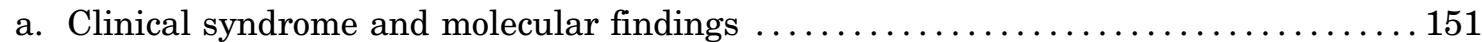

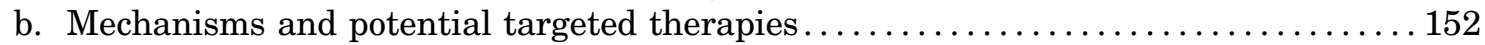

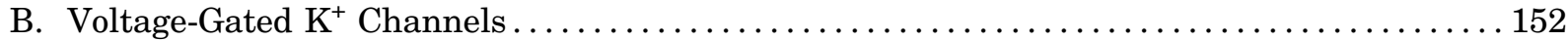

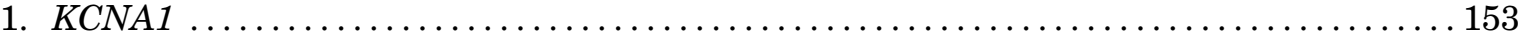

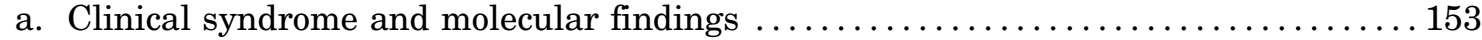

b. Mechanisms and potential targeted therapies............................ 153

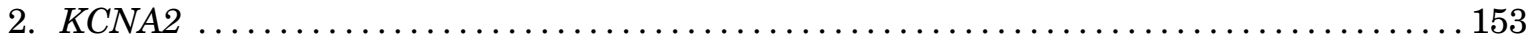

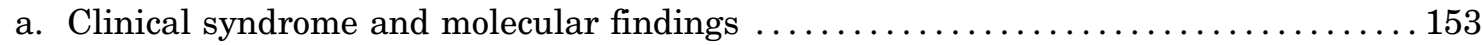

b. Mechanisms and potential targeted therapies............................ 154

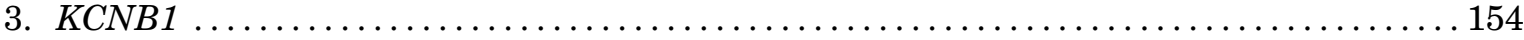

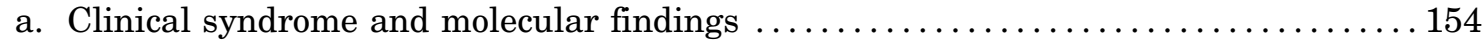

b. Mechanisms and potential targeted therapies.......................... 154

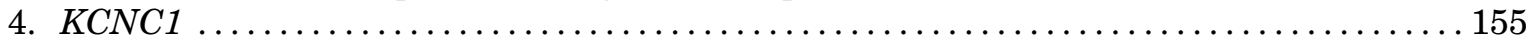

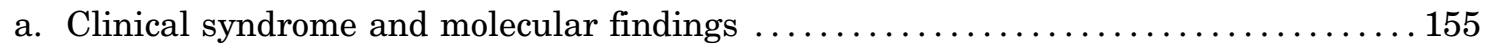

b. Mechanisms and potential targeted therapies............................ 155

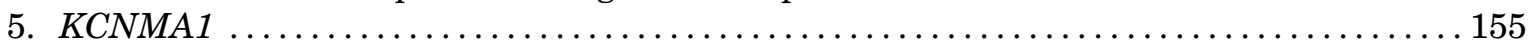

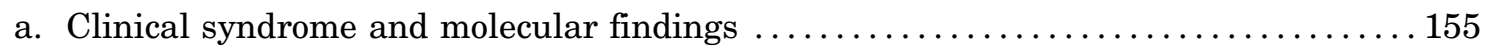

b. Mechanisms and potential targeted therapies.......................... 155

This work was supported by National Institutes of Health National Health and Medical Research Council Program [Grant 10915693 to S.F.B., I.E.S., S.P., and C.A.R.].

http://doi.org/10.1124/pr.117.014456.

Address correspondence to: Dr. Christopher A. Reid, Florey Neuroscience Institutes, University of Melbourne, Parkville, Victoria 3010, Australia. E-mail: christopher.reid@florey.edu.au 


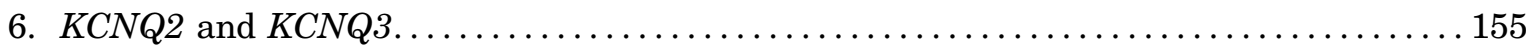

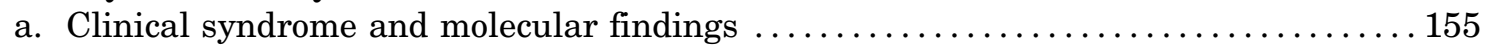

b. Mechanisms and potential targeted therapies......................... 156

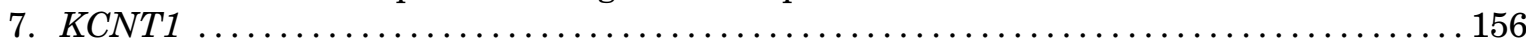

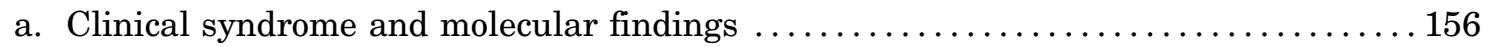

b. Mechanisms and potential targeted therapies......................... 156

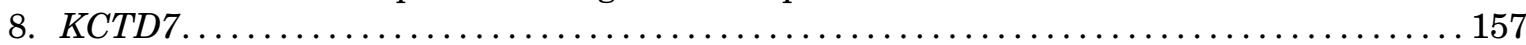

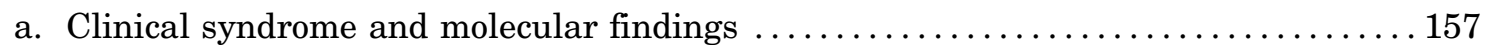

b. Mechanisms and potential targeted therapies.......................... 157

C. Hyperpolarization-Activated Cyclic Nucleotide-Gated Channel $1 \ldots \ldots \ldots \ldots \ldots \ldots \ldots \ldots 7$

1. Clinical Syndrome and Molecular Findings............................ 157

2. Mechanisms and Potential Targeted Therapies.......................... 158

D. Voltage-Gated Calcium Channels ...................................... 158

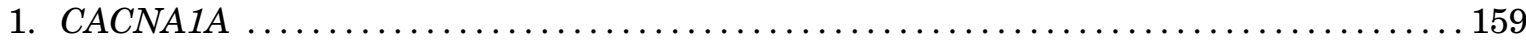

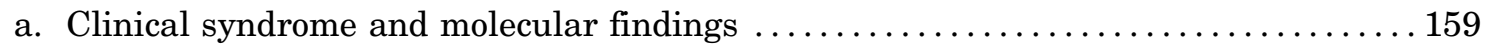

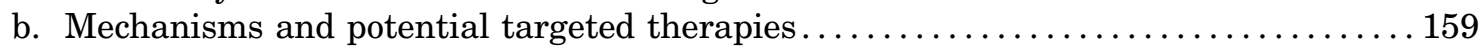

III. Ligand-Gated Ion Channels in Epilepsy...................................... 159

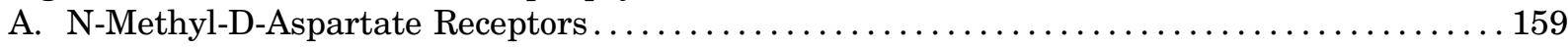

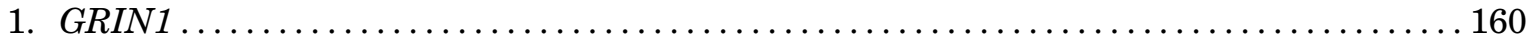

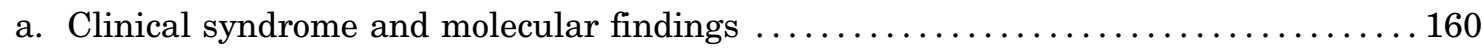

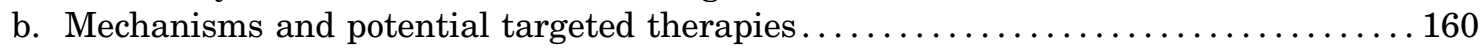

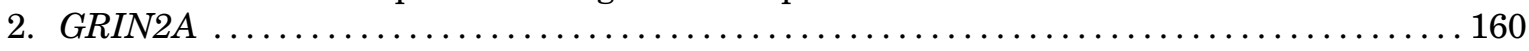

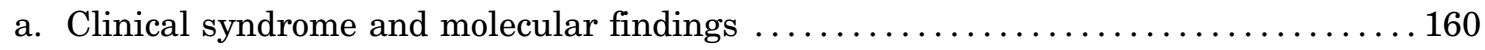

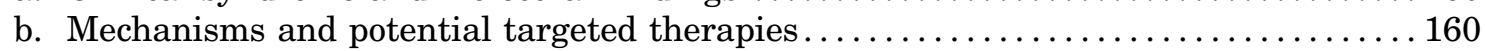

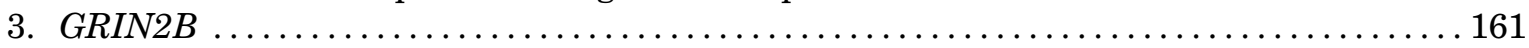

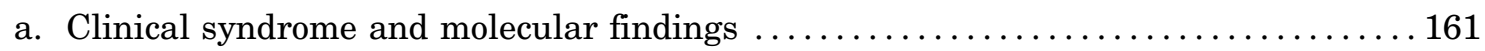

b. Mechanisms and potential targeted therapies.......................... 161

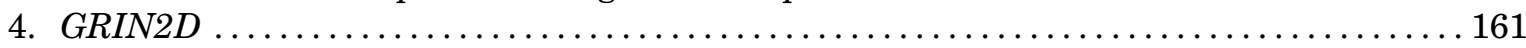

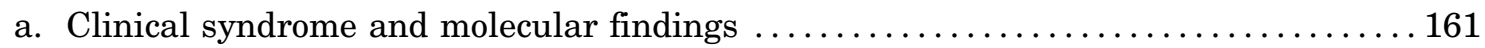

b. Mechanisms and potential targeted therapies.......................... 161

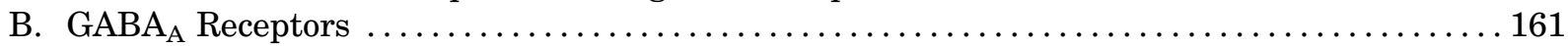

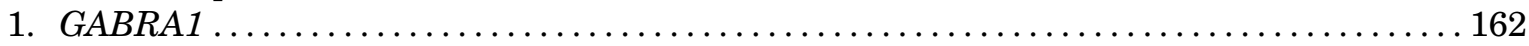

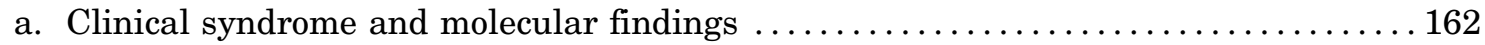

b. Mechanisms and potential targeted therapies............................ 162

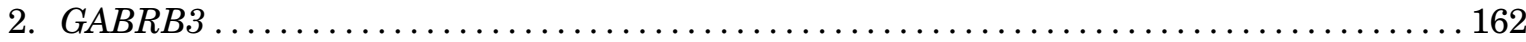

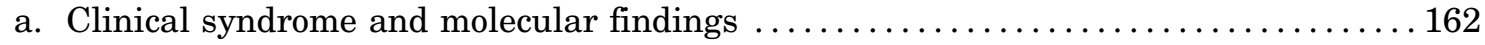

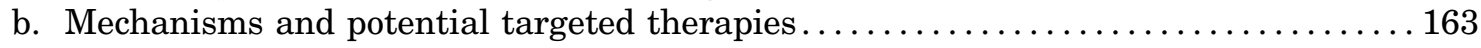

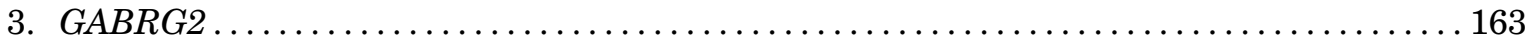

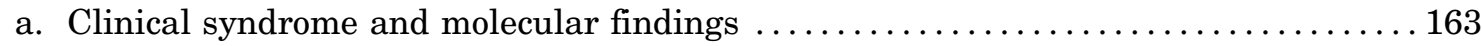

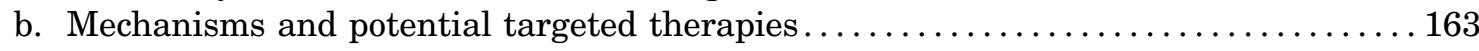

C. Nicotinic Acetylcholine Receptors (CHRNA4, CHRNB2, and CHRNA2) ............... 164

1. Clinical Syndrome and Molecular Findings.............................. 164

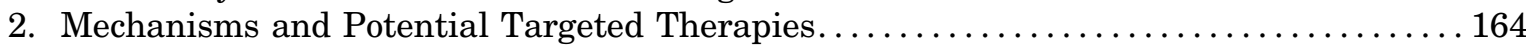

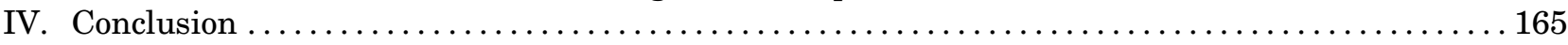

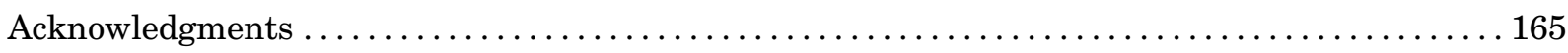

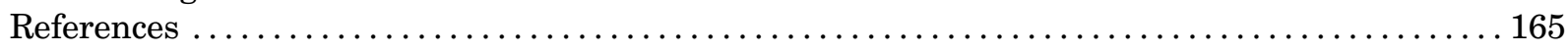

Abstract_-Epilepsy is a common and serious neurologic disease with a strong genetic component. Genetic studies have identified an increasing collection of disease-causing genes. The impact of these genetic discoveries is wide reaching-from precise diagnosis and classification of syndromes to the discovery and validation of new drug targets and the development of disease-targeted therapeutic strategies. About 25\% of genes identified in epilepsy encode ion channels. Much of our understanding of

ABBREVIATIONS: ADNFLE, autosomal dominant nocturnal frontal lobe epilepsy; CAE, childhood absence epilepsy; EEG, electroencephalography; GEFS ${ }^{+}$, genetic epilepsy with febrile seizures plus; GGE, genetic generalized epilepsy; HCN, hyperpolarization-activated cyclic nucleotide-gated; iPSC, induced pluripotent stem cell; JME, juvenile myoclonic epilepsy; nAChR, nicotinic acetylcholinergic receptor; NMDA, N-methyl-D-aspartate. 
disease mechanisms comes from work focused on this class of protein. In this study, we review the genetic, molecular, and physiologic evidence supporting the pathogenic role of a number of different voltage- and ligand-activated ion channels in genetic epilepsy. We also review proposed disease mechanisms for each ion channel and highlight targeted therapeutic strategies.

\section{Introduction}

Epilepsy, with a lifetime prevalence of $3 \%$, is a common and serious neurologic disease occurring due to either primary genetic determinants or as a consequence of a variety of metabolic and structural disorders of the brain. It is characterized by recurrent seizures resulting from hypersynchronous discharges. Despite optimal treatment with modern antiepileptic drugs, about one third of patients still continue to have seizures, and side effects from these drugs are common. Epilepsy was recognized to have a genetic component as early as 400 BC, when Hippocrates suggested that its origins may lie in heredity. The first gene for genetic epilepsy was identified in 1995 (Steinlein et al., 1995), with discoveries in subsequent decades slowly beginning to unravel the genetic basis of the epilepsies (Reid et al., 2009). More recently, a combination of improvements in gene-screening technologies, the creation of large international consortia, and use of more powerful bioinformatic tools has led to an explosion in the number of genes identified in epilepsy. This has allowed the mechanistic basis of human epilepsy to be probed in a way not previously possible.

\section{A. General Clinical Principles in Epilepsy}

Over 50 epilepsy syndromes are described, and they are broadly divided into focal (formerly partial) and generalized epilepsies based on the concept that the former have seizures generated in a local unilateral network, whereas the generalized epilepsies have seizures generated within bilateral networks. Focal epilepsies more often have a macroscopic structural abnormality as the primary underlying cause. The classification of epilepsy and seizure types has recently been revised (Fisher et al., 2017; Scheffer et al., 2017). Diagnosis begins with seizure type(s), and then, where sufficient electroclinical information is available, an epilepsy type can be defined that may be focal, generalized, combined focal and generalized, or unknown. A further aspect of classification is the epilepsy syndrome based on a combination of epilepsy type, etiology (genetic, structural, infectious, metabolic, immune), and comorbidities (e.g., developmental delay, autism spectrum disorders, intellectual disability).

The broad group of generalized epilepsies is largely comprised of genetic generalized epilepsy (GGE), which is also known as idiopathic generalized epilepsy. These are a family of related syndromes, typically beginning in childhood or adolescence and associated with a characteristic electroencephalography (EEG) pattern of generalized spike-and-wave discharges.
Patients have combinations of absence, myoclonic, and tonic-clonic seizures, and the four classic GGE syndromes are childhood absence epilepsy (CAE), juvenile absence epilepsy, juvenile myoclonic epilepsy (JME), and generalized tonic-clonic seizures alone (Scheffer et al., 2017). Rarer genetic epilepsy syndromes include many epileptic encephalopathy syndromes, with refractory seizures and overall developmental delay (McTague et al., 2016). In this review, we highlight specific epilepsy syndromes associated with mutations in a given gene. Table 1 summarizes the clinical aspects of the epilepsy genes discussed, including their Online Mendelian Inheritance in Man number.

\section{B. Genetic Architecture of Epilepsy}

A clearer picture is emerging of epilepsies as a collection of distinct genetically defined disorders. Many of the early gene discoveries were made in familial epilepsies. Data from large families allowed for genetic linkage, with the subsequently identified pathogenic variant running through affected members like a golden thread. More recent studies suggest that many severe epilepsies beginning in infancy and childhood, especially the developmental and epileptic encephalopathies, are due to de novo mutations (absent in both parents) (Allen et al., 2013).

Somatic mosaicism is a concept that is becoming increasingly relevant in neurologic disease (Poduri et al., 2013). In this case, an individual has at least two cell populations with different genotypes. Improved genetic screening methods have allowed for better detection of mosaicism. Somatic mutations can arise at any time during brain development to cause epilepsy. The pathogenic outcome depends on the proportion and cell types affected. It is important to note that unaffected parents, who are germline mosaics for a pathogenic variant, can pass the mutation onto their affected children. The percentage mosaicism in the parental lymphocyte DNA may reflect their extent of affectedness. This has been shown in studies of Dravet children with inherited SCN1A mutations from mosaic parents. Parents who were $<45 \%$ mosaic were unaffected, whereas those with $>45 \%$ mosaicism were affected, and the severity of their epilepsy correlated with their percentage mosaicism (Depienne et al., 2010).

In contrast to rare epilepsies, an understanding of the genetic architecture of more common epilepsies has lagged. GGE has a complex inheritance pattern likely caused by a contribution of multiple susceptibility alleles, or de novo mutations in some cases. There is debate as to whether the genetic contribution is largely 
TABLE 1

Ion channel genes mutated in epilepsy, functional impact, and available mouse models

\begin{tabular}{|c|c|c|c|c|c|}
\hline Gene & Protein & Phenotype & OMIM Nr & $\begin{array}{c}\text { Functional } \\
\text { Impact }\end{array}$ & Human Mutation-Based Mouse Models \\
\hline $\begin{array}{l}\text { Voltage-Gated } \\
\text { SCN1A }\end{array}$ & $\mathrm{Na}_{V} 1.1$ & Dravet syndrome; GEFS ${ }^{+}$ & 182389 & LOF & $\begin{array}{l}\text { R1407X (Yu et al., 2006); } \\
\text { R1648H (Martin et al., 2010) }\end{array}$ \\
\hline$S C N 1 B$ & $\mathrm{Na}_{v} \beta 1$ & $\begin{array}{l}\text { GEFS }^{+} \text {, temporal lobe epilepsy, an } \\
\text { early infantile epileptic } \\
\text { encephalopathy }\end{array}$ & 600235 & LOF & C121W (Wimmer et al., 2010) \\
\hline$S C N 2 A$ & $\mathrm{Na}_{\mathrm{V}} 1.2$ & $\begin{array}{l}\text { BFNIE, early-onset epileptic } \\
\text { encephalopathies, } \\
\text { neurodevelopmental disorders }\end{array}$ & 182390 & GOF LOF & A263V (Schattling et al., 2016) \\
\hline$S C N 8 A$ & $\mathrm{Na}_{\mathrm{v}} 1.6$ & BFIE, epileptic encephalopathy & 600702 & GOF & N1768D (Lopez- Santiago et al., 2017) \\
\hline KCNA1 & $\mathrm{K}_{\mathrm{V}} 1.1$ & $\begin{array}{l}\text { Partial epilepsy and episodic } \\
\text { ataxia }\end{array}$ & 176260 & LOF & V408A (Herson et al., 2003) \\
\hline KCNA2 & $\mathrm{K}_{\mathrm{V}} 1.2$ & Epileptic encephalopathy & 176262 & GOF LOF & \\
\hline KCNB1 & $\mathrm{K}_{\mathrm{V}} 2.1$ & Epileptic encephalopathy & 600397 & LOF & \\
\hline KCNC1 & $\mathrm{K}_{\mathrm{V}} 3.1$ & Progressive myoclonus epilepsy & 176258 & LOF & \\
\hline KCNMA1 & $\mathrm{K}_{\mathrm{Ca}} \mathrm{l} .1$ & $\begin{array}{l}\text { Epilepsy and paroxysmal } \\
\text { dyskinesia }\end{array}$ & 600150 & LOF & \\
\hline KCNQ2 & $\mathrm{K}_{\mathrm{V}} 7.2$ & BFNE, epileptic encephalopathy & 602235 & GOF LOF & A306T (Singh et al., 2008) \\
\hline KCNQ3 & $\mathrm{K}_{\mathrm{V}} 7.3$ & BFNE & 602232 & GOF LOF & G311V (Singh et al., 2008) \\
\hline KCNT1 & $\mathrm{K}_{\mathrm{Na}} \mathrm{l} .1$ & ADNFLE, EIMFS & 608167 & GOF & \\
\hline KCTD7 & KCTD7 & Progressive myoclonus epilepsy & 611725 & LOF & \\
\hline HCN1 & HCN1 & $I G E$ & 602780 & GOF LOF & \\
\hline CACNA1A & $\mathrm{Ca}_{\mathrm{V}} 2.1$ & $\begin{array}{l}\text { Epilepsy, episodic ataxia, epileptic } \\
\text { encephalopathy }\end{array}$ & 601011 & $\mathrm{LOF}$ & \\
\hline$C A C N A 1 H$ & $\mathrm{Ca}_{\mathrm{V}} 3.2$ & GGE & 607904 & GOF & \\
\hline \multicolumn{6}{|l|}{ Ligand-Gated } \\
\hline GRIN1 & GluNl & Epileptic encephalopathy & 138249 & LOF & \\
\hline GRIN2A & GluN2A & Epileptic encephalopathy & 138253 & GOF LOF & \\
\hline GRIN2B & GluN2B & Epileptic encephalopathy & 138252 & GOF LOF & \\
\hline GRIN2D & GluN2D & Epileptic encephalopathy & 602717 & GOF & \\
\hline GABRA1 & GABRA1 & GGE, epileptic encephalopathy & 137160 & LOF & A322D (Arain et al., 2015) \\
\hline$G A B R B 3$ & GABRB3 & CAE, epileptic encephalopathy & 137192 & LOF & \\
\hline GABRG2 & GABRG2 & FS/GEFS ${ }^{+}$, epileptic encephalopathy & 137164 & LOF & $\begin{array}{l}\text { R43Q (Tan et al., 2007); } \\
\text { Q390X (Kang et al., 2015) }\end{array}$ \\
\hline CHRNA2 & CHRNA2 & ADNFLE & 118502 & & \\
\hline CHRNA4 & CHRNA4 & ADNFLE & 118504 & GOF & $\begin{array}{l}\text { S252F (Klaassen et al., 2006); } \\
\quad+\text { L264 (Klaassen et al., 2006) }\end{array}$ \\
\hline CHRNB2 & CHRNB2 & ADNFLE & 605375 & GOF & \\
\hline
\end{tabular}

BFIE, benign familial infantile epilepsy; BFNIE, benign familial neonatal-infantile epilepsy; EIMFS, epilepsy of infancy with migrating focal seizures; FS, febrile seizures GOF, gain-of-function; LOF, loss-of-function; OMIM, Online Mendelian Inheritance in Man.

from numerous common variants of small effect, discoverable by Genome Wide Association Studies (International League Against Epilepsy Consortium on Complex Epilepsies, 2014) or from rare variants of larger effect detectable by massively parallel sequencing. Recent evidence argues that a proportion of GGE is contributed to by ultra-rare variants in known epilepsy genes (Epi4K Consortium and Epilepsy Phenome/ Genome Project, 2017). To date, rare structural genomic variants, including microdeletions at $15 q 13.3,15 q 11.2$, and $16 \mathrm{p} 13.11$, are the most common identified genetic risk factors for GGE, considerably increasing genetic risk (Dibbens et al., 2009; Helbig et al., 2009, 2013; de Kovel et al., 2010). There is also increasing evidence for the genetic basis of focal epilepsies, traditionally believed to be due to acquired insults. This was first appreciated in clinical studies of small and large families (Scheffer et al., 1998; Dibbens et al., 2013), but more recently, clear signals from exome-sequencing studies indicate a genetic component to focal epilepsy that falls outside the familial setting (Epi4K Consortium and Epilepsy Phenome/Genome Project, 2017). Therefore, although it is difficult to establish an exact proportion, it is becoming increasingly clear that genetic factors play a significant pathogenic role in a majority of the epilepsies (Thomas and Berkovic, 2014).

Early gene discovery implicated mostly ion channels and raised the concept that the genetic epilepsies were likely to be a family of channelopathies (Wallace et al., 1998; Reid et al., 2009). Although this concept has evolved, with many biologic pathways now implicated in disease, ion channels still account for a significant proportion of known genetic epilepsies (Fig. 1). As such, there is a rich literature that has begun to unravel the molecular, cellular, and neuronal network mechanisms underlying genetic epilepsy caused by mutations in ion channels. This is laying the foundation for the development of disease-targeted therapy in the genetic epilepsies. In this review, we focus on ion channels as an exemplar of how genetic discoveries have driven basic science, and how the circle back to the clinic is beginning to close (Fig. 2). 


\section{Epilepsy genes}

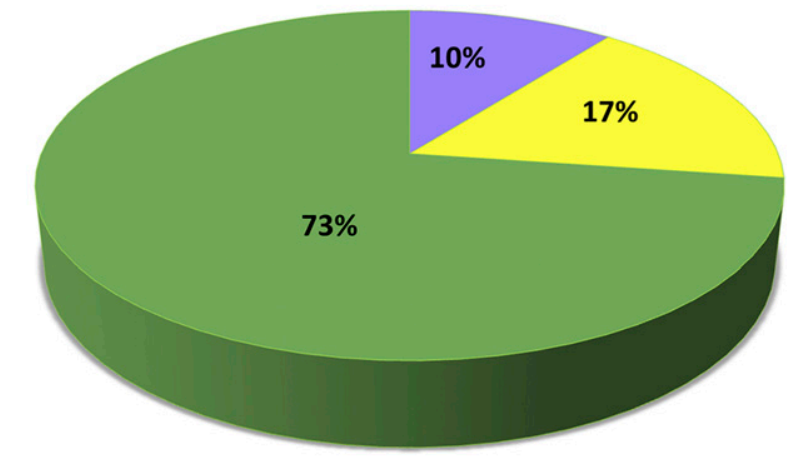

= Ligand gated ion channel genes $\square$ Voltage gated ion channel genes

m Other epilepsy genes

Fig. 1. Visualization showing the contribution of ion channels to genetic epilepsy.

\section{A Path for Translational Research in Genetic Epilepsy Caused by Mutations in Ion Channels}

A mutation in a protein can have its impact on both temporal and spatial scales, and understanding the cellular consequence of these changes is central to our understanding, and eventual treatment, of epilepsy. A translational pathway is beginning to develop based on the use of several experimental platforms (Fig. 2). The mainstay of current discovery uses heterologous expression systems, including Xenopus laevis oocytes or human embryonic kidney cell models. These platforms have the significant advantage of providing an opportunity to investigate protein function in isolation. Electrophysiological methods provide the gold standard for studying ion channels, giving good signal-tonoise and temporal resolution. Much of what we know about the molecular basis of disease has been developed on these platforms. If mutations in a single gene give rise to a common functional consequence, this provides a strong target for therapy. However, as will become apparent, this is not always the case. It is important to note that these platforms cannot report on the cellular components that drive neuronal hyperexcitability. Ion channels in particular operate in very specialized and interactive temporal and spatial domains. For example, $\mathrm{Na}^{+}$channels work with $\mathrm{K}^{+}$ channels in a dynamic manner to generate action potentials. Another important reason that these simple functional assays may not be predictive is that they are opaque to cell compartment-specific trafficking deficits and emerging pathologies. Much mechanistic insight has come from animal models of epilepsy based on genetic manipulation that can, at least partially, overcome these issues.

Genetic rodent models provide a major experimental avenue for dissecting out cellular and neuronal network mechanisms of disease. They also provide invaluable preclinical tools that can be used to test both targeted precision medicine and general therapeutic approaches. Initially, it is worth stipulating what we require our animal models to deliver for them to serve as valid tools for investigating human epilepsy. A good model of disease would be expected 1) to be based on a known human genetic lesion, 2) to recapitulate the seizure phenotypes represented in the epilepsy patients, including their pharmacosensitivity, and 3) to model comorbidities. For variants that cause definitive loss-of-function, traditional knockout mice can be effective models of disease. However, even in this case, the position that a truncation occurs in a gene can be a critical component of the underlying pathogenic mechanism. For example, truncated protein products expressing functional domains may act in a dominant-negative manner, impacting other proteins to cause disease. As such, the new gold standard in genetic research is to engineer knock-in mice based on human mutations. These syndrome-specific models more often recapitulate the epilepsy phenotypes noted in humans, making them good preclinical models that are ideal for investigating disease mechanisms (e.g., Kearney et al., 2001; Yu et al., 2006; Kalume et al., 2007; Ogiwara et al., 2007; Tan et al., 2007; Oakley et al., 2009; Martin et al., 2010; Wimmer et al., 2010; Kang et al., 2015; Wagnon et al., 2015b).

It is important to note that mice lack the neuronal complexity seen in the primate brain, and that knock-in mouse models do not always recapitulate the human disease. It follows that although these approaches represent the most useful methods we have for identifying the mechanistic causes of genetic epilepsy, we need to continue to develop new methods and models (Maljevic et al., 2017). Induced pluripotent stem cell (iPSC) technology provides an avenue in which neurons can be derived directly from patient tissue. Several recent reports have demonstrated the utility of this approach in neurologic disorders, including epilepsy (Parent and Anderson, 2015; Barral and Kurian, 2016; Sun et al., 2016), suggesting that iPSC-based methods are likely to become an important part of the diseasemechanism discovery toolkit.

In the remaining part of this review, we will outline the genetic, molecular, cellular, and behavioral evidence that is used in identifying mechanisms of disease. A cartoon representing the major epilepsy proteins and where they reside on both excitatory and inhibitory neurons is presented in Fig. 3. Although the molecular mechanisms are discussed in terms of gain- and loss-offunction, we accept that in many cases this represents an oversimplification. More complex distinctions will evolve as models of disease for each gene develop. However, in pragmatic terms, this distinction provides a useful way to represent general principles of disease mechanisms and has already helped in defining disease classes caused by different variants within single genes (Wolff et al., 2017). 


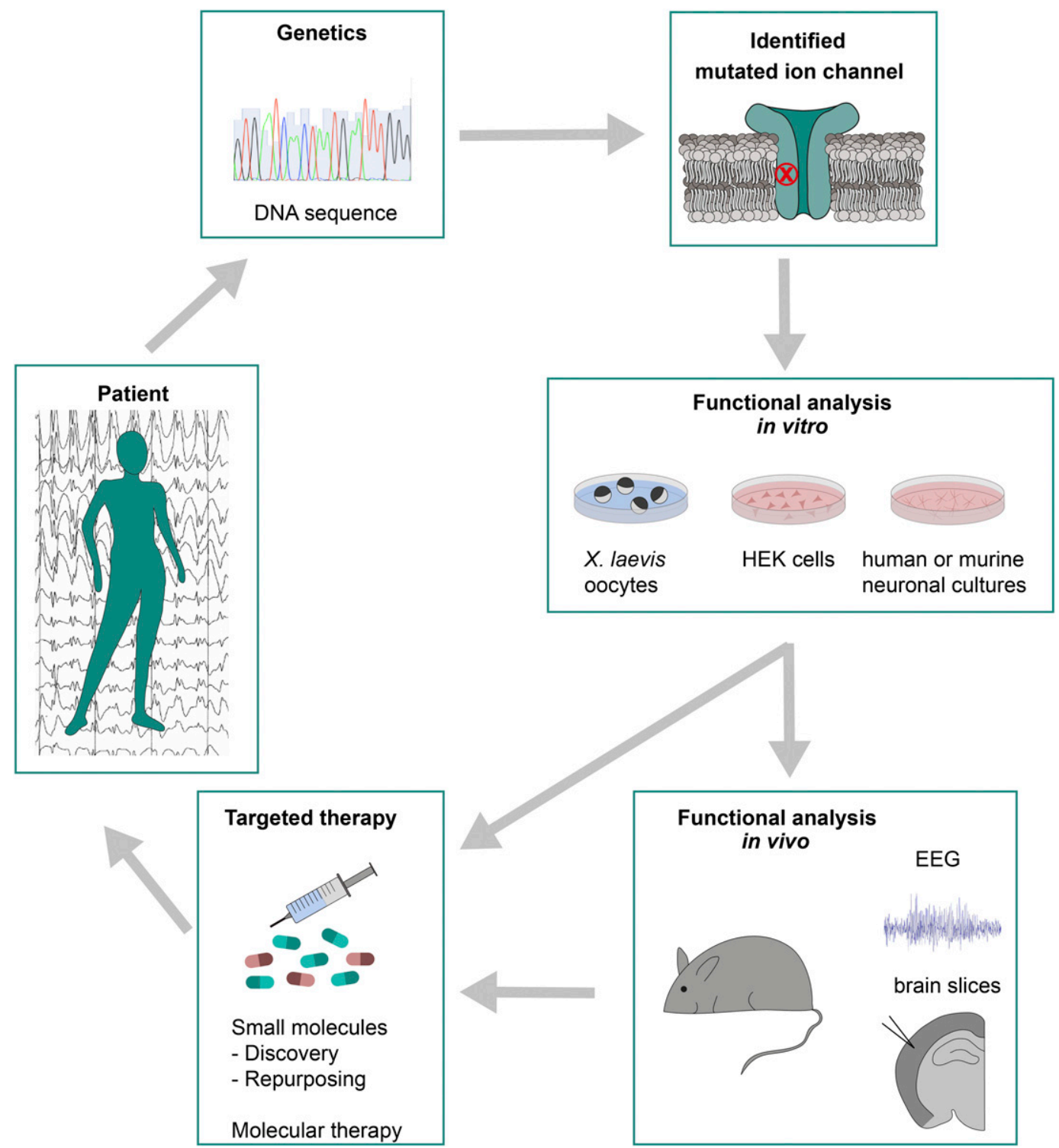

Fig. 2. Schematic illustrating a path to the development of targeted therapeutic strategies in genetic epilepsy. Genetic screening is identifying large numbers of causative mutations. For ion channels, functional analysis usually involves electrophysiological recordings. Knock-in mice based on human mutations provide good preclinical models on which disease mechanisms can be determined and on which treatments can be tested. This can lead to the development of various targeted therapies that can be based on small molecules or newer molecular techniques.

\section{Voltage-Gated Ion Channels in Epilepsy}

\section{A. Voltage-Gated $\mathrm{Na}^{+}$Channels}

The primary role of voltage-gated $\mathrm{Na}^{+}$channels is in the initiation and propagation of action potentials, making them critical determinants of neuronal excitability (Alexander et al., 2015a; www.guidetopharmacology.org/ GRAC/FamilyDisplayForward?familyId=82). Nine genes encode the pore-forming $\alpha$-subunits, with four genes encoding the ancillary $\beta$-subunits. The $\alpha$-subunits have a tetrameric structure comprising four homologous domains (I-IV), each with six transmembrane segments (S1-S6), encoded by a single gene. They are usually associated with one or more $\beta$-subunits, transmembrane proteins with a single extracellular loop that influence $\alpha$-subunit localization and function (Catterall et al., 2005).
To date, mutations have been identified in three major pore-forming $\alpha$-subunits found in the brain, and in one of the $\beta$-subunits.

1. SCN1A. SCN1A encodes the $\mathrm{Na}_{\mathrm{V}} 1.1$ subunit expressed predominantly in inhibitory GABAergic neurons and is enriched at the axon initial segment, implicating a role in the initiation and propagation of action potentials in these cells (Yu et al., 2006; Ogiwara et al., 2007; Duflocq et al., 2008).

a. Clinical syndrome and molecular findings. Since first discovered in 2000, several hundred SCN1A mutations have been described in epilepsy, making it the most common known epilepsy gene (Oliva et al., 2012). Missense mutations are associated with genetic (previously generalized) epilepsy with febrile seizures 


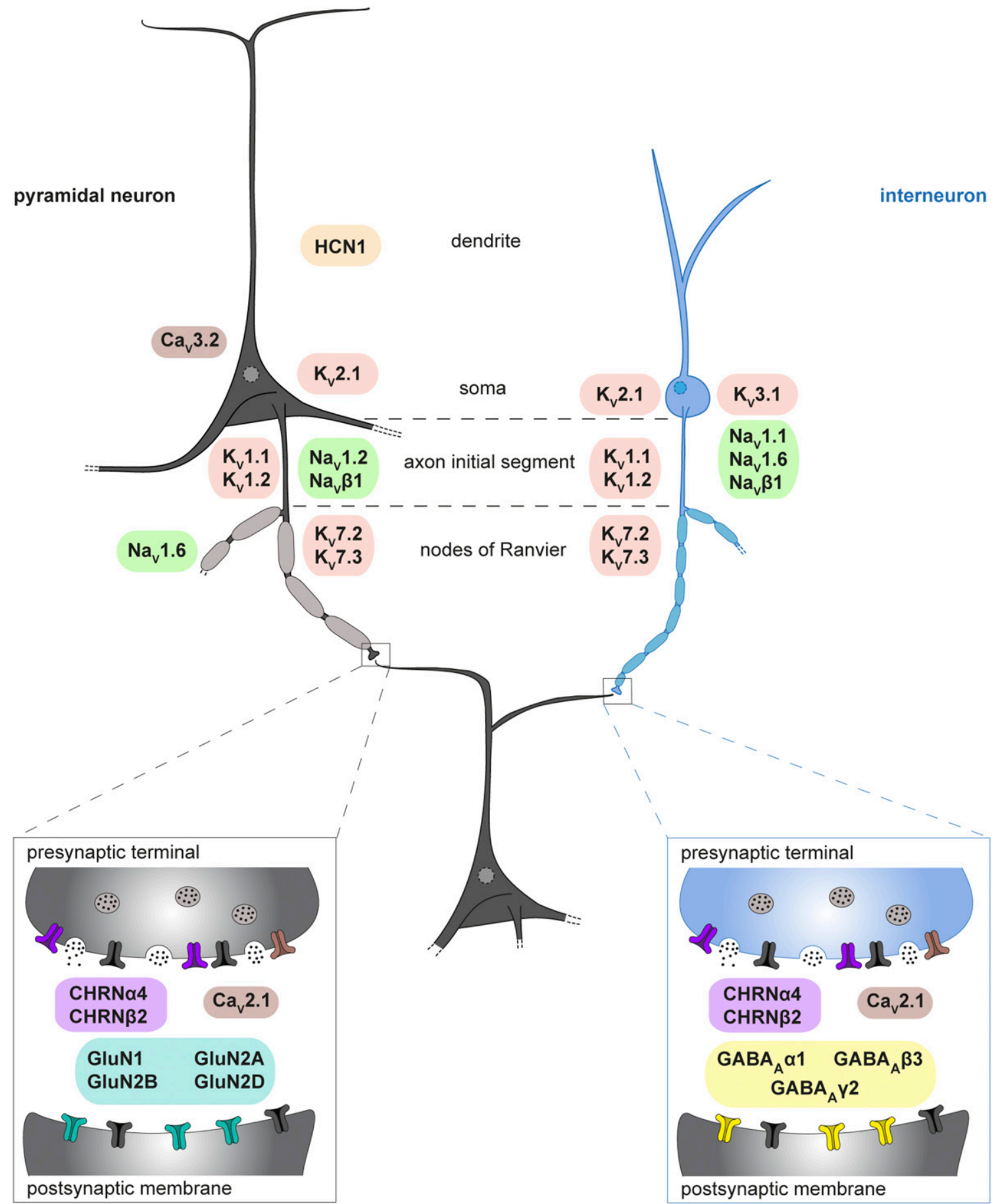

Fig. 3. Cartoon illustrating the known expression patterns of ion channels implicated in genetic epilepsy. Gene groups are represented by different colors.

plus $\left(\mathrm{GEFS}^{+}\right)$. This is a familial syndrome in which affected individuals have a variety of epilepsy phenotypes, including febrile seizures, febrile seizures plus, and febrile seizures associated with absence, myoclonic, and even focal seizures. Seizures typically continue into later childhood or adolescence, where they usually resolve (Scheffer and Berkovic, 1997; Singh et al., 1999).

At the more severe end of the $\mathrm{GEFS}^{+}$phenotypic spectrum, patients harboring SCN1A mutations suffer from Dravet syndrome (Claes et al., 2001; Harkin et al., 2007; Scheffer et al., 2009; Escayg and Goldin, 2010). This devastating disease begins with prolonged seizures with fever at about age 6 months, followed by multiple seizure types, developmental regression, and gait abnormalities (Scheffer, 2012; McTague et al., 2016). Dravet syndrome usually occurs as a sporadic disorder with de novo mutations. Approximately half the mutations are missense mutations, and half predict 
protein truncation with deletions of whole exons, multiple exons, or, more rarely, the whole gene (Claes et al., 2001; Ohmori et al., 2002, 2006; Fujiwara et al., 2003; Nabbout et al., 2003; Kearney et al., 2006; Madia et al., 2006; Mulley et al., 2006; Suls et al., 2006; Marini et al., 2011). Although several biophysical changes that suggest increased channel function have been reported for GEFS $^{+}$SCN1A missense mutations (Spampanato et al., 2001, 2004a,b; Cossette et al., 2003; Kahlig et al., 2006), the prevailing view is that loss-of-function is the likely basis of disease in most cases. Indeed, this is selfevident in cases with haploinsufficiency due to truncation variants.

b. Mechanisms and potential targeted therapies. The Nav1.1 knockout mouse models the loss-of-function mutations suggested by molecular studies (Yu et al., 2006). In some genetic backgrounds, heterozygous mice develop spontaneous seizures and sporadic death, reflecting the severity of the disease in humans. Recordings from this mouse model indicated that, although $\mathrm{Na}^{+}$currents were essentially unchanged in hippocampal excitatory pyramidal neurons, the current was substantially reduced in inhibitory GABAergic interneurons. This reduction is responsible for the collapse of action potentials at higher firing frequencies and occurs only in inhibitory neurons (Yu et al., 2006). Similarly, a pronounced action potential attenuation during continuous firing was seen in fast-spiking parvalbumin-positive inhibitory interneurons of heterozygous $\mathrm{Na}_{V} 1.1$ (R1407X) knock-in mice carrying a truncating mutation (Ogiwara et al., 2007). The $\mathrm{Na}_{\mathrm{V}} 1.1$ (R1648H) mouse model based on a GEFS $^{+}$ mutation also had impaired GABAergic interneuron function (Martin et al., 2010; Hedrich et al., 2014). Furthermore, using a conditional mouse model, it was possible to show that the selective deletion of $\mathrm{Na}_{\mathrm{V}} 1.1$ in GABAergic inhibitory neurons was sufficient to cause a Dravet-like phenotype (Cheah et al., 2012). Even though early studies using human iPSC cells from Dravet patients produced mixed results (Higurashi et al., 2013; Jiao et al., 2013; Liu et al., 2013a), more recent work based on differentiating iPSCs into telencephalic excitatory neurons or medial ganglionic eminence-like inhibitory neurons demonstrates an inhibitory neuron deficit (Liu et al., 2016; Sun et al., 2016). Taken together, these data provide convincing evidence that an inability of GABAergic interneurons to fire robustly results in hyperexcitability, leading to seizures in Dravet syndrome.

The Nav1.1 knockout-based Dravet mouse models recapitulate many of the pharmacosensitivity profiles seen in patients. A loss of GABAergic inhibitory neuron function may provide a basis for the seizure aggravation properties of $\mathrm{Na}^{+}$channel-blocking agents, such as lamotrigine, carbamazepine, and phenytoin, often observed in Dravet syndrome (Guerrini et al., 1998). In this study, the block by these drugs of already compromised
$\mathrm{Na}^{+}$channel function in GABAergic interneurons would be expected to further enhance network excitability. Consistent with this, $\mathrm{Na}^{+}$channel blockers were not effective or exacerbated seizures in a Nav1.1 knockout model of Dravet (Hawkins et al., 2017). The Nav1.1 knockout-based Dravet mouse models also respond well to stiripentol and clobazam, which are commonly used as first drugs in this disease (Chiron and Dulac, 2011; Cao et al., 2012; Oakley et al., 2013; Hawkins et al., 2017). This provides confidence in the preclinical value of such mouse models.

Understanding the molecular, cellular, and network consequences of harboring SCN1A mutations allows predictive design of targeted therapies. The most obvious strategy would be to selectively enhance $\mathrm{Na}_{v} 1.1$ function. Peptides with these properties exist (Osteen et al., 2016). Small molecules (AA43279) with the desired properties have also been reported (Frederiksen et al., 2017). Another approach that restores $\mathrm{Na}_{\mathrm{v}} 1.1$ activity is to take advantage of the recently discovered natural regulatory mechanism based on inhibitory long noncoding RNA. Oligonucleotides designed to block this site enhance $\mathrm{Na}_{\mathrm{V}} 1.1$ expression and, at least partially, rescued the seizure phenotype in a mouse model of Dravet (Hsiao et al., 2016). Other strategies could include enhancing GABAergic inhibitory neuron function through secondary mechanisms. For example, the selective activation of $K_{\mathrm{V}} 3.1$ channels that underlie fast-spiking in certain GABAergic inhibitory neurons may help sustain activity and consequently reduce seizure susceptibility.

A number of strategies that are not disease-target based have been tried in mouse models of Dravet. For example, GS967, a drug that preferentially blocks persistent $\mathrm{Na}^{+}$current, is very effective in reducing seizures and death in a $\mathrm{Na}_{\mathrm{V}} 1.1$ knockout mouse model (Anderson et al., 2017). These mice could also provide a robust model on which to determine the mechanism of action of newer drugs used in the disease. For example, the amphetamine analog, fenfluramine, has been used with some success in a few Dravet patients, but the mechanistic basis of efficacy remains unknown (Schoonjans et al., 2017). These preclinical rodent models can also be used to inform already completed clinical studies. For instance, cannabidiol has recently been shown to be effective in Dravet syndrome, but its mechanism is unknown; interpretation is confounded by the fact that patients were already on several other antiepileptic drugs (Devinsky et al., 2017). Validated preclinical models provide a mechanism for testing drugs in isolation and/or in combination with other drugs (Hawkins et al., 2017), something that is difficult in humans. In summary, patients with SCN1A-based disease are well placed to significantly benefit from disease-targeted therapeutic strategies.

2 . SCN1B. $\quad S C N 1 B$ encodes the $\beta 1$-ancillary subunit of $\mathrm{Na}^{+}$channels. The $\beta$-subunits are multifunctional, 
modulating channel gating, regulating the level of channel expression, and potentially acting as cell adhesion molecules (Isom, 2002). These proteins are found in high abundance in several brain regions and are enriched at axon initial segments and nodes of Ranvier of both excitatory and inhibitory neurons (Wimmer et al., 2015).

a. Clinical syndrome and molecular findings. Heterozygous mutations in $S C N 1 B$ that are located mostly in the immunoglobulin-like extracellular domain of the protein have been described in families with $\mathrm{GEFS}^{+}$(Wallace et al., 1998; Audenaert et al., 2003; Scheffer et al., 2007). Patients harboring SCN1B mutations seem to be at greater risk of developing temporal lobe epilepsy (Scheffer et al., 2007). Also, there are now several reports of homozygous SCN1B mutations causing an early infantile epileptic encephalopathy with features that strongly resemble Dravet syndrome (Patino et al., 2009; Ramadan et al., 2017).

Functional analysis has uniformly ascribed a loss-offunction to mutations in $S C N 1 B$ associated with epilepsy (reviewed in Reid et al., 2009; O'Malley and Isom, 2015 ). However, given that the $\beta 1$-subunit is not poreforming, the consequent impact on neuronal function is more difficult to interpret. Coexpression with other pore-forming $\alpha$-subunits suggests that the loss of modulatory action of the $\beta 1$-subunit can increase excitability through various biophysical mechanisms, including slowing of inactivation, increased availability of channels at hyperpolarized potentials, and reduction in channel rundown during high-frequency activation (Wallace et al., 1998; Meadows et al., 2002; Thomas et al., 2007; Xu et al., 2007). Protein dysfunction is not limited to altered channel kinetics, with a cell adhesion assay indicting a disruption in the ability of mutated $\beta$-subunits to mediate protein-protein interactions (Kruger et al., 2016).

b. Mechanisms and potential targeted therapies. The SCN1B (C121W) knock-in mouse model is based on a $\mathrm{GEFS}^{+}$mutation and recapitulates the febrile seizure phenotype seen in patients (Wimmer et al., 2010; Kruger et al., 2016). A temperature-sensitive increase in axon initial segment excitability was observed, consistent with the exclusion of the mutant protein from this neuronal compartment (Wimmer et al., 2010). It is important to note that a more pronounced febrile seizure phenotype is observed in SCN1B (C121W) mice when compared with SCN1B knockout mice. This suggests that the SCN1B (C121W) epilepsy mutation has an impact over and above simple haploinsufficiency (loss of one allele) that may be related to the $\beta 1$ protein's adhesion role (Kruger et al., 2016). The multiple biologic roles of $\beta 1$ make it difficult to devise a therapeutic strategy that would best target heterozygous disease.

Homozygous $S C N 1 B$ variants are associated with severe epilepsy phenotypes (Patino et al., 2009; Ramadan et al., 2017). This is seen in both the homozygous
SCN1B knockout (Chen et al., 2004) and the SCN1B (C121W) mouse models (Reid et al., 2014), with both having a severe phenotype similar to Dravet syndrome. The homozygous SCN1B (C121W) mouse shows a significant reduction in dendritic branching consistent with a defect in $\beta 1$-mediated cell-cell adhesion (Chen et al., 2004; Davis et al., 2004; Reid et al., 2014). The contraction of the dendritic arbor increases the electrical compactness of the hippocampal neurons, which results in an increase in the voltage depolarization caused by excitatory synaptic input, increasing both the likelihood of action potential firing and consequently network excitability (Reid et al., 2014). Although it is not feasible to correct the morphologic deficit in the SCN1B $(\mathrm{C} 121 \mathrm{~W})$ mouse, the addition of the $\mathrm{K}^{+}$channel activator, retigabine, is able to reverse the impact on electrical compactness, providing a potential targeted therapy. In keeping with this, retigabine is very effective at reducing febrile seizure susceptibility in the homozygous SCN1B (C121W) mouse model of Dravet (Reid et al., 2014).

The severe seizure and comorbid phenotypes observed in both $\mathrm{Na}_{\mathrm{V}} 1.1$ and homozygous SCN1B (C121W) knock-in mouse models recapitulate several features of Dravet syndrome, suggesting that both are good models of the disease (Yu et al., 2006; Reid et al., 2014). Comparisons between these models of Dravet highlight an important concept in genetic epilepsy. Genetic heterogeneity is a phenomenon in which a single disease phenotype may be caused by mutations in different genes. As discussed above, mutations in $S C N 1 A$ are the most common genetic cause of Dravet syndrome in which an inhibitory neuron deficit is the well-established disease mechanism. In contrast, no inhibitory neuron deficit is seen in the homozygous SCN1B (C121W) mouse model, indicating that two very different cellular mechanisms can underlie the same epilepsy syndrome. This has clear implications for targeted therapy, with different strategies possibly required for the same syndrome depending on the causative gene.

3. SCN2A. SCN2A encodes the $\mathrm{Na}_{\mathrm{V}} 1.2$ subunit that is expressed predominantly in excitatory neurons, particularly in the proximal axon initial segment, where it is proposed to play an important role in promoting back propagation to the soma and dendrites (Westenbroek et al., 1989; Hu et al., 2009).

a. Clinical syndrome and molecular findings. For a long time, SCN2A mutations were thought to only associate with benign familial neonatal-infantile seizures, a mild, self-limited epilepsy syndrome of the first year of life (Heron et al., 2002; Berkovic et al., 2004; Herlenius et al., 2007). More recently, SCN2A has emerged as one of the most prominent epilepsy genes associated with a wide spectrum of seizure and neurodevelopmental phenotypes. These include early-onset epileptic encephalopathies with reported epilepsy syndromes, 
including Ohtahara syndrome, epilepsy of infancy with migrating focal seizures, infantile spasms (West syndrome), Lennox-Gastaut syndrome, Dravet-like syndrome, as well as unclassified epileptic encephalopathies (Howell et al., 2015; Wolff et al., 2017). Interestingly, SCN2A has also emerged as one of the most prominent genes associated with neurodevelopmental disorders, including autism, intellectual disability, and schizophrenia, with most patients carrying truncation mutations not having recognized seizures (Jiang et al., 2013; Iossifov et al., 2014; Sanders et al., 2015; Carroll et al., 2016; Wang et al., 2016; Ben-Shalom et al., 2017). The genotypephenotype relationship in epilepsy is more complex with both loss-of-function and gain-of-function changes observed. A recent retrospective study that reversephenotyped epilepsy patients with $S C N 2 A$ mutations began to dissect this conundrum. A phenotypic classification based on seizure onset, cognitive outcome, and movement disorders revealed that patients carrying gain-of-function mutations show an earlier onset of the disease, more severe seizure phenotype, and better responsiveness to $\mathrm{Na}^{+}$channel blockers than the carriers of loss-of-function mutations (Ben-Shalom et al., 2017; Wolff et al., 2017). It is possible that the biophysical measures indicating both loss-of-function and gain-of-function for similar phenotypes are not targeting the critical cellular mechanism of $\mathrm{Na}_{\mathrm{V}} 1.2$ in these disorders. Clarification of this has significant implications for diagnosis, treatment strategies, and mechanistic understanding in diseases associated with $S C N 2 A$ mutations.

b. Mechanisms and potential targeted therapies. The classification of $S C N 2 A$-related epilepsy into either a gain-of-function or a loss-of-function grouping already has significant implications for targeted therapy. As suggested above, one simple prediction of this finding is that antiepileptic drugs that act as $\mathrm{Na}^{+}$ channel blockers should have a differential impact on the two populations. Consistent with this, Wolff et al. (2017) show that phenytoin is reasonably effective in ameliorating disease caused by gain-of-function mutations, but less effective, or possibly even exacerbates seizures in patients with loss-of-function mutations (Wolff et al., 2017). These findings strongly argue that biophysical characterization should be part of a complete evaluation of subjects with SCN2A mutations. With time, a comprehensive database will develop, meaning that many mutations will be ascribed a functional class. This will significantly aid diagnosis and help devise the best treatment strategy for a given patient.

The finding that both loss and gain of $\mathrm{Na}_{\mathrm{v}} 1.2$ function can cause disease adds complexity to the development of targeted therapy (Ben-Shalom et al., 2017; Wolff et al., 2017). For gain-of-function SCN2A mutations, it is reasonable to assume that molecular strategies that reduce protein expression or protein function may be effective. However, in the context of loss-of-function
SCN2A mutations, these would be expected to increase seizure susceptibility, as well as exacerbating neurodevelopmental symptoms. A converse argument for strategies based on loss-of-function mutations can be made. This suggests that any approach that directly targets the specific $S C N 2 A$ deficit is likely to have narrow therapeutic windows and will rely heavily on accurate functional diagnosis.

Mouse models, in which emerging pathologies can be discovered, may provide alternative targets based on disease mechanism. The $\mathrm{Na}_{\mathrm{V}} 1.2$ (Q54) transgenic mouse expresses a gain-of-function channel mutation that results in a progressive epilepsy phenotype beginning with spontaneous focal motor seizures that evolve to include bilateral convulsive seizures with age (Kearney et al., 2001). Recordings from hippocampal pyramidal neurons exhibit an enhanced persistent $\mathrm{Na}^{+}$ current (Kearney et al., 2001). The Nav1.2 (A263V) knock-in mouse line, which is homozygous for a mild disease gain-of-function mutation, presents with frequent seizures and increased mortality (Schattling et al., 2016). At the cellular level, current clamp recordings in slices reveal increased excitability in hippocampal pyramidal neurons (Schattling et al., 2016). These mouse lines provide preclinical models of gain-of-function disease. Comparing the genetically different models may also reveal points of mechanistic convergence that could be targeted. For example, if the increase in persistent $\mathrm{Na}^{+}$current was evident in both, this would provide a clear target for which strategies already exist (see $S C N 8 A$ ).

The $\mathrm{Na}_{\mathrm{V}} 1.2$ knockout mouse model is of interest in light of evidence implicating loss-of-function SCN2A mutations in both epilepsy and other neurodevelopmental disease. Initial observations report that heterozygous $\mathrm{Na}_{\mathrm{V}} 1.2$ knockout mice appear normal (Planells-Cases et al., 2000). This suggests that overt seizures are not part of the heterozygous phenotype, although a full behavioral analysis that includes probing neurodevelopmental deficits is clearly needed. Homozygous $\mathrm{Na}_{\mathrm{V}} 1.2$ knockout mice die within 1-2 days of birth. It will be important to develop new knock-in mouse models of loss-of-function disease based on human mutations, which may have impacts over and above simple haploinsufficiency.

4. SCN8A. SCN8A encodes the $\mathrm{Na}_{\mathrm{v}} 1.6$ subunit that is found throughout the adult mammalian brain. $\mathrm{Na}_{\mathrm{v}} 1.6$ is expressed in the distal compartment of the axon initial segment and thought to be important for action potential initiation (Hu et al., 2009). It is also expressed at nodes of Ranvier and is therefore critical to saltatory conduction along myelinated axons (Caldwell et al., 2000; Van Wart et al., 2007; Gasser et al., 2012).

a. Clinical syndrome and molecular findings. Heterozygous mutations in SCN8A are associated with an epileptic encephalopathy characterized by developmental delay, seizure onset within the first 18 months of life, and intractable epilepsy. These patients have 
multiple seizure types, including infantile spasms, generalized tonic-clonic seizures, absences, and focal seizures (Veeramah et al., 2012; Allen et al., 2013; Carvill et al., 2013a; Vaher et al., 2014; Blanchard et al., 2015; Larsen et al., 2015; Takahashi et al., 2015; Wagnon et al., 2015a; Boerma et al., 2016). Mirroring the situation with SCN1A and SCN2A, where there are both mild and severe phenotypes, very recently there were two reports of familial benign infantile seizures, without cognitive impairment, and some with paroxysmal dyskinesias with missense variants in SCN8A (Anand et al., 2016; Gardella et al., 2016).

The majority of mutations in SCN8A associated with epileptic enecephalopathy are missense mutations. Functional analysis has predominantly identified changes predicting gain-of-function that are likely to increase neuronal excitability. These include incomplete channel inactivation, depolarizing shift in the voltage dependence of steady-state fast inactivation, and hyperpolarizing shifts in the voltage dependence of activation (Veeramah et al., 2012; de Kovel et al., 2014; Estacion et al., 2014; Blanchard et al., 2015; Wagnon et al., 2015a; Barker et al., 2016). One common finding for $S C N 8 A$ variants tested is an increase in persistent $\mathrm{Na}^{+}$current (Estacion et al., 2014), a biophysical property that has been implicated in several epileptic states (Stafstrom, 2007).

b. Mechanisms and potential targeted therapies. The heterozygous Nav1.6 (N1768D/+) knock-in mouse model recapitulates the seizures, ataxia, and sudden death seen in patients with the mutation, providing a robust preclinical model (Wagnon et al., 2015b; Lopez-Santiago et al., 2017; Sprissler et al., 2017). Consistent with functional analysis in heterologous assays, recordings from excitatory and inhibitory neurons reveal an increase in persistent $\mathrm{Na}^{+}$current. CA1 excitatory neurons also have unusual depolarizing events that are proposed to be due to a change in the function of the $\mathrm{Na}^{+} / \mathrm{Ca}^{2+}$ exchanger caused by excessive internal $\mathrm{Na}^{+}$concentrations (Lopez-Santiago et al., 2017).

Although the human genetic evidence is not strong, there is good evidence from animal models that loss of $\mathrm{Na}_{\mathrm{v}} 1.6$ function can also result in nonconvulsive seizures (Papale et al., 2009). Elegant recent work has demonstrated reduced function of inhibitory neurons in the thalamus as the likely basis of increased susceptibility to spike-and-wave discharge seizures (Makinson et al., 2017). Specifically, a reduction in the ability of thalamic reticular nucleus GABAergic neurons to sustain tonic firing results in the disruption of intrathalamic reticular nucleus inhibition, leading to an increase in oscillatory behavior in the thalamus. Interestingly, a pyramidal neuron-specific loss of $\mathrm{Na}_{\mathrm{v}} 1.6$ function is protective against convulsive seizures (Makinson et al., 2017). Reduced Nav1.6 function was also able to ameliorate seizure severity in a $S c n 1 a$ mouse model of Dravet syndrome, suggesting that it could act as a modifier of disease (Martin et al., 2007). This study highlights the importance of understanding the cell-specific impact of epilepsy mutations, allowing insight into not only pathogenic mechanisms, but also the potential adverse impact of any therapeutic intervention.

Mechanistic insights provide a number of potential targeted therapeutic options. In particular, targeting the increased persistent $\mathrm{Na}^{+}$current makes sense. Significantly, GS967 (PRAX-330), a specific blocker of persistent $\mathrm{Na}^{+}$current, extends survival of the $\mathrm{Na}_{\mathrm{V}} 1.6$ $(\mathrm{N} 1768 \mathrm{D} /+)$ mouse (Anderson et al., 2014). A further possibility is the use of the persistent $\mathrm{Na}^{+}$current blocker, riluzole, an approved drug that is used to treat amyotrophic lateral sclerosis. Riluzole is effective in blocking the early depolarization events seen in CA1 pyramidal neurons (Lopez-Santiago et al., 2017), but as yet there is no published evidence of its efficacy in the $\mathrm{Na}_{\mathrm{V}} 1.6(\mathrm{~N} 1768 \mathrm{D} /+)$ mouse. Patel et al. (2016) have also demonstrated that increased persistent current of $\mathrm{Na}_{\mathrm{v}} 1.6$ mutant channels can be preferentially reversed with cannabidiol. Another strategy could be to block the $\mathrm{Na}^{+} / \mathrm{Ca}^{2+}$ exchanger that is implicated in the disease mechanism (Lopez-Santiago et al., 2017). Approved drugs, including amiodarone (Watanabe and Kimura, 2000), bepridil (Watanabe and Kimura, 2001), aprindine (Watanabe et al., 2002), and cibenzoline (Yamakawa et al., 2012), have been found to have inhibitory actions on the $\mathrm{Na}^{+} / \mathrm{Ca}^{2+}$ exchanger, potentially providing repurposing opportunities. Finally, given the gain-of-function observed with the majority of SCN8A epilepsy mutations, developing molecular knockdown strategies may be beneficial. It is worth noting that these knockdown strategies could potentially result in an increase in susceptibility to nonconvulsive spike-and-wave seizures (Makinson et al., 2017).

\section{B. Voltage-Gated $\mathrm{K}^{+}$Channels}

$\mathrm{K}^{+}$channels are the most diverse group of ion channels, playing important roles in a myriad of cellular processes (Alexander et al., 2015a; http://www.guidetopharmacology.org/GRAC/FamilyDisplayForward?familyId=81). They can be classified into three structural families depending on the number of transmembrane domains in each subunit and the gating mechanisms. Voltage-gated $\mathrm{K}^{+}$channels, which are encoded by about 40 genes, comprise four subunits, each with six transmembrane domains. Four (S1-S4) form the voltage sensor, whereas two (S5 and S6) form the pore region. These channels are critical for the regulation of neuronal excitability, including defining the resting membrane potential, modulation of action potential firing, and the modulation of neurotransmitter release (reviewed in Jan and Jan, 2012; Maljevic and Lerche, 2013). 
1. KCNA1. KCNA1 encodes the $\mathrm{K}_{\mathrm{v}} 1.1$ subunit of the voltage-gated $\mathrm{K}^{+}$channel that is widely expressed throughout the central nervous system, with particularly high levels of expression in the hippocampus (Wang et al., 1994; Jan and Jan, 2012). The $\mathrm{K}_{\mathrm{v}} 1.1$ subunit is predominantly localized in the axon initial segment, axon preterminal, and the juxtaparanodal domain adjacent to the nodes of Ranvier, where it helps to repolarize and shape action potentials (Shieh et al., 2000; Goldberg et al., 2008; Trimmer, 2015).

a. Clinical syndrome and molecular findings. The majority of human KCNA1 mutations are associated with episodic ataxia type 1 (Browne et al., 1994, 1995; Zuberi et al., 1999; Eunson et al., 2000; Rajakulendran et al., 2007). Patients with episodic ataxia type 1 are ten times more likely to have seizures than the general population, strongly implicating mutations in this gene as a cause of epilepsy (Rajakulendran et al., 2007). Another common feature of KCN1A disease is myokymia, characterized by involuntary twitching of facial and limb muscles (Browne et al., 1994, 1995). Furthermore, this gene has been suggested as one of the contributing genes to sudden unexpected death in epilepsy in a 3-yearold proband with pharmacoresistant epileptic encephalopathy (Klassen et al., 2014). The majority of functional studies of KCNA1 mutations revealed loss-of-function through a variety of mechanisms, including changes to the voltage threshold and gating properties of $K_{\mathrm{V}}$ 1.1containing $\mathrm{K}^{+}$channels, reduction in peak $\mathrm{K}^{+}$current amplitude, and channel trafficking defects (Rajakulendran et al., 2007; D'Adamo et al., 2015).

b. Mechanisms and potential targeted therapies. $\mathrm{K}_{\mathrm{v}} 1.1$ knockout mice display similar phenotypes to human patients, including frequent spontaneous seizures and in some cases sudden unexpected death, suggesting that it is a good preclinical model of disease (Smart et al., 1998; Lopantsev et al., 2003; Wenzel et al., 2007; Glasscock et al., 2010). The heterozygous $\mathrm{K}_{\mathrm{v}} 1.1$ (V408A) knock-in mouse model based on a human mutation linked to episodic ataxia type 1 has stressfear responses and induced motor dysfunctions that recapitulate some disease phenotypes, but no spontaneous seizures (Herson et al., 2003).

The cellular basis of morbidity is not clear but may involve changes in neurotransmitter release. It is well established that blocking $\mathrm{K}_{\mathrm{V}} 1$ channels broadens the action potential, thus increasing the flux of $\mathrm{Ca}^{2+}$ into the presynaptic terminal and as a consequence increasing triggered neurotransmitter release (Shu et al., 2006; Foust et al., 2011). Consistent with this, the overexpression of a human $\mathrm{K}_{\mathrm{V}} 1.1$ epilepsy mutation in cultured rat hippocampal neurons enhances neurotransmitter release probability (Heeroma et al., 2009). $\mathrm{K}_{\mathrm{V}} 1.1$ is localized in the axon initial segment of fastspiking neocortical GABAergic interneurons and has a critical role in regulating the excitability of these cells (Goldberg et al., 2008). Functional studies have reported an increase in GABAergic inhibitory synaptic transmission in both the $\mathrm{K}_{\mathrm{v}} 1.1$ knockout and $\mathrm{K}_{\mathrm{v}} 1.1$ (V408A) knock-in mouse models (van Brederode et al., 2001; Herson et al., 2003). At a neuronal network level, multielectrode array analysis of hippocampal slices from $\mathrm{K}_{\mathrm{v}} 1.1$ knockout mice indicates an increase in spontaneous spike-wave and high-frequency ripples that are associated with hyperexcitability (Simeone et al., 2013). This is proposed to be due to increased synaptic release within the $C A 3$ region, decreasing precision of $C A 3$ principal cell spike timing, which in turn leads to the altered hippocampal network oscillatory behavior (Simeone et al., 2013).

There are no reported effective targeted therapies based on our understanding of cellular mechanisms. However, the preclinical knockout mouse model has provided some insights. Interestingly, homozygous $\mathrm{K}_{\mathrm{v}} 1.1$ knockout mice have disrupted sleep, and seizures peak during times of light (Wright et al., 2016). Almorexant, a dual orexin receptor antagonist used in sleeping disorders, improves sleep and reduces seizure severity, suggesting that it may be useful for patients with mutations in KCNA1 (Roundtree et al., 2016). Treatment of homozygous $\mathrm{K}_{\mathrm{v}} 1.1$ knockout mice with a ketogenic diet also reduces seizure frequency (Fenoglio-Simeone et al., 2009) and has been shown to successfully extend life span (Simeone et al., 2016). Finally, homozygous $\mathrm{K}_{\mathrm{v}} 1.1$ knockout mice with partial genetic ablation of $\mathrm{Na}_{\mathrm{V}} 1.2$ exhibit reduced duration of spontaneous seizures, and a significant improvement of survival rates argues that blockers of this $\mathrm{Na}^{+}$ channel may have some treatment value (Mishra et al., 2017).

2. KCNA2. KCNA2 encodes the $\mathrm{K}_{\mathrm{V}} 1.2$ shaker-type voltage-gated $\mathrm{K}^{+}$channel subunit, which is highly expressed in the central nervous system, predominately in the axon (Monaghan et al., 2001; Melé et al., 2015). The $\mathrm{K}_{\mathrm{V}} 1.2$ channel belongs to the delayed rectifier class of $\mathrm{K}^{+}$channels, which enable the repolarization of the neuronal membrane following an action potential (Maljevic and Lerche, 2013).

a. Clinical syndrome and molecular findings. De novo mutations in KCNA2 have been identified in cases of early infantile epileptic encephalopathy (Pena and Coimbra, 2015; Syrbe et al., 2015; Allen et al., 2016; Hundallah et al., 2016). Seizure onset is between 5 and 17 months, with a phenotypic spectrum including febrile and afebrile, hemiclonic, myoclonic, myoclonicatonic, absence, focal dyscognitive, focal, and generalized seizures; mild to moderate intellectual disability; delayed speech development; and severe ataxia (Pena and Coimbra, 2015; Syrbe et al., 2015). The KCNA2 spectrum also encompasses milder familial epilepsy (Corbett et al., 2016). De novo KCNA2 mutations in patients with neurodegenerative hereditary spastic paraplegia and ataxia have also been reported (Helbig et al., 2016; Manole et al., 2017). In heterologous 
expression systems, de novo mutations in KCNA2 can cause both loss- and gain-of-function, all with a dominant effect (Syrbe et al., 2015).

b. Mechanisms and potential targeted therapies. The idea that loss-of-function can cause disease is consistent with findings from animal models. Homozygous $\mathrm{K}_{\mathrm{V}} 1.2$ knockout mice display severe seizures and die early (Brew et al., 2007). Heterozygous $\mathrm{K}_{\mathrm{V}} 1.2$ knockout mice do not display spontaneous seizures but are more sensitive to a proconvulsant challenge compared with wild-type littermates (Brew et al., 2007). The Pingu mutant mouse that carries a loss-of-function mutation in $\mathrm{K}_{\mathrm{v}} 1.2$, induced through N-ethyl-Nnitrosourea mutagenesis, provides another potential model of disease (Xie et al., 2010). This mouse carries a mutation in the S6 segment, which is in close proximity to the loss-of-function mutation found in patients with epileptic encephalopathy, including ataxia (Syrbe et al., 2015). Both heterozygous and homozygous mutant mice display significant gait abnormalities (Xie et al., 2010). No mouse models with a gain-of-function KCNA2 variant have been reported to date.

The cellular basis of hyperexcitability due to either loss- or gain-of-function KCNA2 mutations is not clear. This is in part because $\mathrm{K}_{\mathrm{v}} 1.2$ is found in both excitatory and inhibitory neurons (Wang et al., 1994; Lorincz and Nusser, 2008). It is also due to the fact that $\mathrm{K}_{\mathrm{v}} 1.2$ channels potentially play dual roles in defining cellular excitability. By rapidly repolarizing neurons, they can help sustain rapid firing rates. In addition, they play a critical role in defining membrane potential. Cellular studies in mouse models highlight this complexity by showing contrasting changes in firing patterns. Recordings from inhibitory cerebellar basket cells of the Pingu mutant mouse show an increased firing rate (Xie et al., 2010). In contrast, firing is reduced in $K_{\mathrm{V}} 1.2$ knockout glycinergic neurons (Brew et al., 2007).

Despite the limited understanding of the cellular basis of disease, therapeutic strategies based on molecular findings are possible. The 4-aminopyridine is an approved $\mathrm{K}^{+}$blocker already being trialed in patients carrying gain-of-function mutations $(\mathrm{H}$. Lerche, personal communication). The use of molecular knockdown strategies may also prove to be useful in this patient cohort. There are currently no obvious mechanism-based therapeutic strategies for loss-of-function disease. However, Xie et al. (2010) have tested a nontargeted approach and report that the carbonic anhydrase inhibitor, acetazolamide, is capable of rescuing the motor incoordination in Pingu mice. This led to a successful clinical outcome in a single patient with ataxia and myoclonic epilepsy caused by a KCNA2 mutation, which highlights the potential utility of the preclinical mouse model (Pena and Coimbra, 2015).

3. KCNB1. KCNB1 encodes the $\mathrm{K}_{\mathrm{v}} 2.1$ pore-forming and voltage-sensing $\alpha$-subunit of the delayed-rectifier
$\mathrm{K}^{+}$channel (Labro and Snyders, 2012; Maljevic and Lerche, 2013). In the mammalian brain, the $\mathrm{K}_{\mathrm{v}} 2.1$ subunit is expressed in both excitatory and inhibitory neurons, and is localized to the soma, proximal dendrites, and axon initial segments ( $\mathrm{Du}$ et al., 1998; Trimmer, 2015), where it plays a critical role in regulating excitability (Mohapatra et al., 2007; Speca et al., 2014). An interesting characteristic of this channel is that its activity can be modulated by phosphorylation (Mohapatra et al., 2007; Speca et al., 2014). Increased neuronal activity leads to dephosphorylation, which results in facilitated channel opening and consequently suppressed neuronal excitability. Reduced neuronal activity leads to hyperphosphorylation of $\mathrm{K}_{\mathrm{v}} 2.1$ that has the opposite effect (Speca et al., 2014). The widespread expression of $\mathrm{K}_{\mathrm{v}} 2.1$ suggests that this channel may have a major role in homeostatic suppression of both excitatory and inhibitory neuronal excitability (Mohapatra et al., 2007; Speca et al., 2014).

a. Clinical syndrome and molecular findings. Several de novo mutations in KCNB1 have been identified in cases of infantile epileptic encephalopathy (Torkamani et al., 2014; Saitsu et al., 2015; Thiffault et al., 2015; Allen et al., 2016). The phenotypic spectrum includes cognitive and motor dysfunction, severe infantile generalized seizures with high-amplitude spikeand-wave discharges, and prominent stimulus and photosensitive epilepsy (Saitsu et al., 2015; Allen et al., 2016). A range of functional impacts has been reported for epilepsy-associated KCNB1 mutations. For example, mutations located within the pore domain of $\mathrm{K}_{\mathrm{v}} 2.1$ were associated with a loss of $\mathrm{K}^{+}$selectivity. This could lead to an increased inward conductance of cations, resulting in neuronal depolarization (Torkamani et al., 2014; Thiffault et al., 2015). Other biophysical findings include changes in gating, with mutant channels showing less voltage dependence and an ability to be constitutively open (Torkamani et al., 2014). Expression of a de novo missense mutation in heterologous cells revealed significant changes in protein expression and localization (Thiffault et al., 2015).

b. Mechanisms and potential targeted therapies. There are currently no good rodent models for KCNB1 disease. A homozygous $\mathrm{K}_{\mathrm{V}} 2.1$ knockout mouse model exhibits no spontaneous seizures, but does exhibit a reduced threshold for induced seizures, in addition to reduced spatial learning and hyperactivity (Speca et al., 2014). This mimics loss-of-function aspects of disease and argues that it can cause some level of hyperexcitability. However, given the biophysical changes seen, including altered ion selectivity and changes in voltage sensitivity, it is not entirely surprising that simple lossof-function does not recapitulate more severe disease. Saitsu et al. (2015) have investigated the impact of two different human epilepsy mutations on neuronal excitability in an overexpression culture model. They report that expression of both mutant channels slows action 
potential firing in excitatory pyramidal neurons by reducing repolarization. How this translates to increased network excitability in epilepsy remains unclear. Knock-in mutant mice based on human KCNB1 mutations are more likely to serve as better preclinical models. Given the lack of functional insight, it is difficult to propose potential targeted therapy in $K C N B 1$ disease.

4. KCNC1. KCNC1 encodes the $\mathrm{K}_{\mathrm{V}} 3.1$ channel, which has biophysical properties optimized for highfrequency action potential firing (Rudy and McBain, 2001). The channel is preferentially expressed in specific subsets of fast-spiking neurons, including fastspiking inhibitory GABAergic interneurons (Rudy and McBain, 2001). $K_{\mathrm{V}} 3.1$ channels are also expressed in granule cerebellar neurons (Matsukawa et al., 2003).

a. Clinical syndrome and molecular findings. A recurrent de novo mutation in KCNC1 has been identified as a major cause of progressive myoclonus epilepsy (Muona et al., 2015; Oliver et al., 2017). This is a distinctive epilepsy syndrome characterized by myoclonus, generalized tonic-clonic seizures, and progressive neurologic deterioration. An interesting clinical trait is the transient clinical improvement that occurs with fever in some patients (Oliver et al., 2017). In vitro analysis has revealed two key biophysical changes resulting from the recurrent KCNC1 mutation: a dominant-negative impact that significantly reduces currents, and a concomitant hyperpolarizing shift in the activation voltage (Muona et al., 2015; Oliver et al., 2017). A nonsense mutation in KCNC1 has also been described in one family with intellectual disability, but no epilepsy (Poirier et al., 2017).

b. Mechanisms and potential targeted therapies. The cellular mechanism underlying KCNC1-mediated disease is not understood. One possibility is that the reduced current levels lead to an inability of fastspiking GABAergic interneurons to sustain firing, with a consequent increase in network excitability caused by disinhibition (Muona et al., 2015; Oliver et al., 2017). However, the hyperpolarizing shift in activation would act to increase channel function, tempering this reduced current. Interestingly, in vitro analysis demonstrates that the hyperpolarizing shift is enhanced at febrile temperatures, and this may explain the clinical improvement seen with fever (Oliver et al., 2017). The homozygous $\mathrm{K}_{\mathrm{V}} 3.1$ knockout mouse displays only a mild phenotype that includes impaired coordinated motor skills, but no spontaneous seizures, suggesting that this mouse is not a good preclinical model of the disease (Ho et al., 1997). RE1, a $K_{\mathrm{V}} 3.1$ channel opener, provides a potential therapeutic option. Importantly, RE1 partially restores impaired firing in fast-spiking neurons from a mouse model of 15q13.3 microdeletion syndrome (Thelin et al., 2017). However, the utility of this and other $\mathrm{K}_{\mathrm{V}} 3.1$ channel agonists is yet to be tested in KCNC1 disease models.
5. KCNMA1. KCNMA1 encodes the $\alpha$-subunit of the large conductance $\mathrm{Ca}^{2+}$-sensitive $\mathrm{K}^{+}$channel [also known as $\mathrm{BK}$ (for Big $\mathrm{K}^{+}$), Maxi-K, $\mathrm{K}_{\mathrm{Ca}} 1.1$, or Slo1] that is widely expressed in the central nervous system. KCNMA1 channels produce a robust hyperpolarizing potential in response to elevation in intracellular $\mathrm{Ca}^{2+}$ and/or membrane depolarization, which influences the shape, frequency, and propagation of action potentials and modulates neurotransmitter release (Contet et al., 2016).

a. Clinical syndrome and molecular findings. A mutation in KCNMA1 was first reported in a large family with autosomal dominant generalized epilepsy and paroxysmal nonkinesigenic dyskinesia (Du et al., 2005). Two de novo mutations and an autosomal recessive homozygous frameshift duplication have also been described (Zhang et al., 2015b). Functional analysis provided in the first study showed that the mutant BK channel had a greater macroscopic current, likely due to an increase in $\mathrm{Ca}^{2+}$ sensitivity. In contrast, the homozygous frameshift duplication is likely to result in loss-of-function.

b. Mechanisms and potential targeted therapies. The activation of BK channels can both increase and decrease firing activity in neurons depending on context. Du et al. (2005) propose that enhancement of BK channels leads to increased excitability by allowing rapid repolarizing action potentials, resulting in increased firing rates. A reduction in BK activity has been implicated in causing neuronal depolarization at rest that consequently increases excitability by taking the neuron closer to the firing potential (Verma-Ahuja et al., 1995). Therefore, predicting how a given mutation impacts excitability is difficult. The KCNMA1 knockout mouse exhibits intention tremor and abnormal gait consistent with cerebellar ataxia but is seizure-free and is therefore not a good model of epilepsy (Sausbier et al., 2004). There are a range of small organic molecules and peptides that can both activate and block BK channels (Bentzen et al., 2014; Yu et al., 2016). These provide a rich source of pharmacological tools that could be used to probe efficacy once a good model of disease is developed.

6. KCNQ2 and KCNQ3. Heteromeric and homomeric channels encoded by KCNQ2 $\left(\mathrm{K}_{\mathrm{V}} 7.2\right)$ and $K C N Q 3$ $\left(K_{V} 7.3\right)$ can form homo- and heterotetramers that are responsible for the M-current, a slow noninactivating $\mathrm{K}^{+}$current that regulates membrane potential at the subthreshold voltage range and constrains repetitive neuronal firing (Brown and Adams, 1980; Schroeder et al., 1998; Delmas and Brown, 2005).

a. Clinical syndrome and molecular findings. Mutations in both KCNQ2 and KCNQ3 cause an autosomal-dominant self-limited epilepsy known as benign familial neonatal epilepsy (Biervert et al., 1998; Charlier et al., 1998; Schroeder et al., 1998; Singh et al., 1998; Lerche et al., 1999; Maljevic and Lerche, 2014). 
More recently, screening of patients with neonatal onset epileptic encephalopathy revealed many cases of de novo mutations in KCNQ2 (Weckhuysen et al., 2012, 2013; Maljevic and Lerche, 2014), with fewer mutations reported in KCNQ3 (Miceli et al., 2015a,b). Approximately half of KCNQ2 mutations are predicted to truncate the protein, with the other half being missense mutations (Maljevic and Lerche, 2014). Functional analysis revealed a loss-of-function caused by a different molecular mechanism (Maljevic and Lerche, 2014). It should be noted that disease-related gain-of-function mutations have been more rarely reported for both $K C N Q 2$ and KCNQ3 (Miceli et al., 2015b; Millichap et al., 2016). A genotype-phenotype correlation has been suggested, with mutations in severe epileptic encephalopathies more likely to have a dominant-negative impact (Orhan et al., 2014).

b. Mechanisms and potential targeted therapies. $\mathrm{K}_{\mathrm{V}} 7.2$ and $\mathrm{K}_{\mathrm{V}} 7.3$ colocalize at the axon initial segment and/or nodes of Ranvier (Devaux et al., 2004; Schwarz et al., 2006), where they play an integral role in defining excitability, including reducing spiking frequency during trains of activity (spike-frequency adaption) (Schwarz et al., 2006). A reduction in the M-current will reduce adaptation and is the likely basis of neuronal hyperexcitability in loss-of-function $K C N Q 2$ and $K C N Q 3$ disease. Support for this idea comes from a conditional transgenic mouse that has spontaneous seizures and carries a dominant-negative pore mutation (Peters et al., 2005). CA1 pyramidal neurons have a smaller medium after-hyperpolarization current, and as a consequence a reduced ability to adapt action potential firing (Peters et al., 2005). CA1 pyramidal neurons from a spontaneous $\mathrm{K}_{\mathrm{V}} 7.2$ mutant mouse also have a reduced ability to adapt action potential firing (Otto et al., 2006). The mechanism of disease for gain-offunction mutations is less clear. Both $\mathrm{K}_{\mathrm{V}} 7.2$ and $\mathrm{K}_{\mathrm{V}} 7.3$ proteins are found in parvalbumin-positive hippocampal interneurons (Lawrence et al., 2006; Nieto-Gonzalez and Jensen, 2013; Grigorov et al., 2014) with a reduction in spike adaption in these cells possibly increasing network excitability. The $\mathrm{K}_{\mathrm{V}} 7.2$ (A306T) and $\mathrm{K}_{\mathrm{V}} 7.3$ (G311V) knock-in mouse models are both based on loss-of-function mutations found in benign familial neonatal convulsions (Singh et al., 2008; Otto et al., 2009). In both cases, homozygous mice have spontaneous seizures, whereas heterozygous mice have increased seizure susceptibility, suggesting that they may act as reasonable models of mild disease (Singh et al., 2008; Otto et al., 2009). No mouse models with epileptic encephalopathy have been reported to date.

One striking feature of benign familial neonatal seizures is that, within a few weeks or months of birth, symptoms spontaneously remit in the vast majority of patients. The developmental pattern of $\mathrm{K}_{\mathrm{V}} 7.2$ and $\mathrm{K}_{\mathrm{V}} 7.3$ protein expression seems unlikely to explain remission, as the expression of both subunits increases during maturation (Weber et al., 2006; Maljevic and Lerche, 2014). A plausible hypothesis is that remission coincides with a switch of the inhibitory neurotransmitter GABA, from a predominantly excitatory transmitter in early development to a more traditional inhibitory role in later development (Rivera et al., 1999).

From a therapeutic perspective, retigabine, a selective opener of the M-current (Rundfeldt and Netzer, 2000; Gunthorpe et al., 2012), is an obvious drug choice for loss-of-function KCNQ2- and KCNQ3-mediated disease. More broadly, retigabine has been used in the treatment of epileptic encephalopathy patients, with studies revealing significant improvement in some patients (Weckhuysen et al., 2013; Millichap et al., 2016). Unfortunately, the side effects seen in some patients have led to the removal from the market of this drug (Tompson et al., 2016). Ongoing efforts to develop similar but safer M-current activator are required, and these would be predicted to be particularly efficacious in epilepsy caused by most mutations in KCNQ2 and KCNQ3.

7. KCNT1. KCNT1 encodes $\mathrm{K}_{\mathrm{Na}} 1.1$, a $\mathrm{Na}^{+}$-activated $\mathrm{K}^{+}$channel subunit, that has been called Slack (sequence like a $\mathrm{Ca}^{2+}$-activated $\mathrm{K}^{+}$channel, also known as $\mathrm{K}_{\mathrm{Ca}} 4.1$ or Slo2.2). $\mathrm{K}_{\mathrm{Na}} 1.1$ is expressed widely, including in the brain, heart, and kidney. $\mathrm{K}_{\mathrm{Na}} 1.1$ is thought to be expressed in the frontal cortex (Bhattacharjee et al., 2002), but more studies are required to better map its expression pattern. $\mathrm{K}_{\mathrm{Na}} 1.1$ channels may modulate the firing properties and general excitability of many neuronal types, although their precise function is yet to be fully resolved.

a. Clinical syndrome and molecular findings. Mutations in KCNT1 have been identified in familial and sporadic cases with autosomal dominant nocturnal frontal lobe epilepsy (ADNFLE). It is also the cause of about $40 \%$ of cases with a quite different syndrome, epilepsy of infancy with migrating focal seizures (Wilmshurst et al., 2000; Barcia et al., 2012; Heron et al., 2012; Lim et al., 2016). Other epileptic encephalopathies, such as Ohtahara syndrome, have also been linked to this gene (Møller et al., 2015). All mutations in KCNT1 described to date are missense mutations (Lim et al., 2016). Notably, they all result in significantly increased $\mathrm{K}^{+}$current, which argues strongly that this is the basis of disease. The extent of the gain-of-function may correlate with seizure phenotype severity (Milligan et al., 2014). However, the fact that two mutations have been described causing both nocturnal frontal lobe epilepsy and epilepsy of infancy with migrating focal seizures suggests a more complex genotype-phenotype correlation (Lim et al., 2016). KCNT1-mediated epilepsy has become an example of how quickly targeted therapy might enter the clinic through the repurposing of already approved drugs (see below).

b. Mechanisms and potential targeted therapies. The exact mechanisms underlying disease caused by mutation in KCNT1 are still unclear. Rapid elevations 
of intracellular $\mathrm{Na}^{+}$concentrations in neurons are sensed by $\mathrm{Na}^{+}$-activated $\mathrm{K}^{+}$channels influencing firing patterns. For example, rapid repolarization by $\mathrm{K}^{+}$ channels can sustain rapid action potential firing, with an increase in function potentially enabling excitatory neurons to fire at aberrantly high rates (Bhattacharjee and Kaczmarek, 2005). Alternatively, during sustained activity, slow activation of such channels can lead to the cessation of firing that could cause inhibitory dysfunction similar to that observed in SCN1A disease (Bhattacharjee and Kaczmarek, 2005). Given that the expression pattern of $\mathrm{K}_{\mathrm{Na}} 1.1$ is largely unknown, it is difficult to make a prediction as to the likely mechanism. To date, no mouse model based on gain-offunction KCNT1 mutations has been reported.

Despite the lack of progress on the underlying cellular basis of disease, the robust gain-of-function seen in all KCNT1 disease provides a clear target. It has been known for some time that the approved antiarrhythmic drug, quinidine, is able to block rodent $\mathrm{K}_{\mathrm{Na}} 1.1$ channels (Santi et al., 2006; Yang et al., 2006). Milligan et al. (2014) showed that quinidine was able to also block human $\mathrm{K}_{\mathrm{Na}} 1.1$ channels, including those expressing epilepsy mutations. This has motivated clinical studies in which quinidine was repurposed and trialed in patients carrying KCNT1 mutations. Several case reports suggested efficacy, particularly in very young patients (Bearden et al., 2014; Mikati et al., 2015; Fukuoka et al., 2017), whereas others have shown limited or no efficacy (Mikati et al., 2015; Chong et al., 2016; Fukuoka et al., 2017). Quinidine is not a safe drug, with severe life-threatening cardiac liability, and a small clinical trial in adults in ADNFLE failed to show efficacy, and doses were limited by cardiac toxicity (Mullen et al., 2017). The antiarrhythmic drug, clofilium, which also blocks $\mathrm{K}_{\mathrm{Na}} 1.1$ channels, potentially provides another repurposing opportunity, although it too has significant cardiac side effects (Castle, 1991). These drugs do form good lead compounds for the development of more specific and better tolerated drugs targeted against $\mathrm{K}_{\mathrm{Na}}$ 1.1. The consistent gain-of-function seen for all disease mutations in KCNT1 argues that molecular strategies in which the channel is knocked down are likely to be effective. Importantly, the homozygous KCNT1 knockout mouse has only minor phenotypes, suggesting that there may be a large therapeutic window for such strategies (Bausch et al., 2015).

8. KCTD7. KCTD7 encodes a protein that has homology to the $\mathrm{T} 1$ domain in voltage-gated $\mathrm{K}^{+}$channels, a domain critical for tetramerization. The precise nature and role of this protein are unclear. Given the small size of KCTD7, it was thought to be unlikely to be a transmembrane protein and consequently function as $\mathrm{a} \mathrm{K}^{+}$channel. However, recent evidence argues that the KCTD7 protein can support a $\mathrm{K}^{+}$conductance (Moen et al., 2016). KCTD7 was also reported to have a modulatory role on the SAT2 neuronal glutamine transporter (Moen et al., 2016). Modulation of cellular proliferation, differentiation, apoptosis, and metabolism has also been suggested for this class of protein (Liu et al., 2013b).

a. Clinical syndrome and molecular findings. Three members of a family with progressive myoclonic epilepsy were reported to harbor a homozygous mutation in KCTD7 (Van Bogaert et al., 2007). Progressive myoclonic epilepsy is a disorder characterized by myoclonic and tonic-clonic seizures, ataxia, and cognitive regression (see KCNC1). Numerous other cases of progressive myoclonic epilepsy caused by mutations in KCTD7 have since been reported (Blumkin et al., 2012; Kousi et al., 2012; Krabichler et al., 2012; Staropoli et al., 2012; Farhan et al., 2014).

b. Mechanisms and potential targeted therapies. As KCTD7 channels have no clearly defined role, it is difficult to come up with a unifying mechanistic basis of disease. The KCTD7 channel is widely expressed throughout the brain, with immunohistochemical analysis identifying expression in cortical neurons, in granular and pyramidal cell layers of the hippocampus, and in cerebellar Purkinje cells (Kousi et al., 2012). KCTD7 mutations have been recently reported to reduce the ability of KCTD7 channels to sustain a $\mathrm{K}^{+}$ conductance either through a trafficking or biophysical deficit (Moen et al., 2016). This suggests the reduction in function is likely to result in a more depolarized membrane potential of excitatory neurons, leading to hyperexcitability. $\mathrm{K}^{+}$channel openers, such as retigabine, may be expected to be beneficial based on this mechanism. However, the impact of mutations on the SAT2 neuronal glutamine transporter or other cellular roles as a basis of excitability cannot be ruled out. No good animal models of KCTD7-mediated disease have been reported to date.

\section{Hyperpolarization-Activated Cyclic Nucleotide- Gated Channel 1}

Hyperpolarization-activated cyclic nucleotide-gated (HCN) channels are encoded by four genes (HCN1-4) (Alexander et al., 2015a; http://www.guidetopharmacology.org/GRAC/FamilyDisplayForward?familyId=71). HCN channels mediate hyperpolarization-activated currents in the brain, where they contribute to resting membrane potential and to the shaping of synaptic inputs (He et al., 2014). They have also been implicated in the generation of rhythmic and synchronized neuronal activity. Both human and animal studies have reported transcriptional changes in $\mathrm{HCN}$ expression that associate with hyperexcitability in epilepsy (Reid et al., 2012; DiFrancesco and DiFrancesco, 2015).

1. Clinical Syndrome and Molecular Findings. Considering the strong evidence implicating transcriptional changes in HCN channels and excitability in animal models, there is surprisingly little evidence of genetic changes associated with epilepsy. Nava et al. 
(2014) reported de novo $H C N 1$ missense mutations in patients suffering from early infantile epileptic encephalopathy. These patients had symptoms that resembled Dravet syndrome with intellectual impairment and autism. Functional analysis revealed that the majority of HCN1 mutations caused a gain-of-function through changes in various biophysical properties, including depolarized shifts in half activation and changes in activation and deactivation kinetics (Nava et al., 2014). Loss of HCN1 channel function was also reported (Nava et al., 2014). Variations in HCN2 that cause gain-offunction have been reported to confer susceptibility in febrile seizure syndromes (Dibbens et al., 2010; Nakamura et al., 2013), with a further report of a lossof-function homozygous HCN2 mutation in a patient with sporadic GGE (DiFrancesco et al., 2011).

2. Mechanisms and Potential Targeted Therapies. The reported gain- and loss-of-function caused by mutations is consistent with the dual action HCN channels can play in defining neuronal excitability (Dubé et al., 2007; Dyhrfjeld-Johnsen et al., 2009). In neurons, HCN channels are active at rest and contribute a depolarizing current to the resting membrane potential. The majority of reported HCN1 mutations caused a gain-of-function. An increase in HCN channel function will therefore result in a more depolarized resting membrane potential, taking the neuron closer to the firing potential (Chen et al., 2001; Brewster et al., 2002; Dyhrfjeld-Johnsen et al., 2008). An increase in neuronal hyperexcitability can also be explained for loss-of-function HCN1 mutations. HCN1 channels are expressed robustly on dendrites, where they influence synaptic integration. A reduction in $\mathrm{HCN} 1$ channel function increases the temporal summation of synaptic input and facilitates dendritic burst firing (Strauss et al., 2004; Kole et al., 2007). These properties are proposed to contribute to network excitability in the WAG/Rij model of absence epilepsy (Strauss et al., 2004; Kole et al., 2007). This dual role of HCN channels in the central nervous system makes it difficult to develop targeted approaches for genetic epilepsy caused by $H C N 1$ mutations. Nevertheless, in gain-of-function disease, blockers of HCN1 may be useful. Ivabradine is a use-dependent broad-spectrum blocker of HCN channels approved for use in angina pectoris (Abed et al., 2016; Giavarini and de Silva, 2016). Ivabradine has a good safety profile potentially providing a repurposing opportunity, although it is not clear whether it can cross the blood brain barrier (Savelieva and Camm, 2006). Moreover, the hypnotics propofol and ketamine, as well as the anesthetic isoflurane, are reported to inhibit HCN1 channels (Cacheaux et al., 2005; Chen et al., 2005, 2009, a,b; Lyashchenko et al., 2007). Although far from ideal, these drugs may provide some therapeutic options in patients harboring gain-of-function HCN1 mutations. The antiepileptic drugs, lamotrigine and gabapentin, have both been reported to enhance HCN currents (Poolos et al., 2002; Surges et al., 2003; Strauss et al., 2004), with patients harboring loss-of-function mutations potentially benefiting more from these drugs.

\section{Voltage-Gated Calcium Channels}

Voltage-gated $\mathrm{Ca}^{2+}$ channels support a number of critical processes in neurons, from the control of presynaptic transmitter release to the electrogenic properties of dendrites (Alexander et al., 2015a; http://www. guidetopharmacology.org/GRAC/FamilyDisplayForward? familyId=80). Electrophysiological studies indicate that there are six $\mathrm{Ca}^{2+}$ channel types, as follows: L-, N-, P-, Q-, R-, and T-type (Catterall, 2000). They can be divided into high voltage-activated or low voltage-activated classes based on the membrane potential range over which the channel is activated. The key determinant of the character of $\mathrm{Ca}^{2+}$ channel subtypes is their $\alpha 1$ poreforming subunit. The molecular diversity of voltagegated $\mathrm{Ca}^{2+}$ channels is enhanced by auxiliary subunits, including the $\alpha 1-, \beta$-, $\alpha 2 \delta$-, and $\gamma$-subunits that modulate trafficking and current properties (Campiglio and Flucher, 2015). Rodent models that are null for auxillary subunits, including $\alpha 2 \delta$ (ducky) and $\beta 4$ (lethargic) mice, display ataxia and spontaneous seizures (Felix, 2002). However, to date there is little evidence linking voltagegated $\mathrm{Ca}^{2+}$ channel auxillary subunits to genetic epilepsy in humans, and they will not be discussed further.

Much attention has been given to the low-threshold T-type $\mathrm{Ca}^{2+}$ channels due to their role in supporting burst-firing. These channels are found within the thalamocortical loop that is responsible for the aberrant activity that underlies spike-and-wave discharges (Huguenard and McCormick, 1992; Destexhe et al., 1996; Crunelli and Leresche, 2002). Early efforts found that variants in $C A C N A 1 H$, which encodes the $\mathrm{Ca}_{\mathrm{v}} 3.2$ subunit, appear enriched in GGE (Chen et al., 2003; Khosravani et al., 2004; Vitko et al., 2005; Heron et al., 2007). The discovery of a CACNA1H variant in genetic absence epilepsy rats from Strasbourg, a rodent model of genetic generalized epilepsy, further supported the importance of this gene (Powell et al., 2009). Interestingly, the impact of this mutation on channel function was splice-form specific, highlighting an important concept in functional analysis (Powell et al., 2009). Recent large-scale studies of common and rare variants in GGE have not revealed a major impact of CACNA1H variants (Heinzen et al., 2012; Steffens et al., 2012; Epi4K Consortium and Epilepsy Phenome/Genome Project, 2017). Moreover, many of the initially reported variants have emerged in available databases at high frequencies, suggesting that they are benign polymorphisms (Lek et al., 2016; Becker et al., 2017). However, Glauser et al. (2017) have reported that genetic variation in CACNA1H and CACNA1 can play a role in the differential drug response profile in CAE. At present, the most compelling evidence implicates mutations in CACNA1A as a cause of epilepsy in humans. 
1. CACNA1A. CACNA1A encodes the $\alpha 1$-subunit of the $\mathrm{Ca}_{\mathrm{v}} 2.1$ (P/Q-type) calcium channel that is critical for transmitter release within the central nervous system (Simms and Zamponi, 2014). The first link of CACNA1A to epilepsy was the discovery of a mutation in this gene in the tottering mouse (Fletcher et al., 1996). Subsequently, mutations in CACNA1A have been reported to associate with several neurologic conditions, including episodic ataxia (Jodice et al., 1997), spinocerebellar ataxia (Jodice et al., 1997), and familial hemiplegic migraine (Ducros et al., 1999).

a. Clinical syndrome and molecular findings. Early evidence supported the idea that loss-of-function CACNA1A mutations were associated with GGE (Jouvenceau et al., 2001; Imbrici et al., 2004). Microdeletions that encompass CACNA1A and a single truncating mutation have been associated with severe epileptic encephalopathies that include infantile spasms and West syndrome (Auvin et al., 2009; Damaj et al., 2015; Hino-Fukuyo et al., 2015). More recently, de novo missense mutations have been convincingly shown to cause severe epileptic encephalopathies with seizure types that typically include focal, tonic, and tonic-clonic seizures; severe intellectual disability; and motor impairment (Epi4K Consortium, 2016; Reinson et al., 2016). Although the biophysical impacts of all mutations are yet to be reported, the presence of deletions and truncating mutations argues that a loss-of-channel function is the primary underlying molecular deficit.

b. Mechanisms and potential targeted therapies. Homozygous Cacna1a knockout mice have progressive neurologic deficits that result in ataxia and dystonia, with mice dying within 4 weeks of birth (Jun et al., 1999; Fletcher et al., 2001). Similar phenotypes are seen in a range of spontaneous Cacna1a gene mutant mice with dystonia, ataxia, premature death, and epilepsy all observed in leaner, tottering, rolling, and rocker mice (Pietrobon, 2005). These potentially provide good preclinical mouse models of CACNA1A disease. Most reports investigating cellular mechanism in these mouse models implicate a reduction in excitatory synapse transmitter release, consistent with the integral role of these channels in this process. For example, reduced evoked postsynaptic currents have been measured at the Calyx of Held in the homozygous Cacna1a knockout mouse (Caddick et al., 1999). Similarly, a deficit has been reported at the cerebellar parallel fiber-Purkinje cell synapses and excitatory synapses within the ventrobasal nuclei in the leaner mouse model (Caddick et al., 1999). Recently, analysis of a conditional Cacna1a knockout mouse, in which deletion is limited to layer VI, reports that reduced excitatory neurotransmission at cortico-thalamic synapses is sufficient to generate generalized seizures (Bomben et al., 2016). How this change resulted in increased network excitability is not known. This lack of a robust cellular mechanism makes it difficult to develop disease-targeted strategies. However, mouse models may be predictive of pharmacosensitivity. For example, high-power low-frequency oscillations, which are thought to be a marker of cortical excitability in the tottering mouse, were markedly decreased by acetazolamide and 4-aminopyridine, drugs that are treatment options for episodic ataxia 2 (Cramer et al., 2015). Of note is the finding that spontaneous seizures in the Cacna1a knockout mouse can be abolished by knocking out Cacna1g (Song et al., 2004). This suggests that T-type $\mathrm{Ca}^{2+}$ channel blockers, including ethosuximide, may be good therapeutic options (Zamponi, 2016).

\section{Ligand-Gated Ion Channels in Epilepsy}

\section{A. N-Methyl-D-Aspartate Receptors}

Glutamate activates three main groups of ionotropic glutamate receptors named after their selective agonists: N-methyl-D-aspartate-type (NMDA), amino-3hydroxy-5-methyl-4-isoxazole propionic acid-type, and kainate (Smart and Paoletti, 2012; Alexander et al., 2015b; http://www.guidetopharmacology.org/GRAC/ FamilyDisplayForward?familyId=75). There are seven NMDA receptor subunits: GluN1, GluN2A-GluN2D, GluN3A, and GluN3B, each encoded by their respective gene, GRIN1, GRIN2A-D, and GRIN3A-B (Traynelis et al., 2010). NMDA receptors assemble as a tetramer requiring two glycine-binding GluN1 subunits and two glutamate-binding GluN2 subunits (Traynelis et al., 2010; Paoletti et al., 2013). GluN3 can incorporate into NMDA receptors, although its functional role is unclear (Traynelis et al., 2010). NMDA receptor subunits have a structure composed of four modular domains: the extracellular amino-terminal domain also known as the N-terminal domain; the extracellular ligandbinding domain; the transmembrane domain with four hydrophobic regions M1-4, of which M1, M3, and M4 are membrane-spanning helices and M2 forms a re-entrant loop; and the intracellular carboxylterminal domain (Sobolevsky et al., 2009; Meyerson et al., 2014).

NMDA receptors are nonselective cation channels permeable to $\mathrm{Na}^{+}, \mathrm{K}^{+}$, and $\mathrm{Ca}^{2+}$ ions. For typical NMDA receptors, $\sim 15 \%$ of the total inward current is carried by the $\mathrm{Ca}^{2+}$ ion, which acts as a critical second messenger (Burnashev et al., 1995; Schneggenburger, 1996). Due to their extracellular $\mathrm{Mg}^{2+}$ block, NMDA receptors require membrane depolarization to allow ion flow (Mayer and Westbrook, 1987). This strong voltage dependence means that NMDA receptors have the ability to act as coincidence detectors of pre- and postsynaptic activity, a feature that may be crucial to associative synaptic plasticity (Lüscher and Malenka, 2012) and dendritic electrogenesis (Palmer et al., 2012). The different GluN2 subunits define the pharmacological and kinetic properties of NMDA receptors (Traynelis et al., 2010). For example, NMDA receptors containing 
GluN2A are highly sensitive to $\mathrm{Zn}^{2+}$ block (Paoletti, 2011). In disease studies, mutations in epilepsy patients have been identified in GRIN1, GRIN2A, GRIN2B, and GRIN2D.

1. GRIN1. GRIN1 encodes the GluN1 NMDA receptor subunit (also known as NMDAR1 and NR1), which is ubiquitously expressed throughout the central nervous system, in both the adult and developing brain (Traynelis et al., 2010; Paoletti, 2011).

a. Clinical syndrome and molecular findings. Both heterozygous and homozygous GRIN1 mutations have been implicated in a spectrum of disease, including epileptic encephalopathies and intellectual disability. De novo heterozygous mutations seem to associate with profound developmental delay, with a lack of speech as a dominant feature. Associated phenotypes include seizures, hyperkinetic movements, involuntary movement, muscular hypotonia, oculogyric crises, and cortical blindness (Allen et al., 2013; Ohba et al., 2015; Lemke et al., 2016). Heterozygous GRIN1 mutations have also been identified in autosomal-dominant mental retardation (Hamdan et al., 2011; Redin et al., 2014; Zhu et al., 2015; Zehavi et al., 2017). Functional analysis of pathogenic heterozygous de novo GRIN1 mutations suggests they cause a loss-of-function (Lemke et al., 2016). Different mutations in GRIN1 have been shown to exhibit dominant-negative interactions of varying degrees, but with no clear genotypephenotype correlation (Lemke et al., 2016). Patients with homozygous GRIN1 truncation mutations experience continuous seizure activity and early death (Lemke et al., 2016).

b. Mechanisms and potential targeted therapies. Numerous studies use mouse lines that allow the deletion of Grin1 in a subset of neurons potentially modeling loss-of-function disease. Specific forebrain Grin 1 knockout results in impaired synaptic plasticity and memory storage (Nakazawa et al., 2002; Cui et al., 2004; Hasan et al., 2013). Seizures are not observed in any of these rodent models. This said, the impaired synaptic plasticity and memory deficits recapitulate the intellectual disability and motor disorders caused by mutations in GRIN1. The homozygous Grin1 knockout mice die as neonates, but have no seizures, suggesting that they also only partially recapitulate the severe clinical phenotype seen in humans harboring homozygous GRIN1 truncation mutations (Forrest et al., 1994). Therefore, although genetic mouse models exist, they have not faithfully recapitulated key features of GRIN1 disease.

Molecular studies report that most mutations in GRIN1 result in a loss-of-function. It is not immediately clear how this would lead to increased excitability, and it is possible that emerging pathologies are to blame. Correcting the loss-of-function deficit may benefit patients harboring loss-of-function mutations. However, activators of NMDA receptors are likely to increase neuronal activity, arguing that such drugs would have a narrow therapeutic window. The lack of good preclinical models and, as a consequence, a lack of understanding of the mechanisms behind the GRIN1 disease are currently hampering progress in developing targeted therapies.

2. GRIN2A. GRIN2A encodes the GluN2A NMDA receptor subunit. This subunit binds glutamate and is widely expressed throughout the brain (Akazawa et al., 1994).

a. Clinical syndrome and molecular findings. GRIN2A mutations have been associated with epilepsy and speech disorders (also known as epilepsy-aphasia spectrum disorders) that present as a broad clinical spectrum. At the less severe end of the spectrum, seizure phenotypes include typical or atypical rolandic epilepsy (also known as childhood epilepsy with centrotemporal spikes) (Lemke et al., 2013; Lesca et al., 2013). More severe phenotypes include epileptic encephalopathies such as Landau-Kleffner syndrome and epilepsy with continuous spikes and waves during slowwave sleep (Endele et al., 2010; Carvill et al., 2013b; Lemke et al., 2013; Lesca et al., 2013; Turner et al., 2015; Gao et al., 2017). Speech impairment is seen in all individuals with GRIN2A-related disorders and includes acquired aphasia, auditory agnosia, dysarthria, speech dyspraxia, impaired intelligibility and language delay, and regression (Turner et al., 2015; Myers and Scheffer, 2016). Intellectual disability occurs in up to $70 \%$ of individuals (Lemke et al., 2013; Lesca et al., 2013).

GRIN2A mutations include missense, truncating, splice, and copy number variants and can result in both gain- and loss-of-function. To date, no clear genotype-phenotype correlation has emerged (Strehlow et al., 2015). Causes of gain-of-function include reduction of $\mathrm{Zn}^{2+}$-mediated inhibition (Lemke et al., 2013; Serraz et al., 2016), increased glutamate binding (Pierson et al., 2014), altered duration of channel open and closed states (Lesca et al., 2013), and reduced $\mathrm{Mg}^{2+}$ block (Endele et al., 2010). Causes of loss-of-function for missense mutations include reduced agonist potency, decreased total protein levels, and reduced cell surface expression (Addis et al., 2017). Mutations predicted to cause truncation and deletion mutations further support the idea that loss-of-function can result in disease (Reutlinger et al., 2010; Carvill et al., 2013b; Lesca et al., 2013).

b. Mechanisms and potential targeted therapies. How both loss-of-function and gain-of-function mutations in GRIN2A cause disease is not clear. Gain-offunction mutations in NMDA receptor activation will increase hyperexcitability in brain networks. Blockers of NMDA receptors are therefore a potential effective targeted therapy. Pierson et al. (2014) have shown that the approved use-dependent NMDA receptor antagonist, memantine, can reduce currents back to normal levels for a gain-of-function mutation. Promisingly, 
memantine has been shown to reduce seizure activity in a patient with this mutation, although cognitive function showed no improvement. The mechanism underlying pathology in loss-of-function mutations is less intuitive and likely to be part of an emerging pathology. In this case, a targeted therapy would enhance GluN2Acontaining receptor function. Recently, a positive allosteric modulator of GluN2A-containing receptors (compound 275) has been reported to rescue loss-offunction missense mutations providing a preclinical pharmacologic tool, although this is yet to be tested in rodent models (Yu et al., 2015; Addis et al., 2017). With strategies for dealing with both gain- and loss-of-function available, epilepsy due to mutations in GRIN2A should benefit from targeted therapy led by genetic diagnostics and functional screening.

3. GRIN2B. GRIN2B encodes the NMDA receptor subunit GluN2B. GluN2B is expressed prenatally, and its expression decreases with age (Akazawa et al., 1994), paralleled by an increase in GluN2A expression (Monyer et al., 1994). This suggests a role for GluN2B in brain development and circuit formation (Hall et al., 2007).

a. Clinical syndrome and molecular findings. Mutations in GRIN2B have been associated with early infantile epileptic encephalopathies, including West syndrome with severe developmental delay, LennoxGastaut syndrome, and early-onset seizures with intellectual disability (Allen et al., 2013; Lemke et al., 2014; Zhang et al., 2015a; Smigiel et al., 2016). The mutated gene has also been associated with milder seizure syndromes, including early-onset focal epilepsy (Lemke et al., 2014). Intellectual disability associated with GRIN2B mutations can occur independently of epilepsy (Endele et al., 2010; Hamdan et al., 2014).

Initial functional assessment showed a decrease of $\mathrm{Mg}^{2+}$ block and higher $\mathrm{Ca}^{2+}$ permeability that correlated with the clinical phenotype severity (Lemke et al., 2014). These effects were seen for mutations located in the extracellular glutamate-binding domain region, as well as those variants affecting the re-entrant poreforming loop implicated in $\mathrm{Mg}^{2+}$ block. Early-onset epileptic encephalopathy has also been associated with a de novo GRIN2B splice-site mutation, providing evidence for GRIN2B loss-of-function as a cause of epileptic encephalopathies. Thus, both gain and loss of NMDA receptor function can cause similar disease phenotypes (Smigiel et al., 2016).

b. Mechanisms and potential targeted therapies. It is yet to be understood how both gain- and loss-ofGluN2B function leads to a similar disease phenotype. The use-dependent NMDA receptor blocker, memantine, would be predicted to be useful in gain-of-function disease. However, despite some efficacy in vitro, memantine had limited impact in patients with gain-offunction GRIN2B mutations (Platzer et al., 2017). For loss-of-function GRIN2B mutations, a strategy based on selective antagonism may be beneficial, but has not been tested. Again, a lack of good preclinical models is hampering progress with heterozygous GluN2B knockout mice not displaying a seizure phenotype. Homozygous Grin $2 b$ knockout mice die shortly after birth, but this is thought to be due to a defect in the suckling response (Kutsuwada et al., 1996).

4. GRIN2D. GRIN2D encodes the GluN2D NMDA receptor subunit. GluN2D expression is widespread during early development in the brain and decreases during adulthood (Akazawa et al., 1994; Monyer et al., 1994; von Engelhardt et al., 2015; Perszyk et al., 2016). In the adult hippocampus, striatum, and cortex, GluN2D is expressed in interneurons (Monyer et al., 1994; Standaert et al., 1996; Perszyk et al., 2016).

a. Clinical syndrome and molecular findings. A recurrent de novo mutation in GRIN2D has been identified in patients with early infantile epileptic encephalopathy, with phenotypes that include severe developmental delay, intellectual disability, and movement disorders ( $\mathrm{Li}$ et al., 2016). The missense mutation found in GRIN2D occurs in the M3 transmembrane domain and results in a gain-of-function through slower deactivation, increased channel open probability, and increased glutamate and glycine potency ( $\mathrm{Li}$ et al., 2016).

b. Mechanisms and potential targeted therapies. Transfection of cortical neurons with mutant GluN2D subunits leads to cell death. This is consistent with NMDA receptor overactivation and is blocked by the NMDA receptor blocker, memantine ( $\mathrm{Li}$ et al., 2016). A clinical study using oral memantine decreased seizures in patients in which conventional antiepileptic drugs were unsuccessful (Li et al., 2016). One patient, who developed status epilepticus, improved with treatment of ketamine and magnesium, both NMDA receptor blockers (Li et al., 2016).

GluN2D knockout mice partially recapitulate some of the clinical features of human disease, with a reduction in spontaneous locomotor activity similar to that seen in patients (Ikeda et al., 1995). However, no seizures have been reported in heterozygous or homozygous GluN2D knockout mice (Ikeda et al., 1995). There is a clear need for a knock-in mouse model to provide further insights into the disease mechanism. Given the importance of this subunit in early development, the engineering of conditional mouse models will be important in dissecting out developmental versus acute impact of the mutation in defining seizure susceptibility (Perszyk et al., 2016).

\section{B. $G A B A_{A}$ Receptors}

The neurotransmitter GABA drives the majority of inhibitory signaling in the mature brain. It can activate two classes of receptors: the ligand-gated ionotropic $\mathrm{GABA}_{\mathrm{A}}$ receptors and the $\mathrm{G}$ protein-coupled metabotropic $\mathrm{GABA}_{\mathrm{B}}$ receptors (Alexander et al., 2015b; 
http://www.guidetopharmacology.org/GRAC/FamilyDisplayForward?familyId=72). The $\mathrm{GABA}_{\mathrm{A}}$ receptors are members of the Cys-loop receptor family and are heteropentameric proteins that assemble from various combinations of proteins encoded by the $\alpha, \beta, \gamma, \delta, \varepsilon, \theta$, and $\rho$ subunit gene families. These subunit combinations introduce considerable receptor heterogeneity and vary in their functional properties, response to pharmacological agents, and brain expression patterns. The common subunit combinations exist as two $\alpha$-, two $\beta$-, and one $\gamma$ - or $\delta$-subunit (Macdonald and Olsen, 1994; Fritschy and Panzanelli, 2014).

GABA $_{A}$-mediated inhibition acts predominately through GABA release from synaptic vesicles onto postsynaptically located $\mathrm{GABA}_{\mathrm{A}}$ receptors. In the mature central nervous system, this leads to a brief inward flow of $\mathrm{Cl}^{-}$and an inhibitory postsynaptic potential. This transient receptor activation, with high GABA concentrations acting at the synapse, is termed phasic inhibition. There is a less spatially and temporally restricted $\mathrm{GABA}_{\mathrm{A}}$-mediated inhibition, in which low concentrations of GABA can act remotely from the synapse, termed tonic inhibition (Farrant and Nusser, 2005). Mutations in several genes encoding GABA $_{A}$ receptor subunits have been implicated in epilepsy. These include GABRA1, GABRB3, and GABRG2, which will be discussed in more detail below. Variants in GABRB2, GABRD, and GABRA3 have also been reported (Dibbens et al., 2004; Lenzen et al., 2005; Srivastava et al., 2014; Ishii et al., 2017; Niturad et al., 2017).

1. GABRA1. GABRA1 encodes the $\mathrm{GABA}_{\mathrm{A}}$ receptor $\alpha 1$-subunit, which is among the most abundantly expressed $\mathrm{GABA}_{\mathrm{A}}$ receptor subunits in the brain (Pirker et al., 2000). The $\alpha 1$-subunit containing GABA $_{A}$ receptors form the majority of postsynaptic $\mathrm{GABA}_{\mathrm{A}}$ receptors. These receptors mediate phasic inhibition (Hörtnagl et al., 2013).

a. Clinical syndrome and molecular findings. GABRA1 mutations have been reported to associate with GGE (Cossette et al., 2002; Maljevic et al., 2006; Lachance-Touchette et al., 2011; Johannesen et al., 2016). Epilepsy syndromes include JME, CAE, and febrile seizures (Cossette et al., 2002; Maljevic et al., 2006; Lachance-Touchette et al., 2011; Johannesen et al., 2016). More recent evidence implicates GABRA1 mutations in early infantile epileptic encephalopathies, including phenotypes of Dravet, Ohtahara, or West syndromes (Carvill et al., 2014; Johannesen et al., 2016; Kodera et al., 2016). Both GGE and the severe encephalopathies share common clinical features, including myoclonic seizures, tonic-clonic seizures, and photosensitivity (Cossette et al., 2002; LachanceTouchette et al., 2011; Johannesen et al., 2016). Functional analysis has unanimously shown loss-of-function, including reduced surface expression of the assembled $\mathrm{GABA}_{\mathrm{A}}$ receptor (Lachance-Touchette et al., 2011). This can be caused by increased endoplasmic degradation of the misfolded protein, as noted for the GABRA1 (A322D) variant (Gallagher et al., 2004, 2005). A reduction in the sensitivity to GABA has also been reported (Krampfl et al., 2005; Carvill et al., 2014). Interestingly, there is a correlation between GABRA1 mutations causing severe epilepsy and a significant loss of the GABA sensitivity of the receptor (Johannesen et al., 2016).

b. Mechanisms and potential targeted therapies. Heterozygous Gabra1 knockout mice have spontaneous electrographic spike-wave discharges and behavioral absence-like seizures (Arain et al., 2012), recapitulating some of the milder GGE phenotypes. The GABRA1 (A322D) knock-in mouse model based on a JME mutation (Cossette et al., 2002) also develops a spike-andwave electrographic phenotype (Arain et al., 2015). A direct comparison with the Gabra1 knockout indicated that both equally expressed the spike-and-wave discharge phenotype, suggesting that simple haploinsufficiency was the basis of disease (Arain et al., 2015). Both mutant mice develop myoclonic seizures later in life, which may model JME (Arain et al., 2015). These mice lines therefore are good preclinical models of GGE, providing an opportunity to devise and test new therapeutic strategies. New models that recapitulate more severe disease are still required.

Given that GABRA1 mutations impair GABAergic inhibition, it is not surprising that they increase neuronal excitability and consequently result in seizure phenotypes. Drugs that specifically increase $\mathrm{GABA}_{\mathrm{A}}$ function are therefore likely to be highly effective in patients carrying GABRA1 mutations. Consistent with this, vigabatrin and sodium valproate, both of which have been shown to maintain high GABA concentrations in the synaptic cleft (Connelly, 1993; Johannessen, 2000), successfully control seizures of patients with GABRA1 mutations (Kodera et al., 2016). Unfortunately, barbiturates and benzodiazepines that specifically target phasic $\mathrm{GABA}_{\mathrm{A}}$ inhibition have significant side effects (Kwan et al., 2001).

2. GABRB3. GABRB3 encodes the $\mathrm{GABA}_{\mathrm{A}}$ receptor $\beta 3$-subunit. The $\beta 3$-subunit is expressed at high levels in the embryonic brain, but its expression decreases to lower levels in the adult, except in the hippocampus. Additionally, $\beta 3$-subunit expression overlaps significantly with $\alpha 2$-subunit expression (Hörtnagl et al., 2013; Fritschy and Panzanelli, 2014).

a. Clinical syndrome and molecular findings. The Epi4K Consortium and Epilepsy Phenome/Genome Project were the first to provide strong evidence of GABRB3 mutations in early infantile epileptic encephalopathy (Allen et al., 2013). Several more recent studies have confirmed this original finding (Allen et al., 2013; Hamdan et al., 2014; Zhang et al., 2015a; Papandreou et al., 2016; Møller et al., 2017). The affected patients display a broad spectrum of seizure types, which includes absence, tonic, myoclonic, and 
generalized tonic-clonic seizures. Some of them also show delayed development, and mild to severe intellectual disabilities (Allen et al., 2013; Papandreou et al., 2016; Møller et al., 2017). Epilepsy syndromes reported include Lennox-Gastaut, infantile spasms, West, and Dravet syndromes (Allen et al., 2013; Møller et al., 2017). Milder syndromes caused by mutations in GABRB3 include $\mathrm{GEFS}^{+}$, early-onset absence epilepsy, epilepsy with myoclonic-atonic seizures, and multifocal epilepsy (Møller et al., 2017). Mutations in GABRB3, typically whole-gene deletions, have also been associated with Angelman syndrome (Tanaka et al., 2012).

Functional analysis uniformly suggests loss-of-function of GABRB3 variants through a variety of biophysical and trafficking deficits (Janve et al., 2016; Møller et al., 2017). As seen for GABRA1 mutations, some $G A B R B 3$ mutations causing more severe epilepsy show a significant loss of GABA sensitivity, suggesting a potential genotype-phenotype correlation (Møller et al., 2017). Similarly, mutations associated with Lennox-Gastaut syndrome have reduced GABAevoked current amplitudes, whereas infantile seizure variants show changes in current kinetics (Janve et al., 2016).

b. Mechanisms and potential targeted therapies. Given the role of GABRB3 in neuronal migration, synaptogenesis, and overall brain development, mutations in GABRB3 are likely to be linked to abnormal development of neuronal networks (Noebels et al., 2012; Tanaka et al., 2012). Therefore, targeting therapies in early development may be required to rescue seizure and neurodevelopmental symptoms in these patients. Homozygous Gabrb3 knockout mice show increased mortality and seizures and impaired social behavior, cognition, and motor coordination, whereas heterozygous mice have increased epileptiform EEG activity and seizure susceptibility (Homanics et al., 1997; DeLorey et al., 1998, 2008). These features recapitulate some of the phenotypes seen in GABRB3 disease, including Angelman syndrome.

3. GABRG2. GABRG2 encodes the $\gamma 2$-subunit found in the most common $\mathrm{GABA}_{\mathrm{A}}$ receptor in the brain, the $\alpha 1 \beta 2 \gamma 2$ complex.

a. Clinical syndrome and molecular findings. Mutations in GABRG2 have been associated with $\mathrm{GEFS}^{+}$, Dravet syndrome, CAE, familial febrile seizures, and epileptic encephalopathy (Baulac et al., 2001; Wallace et al., 2001; Harkin et al., 2002; Kananura et al., 2002; Audenaert et al., 2006; Shen et al., 2016; Hernandez et al., 2017). In vitro studies suggest a range of mutation-mediated functional deficits, including changes in benzodiazepine sensitivity, receptor kinetics, assembly, trafficking, and cell surface expression (Baulac et al., 2001; Bianchi et al., 2002; Bowser et al., 2002; Sancar and Czajkowski, 2004; Hales et al., 2005; Krampfl et al., 2005; Kang et al., 2006; Eugène et al., 2007; Kang and Macdonald, 2016; Hernandez et al.,
2017). In general, these functional analyses suggest that epilepsy-causing mutations result in a reduction in $\mathrm{GABA}_{\mathrm{A}}$ receptor-mediated inhibition, albeit through varying mechanisms. A consequent reduction in both phasic and/or tonic inhibition is proposed to underlie increases in neuronal hyperexcitability, resulting in seizures.

b. Mechanisms and potential targeted therapies. The GABRG2 (R43Q) knock-in mouse model was one of the first syndrome-specific models developed for genetic epilepsy, and faithfully recapitulates both the absence epilepsy and febrile seizures seen in the family (Tan et al., 2007). The GABRG2 (R43Q) mutation mouse model also recapitulates some of the genetic complexity seen in patients. Namely, the GABRG2 (R43Q) mice only display an absence phenotype in a spike-and-wave prone mouse strain (DBA), whereas the febrile seizure phenotype is robust in all mouse strains tested. This observation matches the penetrance seen in humans, which is low for absence seizures, whereas febrile seizures segregate as a highly penetrant autosomal dominant trait (Wallace et al., 2001). This implies that genetic principles that occur in human populations can be recapitulated in mouse models, providing the tools to interrogate complex heritability. The GABRG2 (R43Q) mouse model also has an expected pharmacosensitivity profile responding to first-line anti-absence drugs, ethosuximide and sodium valproate (Tan et al., 2007; Kim et al., 2015). The GABRG2 (Q390X) knock-in mouse model recapitulates the more severe seizure phenotype seen in patients with truncation mutations (Warner et al., 2016). These models provide an excellent opportunity to identify cellular mechanisms, and act as good preclinical models of disease.

A comparison between GABRG2 knock-in and knockout mice reveals that the molecular mechanisms for different seizure phenotypes may result from distinct molecular deficits. A spike-and-wave discharge phenotype in both the GABRG2 (R43Q) and heterozygous Gabrg2 knockout mice suggested that haploinsufficiency was sufficient to cause absence seizures (Reid et al., 2013; Warner et al., 2016). In contrast, only the GABRG2 (R43Q) model displayed a thermogenic seizure phenotype, suggesting a mechanism over and above haploinsufficiency was responsible for febrile seizures. In the GABRG2 (Q390X) mouse, which models a more severe epilepsy phenotype, a reduction in the expression of the $\mathrm{GABA}_{\mathrm{A}} \gamma 2$-subunit is greater than that seen in the Gabrg2 knockout, suggesting a dominant-negative effect of the mutant on the wildtype subunits (Warner et al., 2016). Whether disease caused by these distinct molecular mechanisms will require different targeted therapeutic strategies is yet to be determined.

The conditional GABRG2 (R43Q) mouse model provides an opportunity to explore the impact of the mutation in early development (Chiu et al., 2008). Mice 
harboring the GABRG2 (R43Q) mutation from birth were reported to be more susceptible to seizures (Chiu et al., 2008). This argues that mutation-mediated dysfunction can trigger a cascade of events (e.g., morphologic and/or transcriptional changes) that define long-term network stability. Therefore, targeted treatment early in development may be necessary to fully rescue patients harboring epilepsy-causing mutations.

In summary, mouse models of GABRG2-associated epilepsy have provided key insights into disease mechanisms. They suggest that phenotype severity may depend on the extent of dominant-negative impact of mutations and that different therapeutic strategies may be required for different seizure phenotypes. These models also highlight the potential need to treat early in development. Clearly, activators of the $\mathrm{GABA}_{\mathrm{A}}$ receptors, such as benzodiazepines, are likely to benefit these patients, with the early use of this class potentially overcoming the developmental consequences of harboring GABRG2 mutations (Haas et al., 2013).

\section{Nicotinic Acetylcholine Receptors (CHRNA4, CHRNB2, and CHRNA2)}

Vertebrate nicotinic acetylcholinergic receptors (nAChRs) are pentameric ligand-gated ion channels assembled from homologous subunits. CHRNA4 and CHRNB2 encode the $\alpha 4$ - and $\beta 2$-subunits, respectively, which combine to form the most abundant nAChR in the brain (Gotti et al., 1997; Hogg et al., 2003; Alexander et al., 2015b; http://www.guidetopharmacology.org/ GRAC/FamilyDisplayForward?familyId=76). CHRNA2 encodes the $\alpha 2$-subunit that is found predominantly in GABAergic interneurons (Son and Winzer-Serhan, 2006). Synaptic responses mediated by nAChRs appear to mediate only a small fraction of cholinergic transmission (Dani, 2001). Consistent with this, nAChRs are predominantly located on presynaptic, perisynaptic, and extrasynaptic sites (Hurst et al., 2013). A major role of central $\mathrm{nAChRs}$ is to modulate the release of other neurotransmitters, including glutamate, GABA, dopamine, and noradrenaline (Hurst et al., 2013).

1. Clinical Syndrome and Molecular Findings. As the first epilepsy gene, CHRNA4 holds an important place in the history of research into the genetic basis of epilepsy (Steinlein et al., 1995). It was discovered in an Australian family that presented with ADNFLE, an idiopathic epileptic syndrome with focal seizures arising from the frontal regions that occur predominantly during stage 2 of sleep (Scheffer et al., 1994). Several other mutations in CHRNA4, CHRNA2, and CHRNB2 have been found in families with ADNFLE (Steinlein et al., 1995, 1997; Hirose et al., 1999; De Fusco et al., 2000; Phillips et al., 2001; Bertrand et al., 2005; Aridon et al., 2006; Conti et al., 2015; Trivisano et al., 2015). A range of biophysical consequences of the various identified mutations has been reported (Sutor and Zolles, 2001; Becchetti et al., 2015). However, a common effect of mutations in the $\alpha 4-, \beta 2$-, and $\alpha 2$-subunits is an increase in the sensitivity of the receptor to acetylcholine, suggesting a convergent physiologic pathway may underpin disease (Bertrand et al., 2002, 2005; Aridon et al., 2006; Hoda et al., 2008).

2. Mechanisms and Potential Targeted Therapies. CHRNA4 (S252F) and CHRNA4 (+L264) knock-in mouse models based on human mutations provide support for a gain-of-function of the nAChR in ADNFLE (Klaassen et al., 2006). Mutant mice display abnormal EEG patterns consistent with seizure activity (Klaassen et al., 2006), as well as a dystonic phenotype that may form part of the spectrum observed in ADNFLE (Teper et al., 2007). One striking cellular phenotype is a more than 20 -fold increase in nicotineevoked synaptic release exclusively at inhibitory synapses (Klaassen et al., 2006). This implicates increased inhibitory activity as the basis of hyperexcitability, an idea supported by the fact that seizures are blocked by subconvulsive doses of a $\mathrm{GABA}_{\mathrm{A}}$ receptor antagonist. Although seemingly paradoxical, it has been proposed by others that circuit level increases in neocortical $\mathrm{GABA}_{\mathrm{A}}$ receptor-mediated current can be epileptogenic (Mann and Mody, 2008).

A transgenic mouse model based on a gain-of-function mutation in CHRNB2 displays a spontaneous epileptic phenotype with very frequent interictal spikes and seizures (Manfredi et al., 2009). Mutant $\beta 2$-subunit expression is driven under a conditionally controlled promoter allowing the silencing of transgene expression. Using this model, it was shown that silencing during early development was sufficient to prevent the occurrence of seizures in adulthood (Manfredi et al., 2009). This is similar to findings in the conditional GABRG2 (R43Q) mouse model (see above), and highlights that mutation-mediated long-lasting alterations of neuronal networks in the developing brain may lead to epilepsy. Cellular analysis in this mouse model is limited to the relatively crude synaptosome preparation, but does reveal increased sensitivity of acetylcholinergic-mediated release of dopamine (O'Neill et al., 2013). A transgenic rat with a gain-offunction mutation also displays infrequent spontaneous epileptic seizures that are described as being similar to paroxysmal arousals observed in human ADNFLE, providing another potential preclinical model (Shiba et al., 2015).

Despite being identified over 20 years ago, no targeted therapies for mutations in acetylcholinergic receptor have eventuated. The mainstay of therapy in patients with nAChR mutations is carbamazepine with approximately $70 \%$ showing remission on low doses. Molecular and cellular studies argue that drugs that block nAChR should be effective in disease caused by mutation in CHRNA4, CHRNB2, and CHRNA2. Several studies have shown the potential of nAChR antagonists as antiseizure drugs (Ghasemi and Hadipour-Niktarash, 2015). 
Mechanistic studies in rodent models suggest that increased release of GABA may underlie hypersynchrony at the neuronal network scale (Klaassen et al., 2006). Therefore, low-dose $\mathrm{GABA}_{\mathrm{A}}$ receptor antagonists may benefit patients harboring CHRNA4 mutations. However, this is unlikely to become a treatment strategy given the obvious narrow therapeutic window of such drugs. Finally, the developmental impact of the gain-of-function CHRNB2 mutation suggests that it may be necessary to treat patients early to fully overcome the epileptogenic process.

\section{Conclusion}

The last two decades have begun to unravel the complexity of the genetic architecture of human epilepsy. It is now clear that hundreds of genes can play a pathogenic role in the disease. Table 1 summarizes the ion channels discussed and the proposed molecular and cellular deficits. Much of the hidden genetics in epilepsy that has not been apparent from traditional clinical studies can be explained by de novo mutations and mosaicism (Thomas and Berkovic, 2014). However, most common epilepsy syndromes still lack comprehensive genetic models. Electrophysiological testing on heterologously expressed ion channels remains the mainstay of functional validation. These are opaque to a number of important biologic readouts, and newer, more sophisticated in vitro models need to be developed, with assays based on human iPSC-derived neurons showing some promise. For loss-of-function mutations, standard knockout rodent models have proven to be useful. However, in most cases, the development of syndrome-specific mouse models based on human mutation (Table 1) has become the new expected standard. It is remarkable how frequently these knock-in mouse models recapitulate the disease phenotypes seen in patients and allow cellular and neuronal network function to be probed. They also act as good preclinical tools. Using a combination of these tools, we have been developing a much clearer idea of disease mechanisms in genetic epilepsy and consequently devising therapeutic strategies based on these mechanisms. Some success has been achieved in the repurposing of drugs that target the disease processes. Epilepsy is also well placed to take advantage of newer molecular and antibody technologies that can selectively target the affected genes. This includes antisense technology to reduce function where mutations cause a gain-of-function. Also, ingenious application of new molecular technologies can be used to increase function in loss-of-function disease. For example, the use of CRISPR-on could activate genes to increase activity to restore function (Cheng et al., 2013). Genetic epilepsy is primed to benefit from the genetic revolution, with the promise of further powerful and targeted therapeutic strategies to come.

\section{Acknowledgments}

We thank Ian Forster, Marie Phillips, Lauren Bleakley, and Tim Sissons for carefully reading this manuscript and Svenja Pachernegg for help with the graphic design of figures.

\section{Authorship Contributions}

Wrote or contributed to the writing of the manuscript: Oyrer, Maljevic, Scheffer, Berkovic, Petrou, Reid.

\section{References}

Abed HS, Fulcher JR, Kilborn MJ, and Keech AC (2016) Inappropriate sinus tachycardia: focus on ivabradine. Intern Med $J$ 46:875-883.

Addis L, Virdee JK, Vidler LR, Collier DA, Pal DK, and Ursu D (2017) Epilepsyassociated GRIN2A mutations reduce NMDA receptor trafficking and agonist potency: molecular profiling and functional rescue. Sci Rep 7:66.

Akazawa C, Shigemoto R, Bessho Y, Nakanishi S, and Mizuno N (1994) Differential expression of five N-methyl-D-aspartate receptor subunit mRNAs in the cerebellum of developing and adult rats. J Comp Neurol 347:150-160.

Alexander SP, Catterall WA, Kelly E, Marrion N, Peters JA, Benson HE, Faccenda E, Pawson AJ, Sharman JL, Southan C, et al.; CGTP Collaborators (2015a) The concise guide to pharmacology 2015/16: voltage-gated ion channels. Br J Pharmacol 172:5904-5941.

Alexander SP, Peters JA, Kelly E, Marrion N, Benson HE, Faccenda E, Pawson AJ, Sharman JL, Southan C, and Davies JA; CGTP Collaborators (2015b) The concise guide to pharmacology 2015/16: ligand-gated ion channels. Br J Pharmacol 172: $5870-5903$.

Allen AS, Berkovic SF, Cossette P, Delanty N, Dlugos D, Eichler EE, Epstein MP, Glauser T, Goldstein DB, Han Y, et al.; Epi4K Consortium; ; Epilepsy Phenome/ Genome Project (2013) De novo mutations in epileptic encephalopathies. Nature 501:217-221.

Allen NM, Conroy J, Shahwan A, Lynch B, Correa RG, Pena SDJ, McCreary D, Magalhães TR, Ennis S, Lynch SA, et al. (2016) Unexplained early onset epileptic encephalopathy: exome screening and phenotype expansion. Epilepsia 57:e12-e17.

Anand G, Collett-White F, Orsini A, Thomas S, Jayapal S, Trump N, Zaiwalla Z, and Jayawant S (2016) Autosomal dominant SCN8A mutation with an unusually mild phenotype. Eur J Paediatr Neurol 20:761-765.

Anderson LL, Hawkins NA, Thompson CH, Kearney JA, and George AL Jr (2017) Unexpected efficacy of a novel sodium channel modulator in Dravet syndrome. Sci Rep 7:1682.

Anderson LL, Thompson CH, Hawkins NA, Nath RD, Petersohn AA, Rajamani S, Bush WS, Frankel WN, Vanoye CG, Kearney JA, et al. (2014) Antiepileptic activity of preferential inhibitors of persistent sodium current. Epilepsia 55:1274-1283.

Arain F, Zhou C, Ding L, Zaidi S, and Gallagher MJ (2015) The developmental evolution of the seizure phenotype and cortical inhibition in mouse models of juvenile myoclonic epilepsy. Neurobiol Dis 82:164-175.

Arain FM, Boyd KL, and Gallagher MJ (2012) Decreased viability and absence-like epilepsy in mice lacking or deficient in the GABAA receptor $\alpha 1$ subunit. Epilepsia 53:e161-e165.

Aridon P, Marini C, Di Resta C, Brilli E, De Fusco M, Politi F, Parrini E, Manfredi I, Pisano T, Pruna D, et al. (2006) Increased sensitivity of the neuronal nicotinic receptor alpha 2 subunit causes familial epilepsy with nocturnal wandering and ictal fear. Am J Hum Genet 79:342-350.

Audenaert D, Claes L, Ceulemans B, Löfgren A, Van Broeckhoven C, and De Jonghe P (2003) A deletion in SCN1B is associated with febrile seizures and early-onset absence epilepsy. Neurology 61:854-856.

Audenaert D, Schwartz E, Claeys KG, Claes L, Deprez L, Suls A, Van Dyck T, Lagae L, Van Broeckhoven C, Macdonald RL, et al. (2006) A novel GABRG2 mutation associated with febrile seizures. Neurology 67:687-690.

Auvin S, Holder-Espinasse M, Lamblin M-D, and Andrieux J (2009) Array-CGH detection of a de novo 0.7-Mb deletion in 19p13.13 including CACNA1A associated with mental retardation and epilepsy with infantile spasms. Epilepsia 50:2501-2503.

Barcia G, Fleming MR, Deligniere A, Gazula V-R, Brown MR, Langouet M, Chen H, Kronengold J, Abhyankar A, Cilio R, et al. (2012) De novo gain-of-function KCNT1 channel mutations cause malignant migrating partial seizures of infancy. Nat Genet 44:1255-1259.

Barker BS, Ottolini M, Wagnon JL, Hollander RM, Meisler MH, and Patel MK (2016 The SCN8A encephalopathy mutation p.Ile1327Val displays elevated sensitivity to the anticonvulsant phenytoin. Epilepsia 57:1458-1466.

Barral S and Kurian MA (2016) Utility of induced pluripotent stem cells for the study and treatment of genetic diseases: focus on childhood neurological disorders. Front Mol Neurosci 9:78.

Baulac S, Huberfeld G, Gourfinkel-An I, Mitropoulou G, Beranger A, Prud'homme JF, Baulac M, Brice A, Bruzzone R, and LeGuern E (2001) First genetic evidence of GABA(A) receptor dysfunction in epilepsy: a mutation in the gamma2-subunit gene. Nat Genet 28:46-48.

Bausch AE, Dieter R, Nann Y, Hausmann M, Meyerdierks N, Kaczmarek LK, Ruth P, and Lukowski R (2015) The sodium-activated potassium channel slack is required for optimal cognitive flexibility in mice. Learn Mem 22:323-335.

Bearden D, Strong A, Ehnot J, DiGiovine M, Dlugos D, and Goldberg EM (2014) Targeted treatment of migrating partial seizures of infancy with quinidine. Ann Neurol 76:457-461.

Becchetti A, Aracri P, Meneghini S, Brusco S, and Amadeo A (2015) The role of nicotinic acetylcholine receptors in autosomal dominant nocturnal frontal lobe epilepsy. Front Physiol 6:22.

Becker F, Reid CA, Hallmann K, Tae H-S, Phillips AM, Teodorescu G, Weber YG, Kleefuss-Lie A, Elger C, Perez-Reyes E, et al. (2017) Functional variants in HCN4 
andCACNA1H may contribute to genetic generalized epilepsy. Epilepsia Open 2: 334-342.

Ben-Shalom R, Keeshen CM, Berrios KN, An JY, Sanders SJ, and Bender KJ (2017) Opposing effects on nav1.2 function underlie differences between SCN2A variants observed in individuals with autism spectrum disorder or infantile seizures. Biol Psychiatry 82:224-232.

Bentzen BH, Olesen S-P, Rønn LCB, and Grunnet M (2014) BK channel activators and their therapeutic perspectives. Front Physiol 5:389.

Berkovic SF, Heron SE, Giordano L, Marini C, Guerrini R, Kaplan RE, Gambardella A, Steinlein OK, Grinton BE, Dean JT, et al. (2004) Benign familial neonatal-infantile seizures: characterization of a new sodium channelopathy. Ann Neurol 55:550-557.

Bertrand D, Elmslie F, Hughes E, Trounce J, Sander T, Bertrand S, and Steinlein OK (2005) The CHRNB2 mutation I312M is associated with epilepsy and distinct memory deficits. Neurobiol Dis 20:799-804

Bertrand D, Picard F, Le Hellard S, Weiland S, Favre I, Phillips H, Bertrand S, Berkovic SF, Malafosse A, and Mulley J (2002) How mutations in the nAChRs can cause ADNFLE epilepsy. Epilepsia 43 (Suppl 5):112-122.

Bhattacharjee A, Gan L, and Kaczmarek LK (2002) Localization of the slack potassium channel in the rat central nervous system. J Comp Neurol 454:241-254.

Bhattacharjee A and Kaczmarek LK (2005) For K+ channels, Na+ is the new Ca2+. Trends Neurosci 28:422-428.

Bianchi MT, Song L, Zhang H, and Macdonald RL (2002) Two different mechanisms of disinhibition produced by GABAA receptor mutations linked to epilepsy in humans. J Neurosci 22:5321-5327.

Biervert C, Schroeder BC, Kubisch C, Berkovic SF, Propping P, Jentsch TJ, and Steinlein OK (1998) A potassium channel mutation in neonatal human epilepsy. Science 279:403-406.

Blanchard MG, Willemsen MH, Walker JB, Dib-Hajj SD, Waxman SG, Jongmans MCJ, Kleefstra T, van de Warrenburg BP, Praamstra P, Nicolai J, et al. (2015) De novo gain-of-function and loss-of-function mutations of SCN8A in patients with intellectual disabilities and epilepsy. $J$ Med Genet 52:330-337.

Blumkin L, Kivity S, Lev D, Cohen S, Shomrat R, Lerman-Sagie T, and LeshinskySilver E (2012) A compound heterozygous missense mutation and a large deletion in the KCTD7 gene presenting as an opsoclonus-myoclonus ataxia-like syndrome. $J$ Neurol 259:2590-2598.

Boerma RS, Braun KP, van den Broek MPH, van Berkestijn FMC, Swinkels ME, Hagebeuk EO, Lindhout D, van Kempen M, Boon M, Nicolai J, et al. (2016) Remarkable phenytoin sensitivity in 4 children with SCN8A-related epilepsy: a molecular neuropharmacological approach. Neurotherapeutics 13:192-197.

Bomben VC, Aiba I, Qian J, Mark MD, Herlitze S, and Noebels JL (2016) Isolated P/Q calcium channel deletion in layer VI corticothalamic neurons generates absence epilepsy. J Neurosci 36:405-418.

Bowser DN, Wagner DA, Czajkowski C, Cromer BA, Parker MW, Wallace RH, Harkin LA, Mulley JC, Marini C, Berkovic SF, et al. (2002) Altered kinetics and benzodiazepine sensitivity of a GABAA receptor subunit mutation [gamma 2(R43Q)] found in human epilepsy. Proc Natl Acad Sci USA 99:15170-15175.

Brew HM, Gittelman JX, Silverstein RS, Hanks TD, Demas VP, Robinson LC, Robbins CA, McKee-Johnson J, Chiu SY, Messing A, et al. (2007) Seizures and reduced life span in mice lacking the potassium channel subunit Kv1.2, but hypoexcitability and enlarged Kv1 currents in auditory neurons. J Neurophysiol 98:1501-1525.

Brewster A, Bender RA, Chen Y, Dube C, Eghbal-Ahmadi M, and Baram TZ (2002) Developmental febrile seizures modulate hippocampal gene expression of hyperpolarization-activated channels in an isoform- and cell-specific manner. J Neurosci 22:4591-4599.

Brown DA and Adams PR (1980) Muscarinic suppression of a novel voltage-sensitive $\mathrm{K}+$ current in a vertebrate neurone. Nature 283:673-676.

Browne DL, Brunt ER, Griggs RC, Nutt JG, Gancher ST, Smith EA, and Litt M (1995) Identification of two new KCNA1 mutations in episodic ataxia/myokymia families. Hum Mol Genet 4:1671-1672.

Browne DL, Gancher ST, Nutt JG, Brunt ER, Smith EA, Kramer P, and Litt M (1994) Episodic ataxia/myokymia syndrome is associated with point mutations in the human potassium channel gene, KCNA1. Nat Genet 8:136-140.

Burnashev N, Zhou Z, Neher E, and Sakmann B (1995) Fractional calcium currents through recombinant GluR channels of the NMDA, AMPA and kainate receptor subtypes. J Physiol 485:403-418.

Cacheaux LP, Topf N, Tibbs GR, Schaefer UR, Levi R, Harrison NL, Abbott GW, and Goldstein PA (2005) Impairment of hyperpolarization-activated, cyclic nucleotide-gated channel function by the intravenous general anesthetic propofol. $J$ Pharmacol Exp Ther 315:517-525.

Caddick SJ, Wang C, Fletcher CF, Jenkins NA, Copeland NG, and Hosford DA (1999) Excitatory but not inhibitory synaptic transmission is reduced in lethargic (Cacnb4(lh)) and tottering (Cacna1atg) mouse thalami. J Neurophysiol $\mathbf{8 1}$ 2066-2074.

Caldwell JH, Schaller KL, Lasher RS, Peles E, and Levinson SR (2000) Sodium channel $\mathrm{Na}(\mathrm{v}) 1.6$ is localized at nodes of ranvier, dendrites, and synapses. Proc Natl Acad Sci USA 97:5616-5620.

Campiglio M and Flucher BE (2015) The role of auxiliary subunits for the functional diversity of voltage-gated calcium channels. J Cell Physiol 230:2019-2031.

Cao D, Ohtani H, Ogiwara I, Ohtani S, Takahashi Y, Yamakawa K, and Inoue Y (2012) Efficacy of stiripentol in hyperthermia-induced seizures in a mouse model of Dravet syndrome. Epilepsia 53:1140-1145.

Carroll LS, Woolf R, Ibrahim Y, Williams HJ, Dwyer S, Walters J, Kirov G, O'Donovan MC, and Owen MJ (2016) Mutation screening of SCN2A in schizophrenia and identification of a novel loss-of-function mutation. Psychiatr Genet 26:60-65.

Carvill GL, Heavin SB, Yendle SC, McMahon JM, O'Roak BJ, Cook J, Khan A, Dorschner MO, Weaver M, Calvert S, et al. (2013a) Targeted resequencing in epileptic encephalopathies identifies de novo mutations in CHD2 and SYNGAP1. Nat Genet 45:825-830.
Carvill GL, Regan BM, Yendle SC, O’Roak BJ, Lozovaya N, Bruneau N, Burnashev N, Khan A, Cook J, Geraghty E, et al. (2013b) GRIN2A mutations cause epilepsyaphasia spectrum disorders. Nat Genet 45:1073-1076.

Carvill GL, Weckhuysen S, McMahon JM, Hartmann C, Møller RS, Hjalgrim H, Cook J, Geraghty E, O'Roak BJ, Petrou S, et al. (2014) GABRA1 and STXBP1: novel genetic causes of Dravet syndrome. Neurology 82:1245-1253.

Castle NA (1991) Selective inhibition of potassium currents in rat ventricle by clofilium and its tertiary homolog. J Pharmacol Exp Ther 257:342-350.

Catterall WA (2000) Structure and regulation of voltage-gated Ca2+ channels. Annu Rev Cell Dev Biol 16:521-555.

Catterall WA, Goldin AL, and Waxman SG (2005) International Union of Pharmacology. XLVII. Nomenclature and structure-function relationships of voltage-gated sodium channels. Pharmacol Rev 57:397-409.

Charlier C, Singh NA, Ryan SG, Lewis TB, Reus BE, Leach RJ, and Leppert M (1998) A pore mutation in a novel KQT-like potassium channel gene in an idiopathic epilepsy family. Nat Genet 18:53-55.

Cheah CS, Yu FH, Westenbroek RE, Kalume FK, Oakley JC, Potter GB, Rubenstein JL, and Catterall WA (2012) Specific deletion of NaV1.1 sodium channels in inhibitory interneurons causes seizures and premature death in a mouse model of Dravet syndrome. Proc Natl Acad Sci USA 109:14646-14651.

Chen C, Westenbroek RE, Xu X, Edwards CA, Sorenson DR, Chen Y, McEwen DP, O'Malley HA, Bharucha V, Meadows LS, et al. (2004) Mice lacking sodium channel beta1 subunits display defects in neuronal excitability, sodium channel expression, and nodal architecture. $J$ Neurosci 24:4030-4042.

Chen K, Aradi I, Thon N, Eghbal-Ahmadi M, Baram TZ, and Soltesz I (2001) Persistently modified h-channels after complex febrile seizures convert the seizureinduced enhancement of inhibition to hyperexcitability. Nat Med 7:331-337.

Chen X, Shu S, and Bayliss DA (2005) Suppression of ih contributes to propofolinduced inhibition of mouse cortical pyramidal neurons. $J$ Neurophysiol 94: $3872-3883$

Chen X, Shu S, and Bayliss DA (2009a) HCN1 channel subunits are a molecular substrate for hypnotic actions of ketamine. J Neurosci 29:600-609.Chen X, Shu S, Kennedy DP, Willcox SC, and Bayliss DA (2009b) Subunit-specific effects of isoflurane on neuronal Ih in HCN1 knockout mice. J Neurophysiol 101:129-140.

Chen Y, Lu J, Pan H, Zhang Y, Wu H, Xu K, Liu X, Jiang Y, Bao X, Yao Z, et al. (2003) Association between genetic variation of CACNA1H and childhood absence epilepsy. Ann Neurol 54:239-243.

Cheng AW, Wang H, Yang H, Shi L, Katz Y, Theunissen TW, Rangarajan S, Shivalila CS, Dadon DB, and Jaenisch R (2013) Multiplexed activation of endogenous genes by CRISPR-on, an RNA-guided transcriptional activator system. Cell Res 23:1163-1171. Chiron C and Dulac O (2011) The pharmacologic treatment of Dravet syndrome. Epilepsia 52 (Suppl 2):72-75.

Chiu C, Reid CA, Tan HO, Davies PJ, Single FN, Koukoulas I, Berkovic SF, Tan S-S, Sprengel R, Jones MV, et al. (2008) Developmental impact of a familial GABAA receptor epilepsy mutation. Ann Neurol 64:284-293.

Chong PF, Nakamura R, Saitsu H, Matsumoto N, and Kira R (2016) Ineffective quinidine therapy in early onset epileptic encephalopathy with KCNT1 mutation. Ann Neurol 79:502-503.

Claes L, Del-Favero J, Ceulemans B, Lagae L, Van Broeckhoven C, and De Jonghe P (2001) De novo mutations in the sodium-channel gene SCN1A cause severe myoclonic epilepsy of infancy. Am J Hum Genet 68:1327-1332.

Connelly JF (1993) Vigabatrin. Ann Pharmacother 27:197-204.

Contet C, Goulding SP, Kuljis DA, and Barth AL (2016) BK channels in the central nervous system. Int Rev Neurobiol 128:281-342.

Conti V, Aracri P, Chiti L, Brusco S, Mari F, Marini C, Albanese M, Marchi A, Liguor C, Placidi F, et al. (2015) Nocturnal frontal lobe epilepsy with paroxysmal arousals due to CHRNA2 loss of function. Neurology 84:1520-1528.

Corbett MA, Bellows ST, Li M, Carroll R, Micallef S, Carvill GL, Myers CT, Howell KB, Maljevic S, Lerche H, et al. (2016) Dominant KCNA2 mutation causes episodic ataxia and pharmacoresponsive epilepsy. Neurology 87:1975-1984.

Cossette P, Liu L, Brisebois K, Dong H, Lortie A, Vanasse M, Saint-Hilaire J-M Carmant L, Verner A, Lu W-Y, et al. (2002) Mutation of GABRA1 in an autosomal dominant form of juvenile myoclonic epilepsy. Nat Genet 31:184-189.

Cossette $\mathrm{P}$, Loukas $\mathrm{A}$, Lafrenière RG, Rochefort $\mathrm{D}$, Harvey-Girard $\mathrm{E}$, Ragsdale DS, Dunn RJ, and Rouleau GA (2003) Functional characterization of the D188V mutation in neuronal voltage-gated sodium channel causing generalized epilepsy with febrile seizures plus (GEFS). Epilepsy Res 53:107-117.

Cramer SW, Popa LS, Carter RE, Chen G, and Ebner TJ (2015) Abnormal excitability and episodic low-frequency oscillations in the cerebral cortex of the tottering mouse. $J$ Neurosci 35:5664-5679.

Crunelli V and Leresche N (2002) Childhood absence epilepsy: genes, channels, neurons and networks. Nat Rev Neurosci 3:371-382.

Cui Z, Wang H, Tan Y, Zaia KA, Zhang S, and Tsien JZ (2004) Inducible and reversible NR1 knockout reveals crucial role of the NMDA receptor in preserving remote memories in the brain. Neuron 41:781-793.

D’Adamo MC, Hasan S, Guglielmi L, Servettini I, Cenciarini M, Catacuzzeno L, and Franciolini F (2015) New insights into the pathogenesis and therapeutics of episodic ataxia type 1. Front Cell Neurosci 9:317.

Damaj L, Lupien-Meilleur A, Lortie A, Riou É, Ospina LH, Gagnon L, Vanasse C, and Rossignol E (2015) CACNA1A haploinsufficiency causes cognitive impairment, autism and epileptic encephalopathy with mild cerebellar symptoms. Eur J Hum Genet 23:1505-1512.

Dani JA (2001) Overview of nicotinic receptors and their roles in the central nervous system. Biol Psychiatry 49:166-174.

Davis TH, Chen C, and Isom LL (2004) Sodium channel beta1 subunits promote neurite outgrowth in cerebellar granule neurons. $J$ Biol Chem 279: 51424-51432.

De Fusco M, Becchetti A, Patrignani A, Annesi G, Gambardella A, Quattrone A, Ballabio A, Wanke E, and Casari G (2000) The nicotinic receptor beta 2 subunit is mutant in nocturnal frontal lobe epilepsy. Nat Genet 26:275-276. 
de Kovel CGF, Meisler MH, Brilstra EH, van Berkestijn FMC, van 't Slot R, van Lieshout S, Nijman IJ, O'Brien JE, Hammer MF, Estacion M, et al. (2014) Characterization of a de novo SCN8A mutation in a patient with epileptic encephalopathy. Epilepsy Res 108:1511-1518.

de Kovel CGF, Trucks H, Helbig I, Mefford HC, Baker C, Leu C, Kluck C, Muhle H, von Spiczak S, Ostertag P, et al. (2010) Recurrent microdeletions at 15q11.2 and 16p13.11 predispose to idiopathic generalized epilepsies. Brain 133:23-32.

Delmas P and Brown DA (2005) Pathways modulating neural KCNQ/M (Kv7) potassium channels. Nat Rev Neurosci 6:850-862.

DeLorey TM, Handforth A, Anagnostaras SG, Homanics GE, Minassian BA Asatourian A, Fanselow MS, Delgado-Escueta A, Ellison GD, and Olsen RW (1998) Mice lacking the beta3 subunit of the GABAA receptor have the epilepsy phenotype and many of the behavioral characteristics of Angelman syndrome. $J$ Neurosci 18:8505-8514

DeLorey TM, Sahbaie P, Hashemi E, Homanics GE, and Clark JD (2008) Gabrb3 gene deficient mice exhibit impaired social and exploratory behaviors, deficits in non-selective attention and hypoplasia of cerebellar vermal lobules: a potential model of autism spectrum disorder. Behav Brain Res 187:207-220.

Depienne C, Trouillard O, Gourfinkel-An I, Saint-Martin C, Bouteiller D, Graber D, Barthez-Carpentier M-A, Gautier A, Villeneuve N, Dravet C, et al. (2010) Mechanisms for variable expressivity of inherited SCN1A mutations causing Dravet syndrome. J Med Genet 47:404-410.

Destexhe A, Contreras D, Steriade M, Sejnowski TJ, and Huguenard JR (1996) In vivo, in vitro, and computational analysis of dendritic calcium currents in thalamic reticular neurons. $J$ Neurosci 16:169-185.

Devaux JJ, Kleopa KA, Cooper EC, and Scherer SS (2004) KCNQ2 is a nodal K+ channel. J Neurosci 24:1236-1244.

Devinsky O, Cross JH, Laux L, Marsh E, Miller I, Nabbout R, Scheffer IE, Thiele EA, and Wright S; Cannabidiol in Dravet Syndrome Study Group (2017) Trial of cannabidiol for drug-resistant seizures in the Dravet syndrome. $N$ Engl $J$ Med 376: 2011-2020

Dibbens LM, de Vries B, Donatello S, Heron SE, Hodgson BL, Chintawar S, Crompton DE, Hughes JN, Bellows ST, Klein KM, et al. (2013) Mutations in DEPDC5 cause familial focal epilepsy with variable foci. Nat Genet 45:546-551.

Dibbens LM, Feng H-J, Richards MC, Harkin LA, Hodgson BL, Scott D, Jenkins M, Petrou S, Sutherland GR, Scheffer IE, et al. (2004) GABRD encoding a protein for extra- or peri-synaptic GABAA receptors is a susceptibility locus for generalized epilepsies. Hum Mol Genet 13:1315-1319.

Dibbens LM, Mullen S, Helbig I, Mefford HC, Bayly MA, Bellows S, Leu C, Trucks H, Obermeier T, Wittig M, et al.; EPICURE Consortium (2009) Familial and sporadic 15q13.3 microdeletions in idiopathic generalized epilepsy: precedent for disorders with complex inheritance. Hum Mol Genet 18:3626-3631.

Dibbens LM, Reid CA, Hodgson B, Thomas EA, Phillips AM, Gazina E, Cromer BA, Clarke AL, Baram TZ, Scheffer IE, et al. (2010) Augmented currents of an HCN2 variant in patients with febrile seizure syndromes. Ann Neurol 67:542-546.

DiFrancesco JC, Barbuti A, Milanesi R, Coco S, Bucchi A, Bottelli G, Ferrarese C, Franceschetti S, Terragni B, Baruscotti M, et al. (2011) Recessive loss-of-function mutation in the pacemaker HCN2 channel causing increased neuronal excitability in a patient with idiopathic generalized epilepsy. J Neurosci 31:17327-17337.

DiFrancesco JC and DiFrancesco D (2015) Dysfunctional HCN ion channels in neurological diseases. Front Cell Neurosci 6:174.

Du J, Tao-Cheng JH, Zerfas P, and McBain CJ (1998) The K+ channel, Kv2.1, is apposed to astrocytic processes and is associated with inhibitory postsynaptic membranes in hippocampal and cortical principal neurons and inhibitory interneurons. Neuroscience 84:37-48.

Du W, Bautista JF, Yang H, Diez-Sampedro A, You S-A, Wang L, Kotagal P, Lüders HO, Shi J, Cui J, et al. (2005) Calcium-sensitive potassium channelopathy in human epilepsy and paroxysmal movement disorder. Nat Genet 37:733-738.

Dubé CM, Brewster AL, Richichi C, Zha Q, and Baram TZ (2007) Fever, febrile seizures and epilepsy. Trends Neurosci 30:490-496.

Ducros A, Denier C, Joutel A, Vahedi K, Michel A, Darcel F, Madigand M, Guerouaou D, Tison F, Julien J, et al. (1999) Recurrence of the T666M calcium channel CACNA1A gene mutation in familial hemiplegic migraine with progressive cerebellar ataxia. Am J Hum Genet 64:89-98.

Duflocq A, Le Bras B, Bullier E, Couraud F, and Davenne M (2008) Nav1.1 is predominantly expressed in nodes of Ranvier and axon initial segments. Mol Cell Neurosci 39:180-192.

Dyhrfjeld-Johnsen J, Morgan RJ, Földy C, and Soltesz I (2008) Upregulated $\mathrm{H}$-current in hyperexcitable CA1 dendrites after febrile seizures. Front Cell Neurosci 2:2.

Dyhrfjeld-Johnsen J, Morgan RJ, and Soltesz I (2009) Double trouble? Potential for hyperexcitability following both channelopathic up- and downregulation of $\mathrm{I}(\mathrm{h})$ in epilepsy. Front Neurosci 3:25-33.

Endele S, Rosenberger G, Geider K, Popp B, Tamer C, Stefanova I, Milh M, Kortüm F, Fritsch A, Pientka FK, et al. (2010) Mutations in GRIN2A and GRIN2B encoding regulatory subunits of NMDA receptors cause variable neurodevelopmental phenotypes. Nat Genet 42:1021-1026.

Epi4K Consortium (2016) De novo mutations in SLC1A2 and CACNA1A are important causes of epileptic encephalopathies. Am J Hum Genet 99:287-298.

Epi4K Consortium, and Epilepsy Phenome/Genome Project (2017) Ultra-rare genetic variation in common epilepsies: a case-control sequencing study. Lancet Neurol 16 135-143.

Escayg A and Goldin AL (2010) Sodium channel SCN1A and epilepsy: mutations and mechanisms. Epilepsia 51:1650-1658.

Estacion M, O'Brien JE, Conravey A, Hammer MF, Waxman SG, Dib-Hajj SD, and Meisler MH (2014) A novel de novo mutation of SCN8A (Nav1.6) with enhanced channel activation in a child with epileptic encephalopathy. Neurobiol Dis 69:117-123.

Eugène E, Depienne C, Baulac S, Baulac M, Fritschy JM, Le Guern E, Miles R, and Poncer JC (2007) GABA(A) receptor gamma 2 subunit mutations linked to human epileptic syndromes differentially affect phasic and tonic inhibition. $J$ Neurosci 27:14108-14116.

Eunson LH, Rea R, Zuberi SM, Youroukos S, Panayiotopoulos CP, Liguori R, Avoni P McWilliam RC, Stephenson JB, Hanna MG, et al. (2000) Clinical, genetic, and expression studies of mutations in the potassium channel gene KCNA1 reveal new phenotypic variability. Ann Neurol 48:647-656.

Farhan SMK, Murphy LM, Robinson JF, Wang J, Siu VM, Rupar CA, Prasad AN, and Hegele RA; FORGE Canada Consortium (2014) Linkage analysis and exome sequencing identify a novel mutation in KCTD7 in patients with progressive myoclonus epilepsy with ataxia. Epilepsia 55:e106-e111.

Farrant M and Nusser Z (2005) Variations on an inhibitory theme: phasic and tonic activation of GABA(A) receptors. Nat Rev Neurosci 6:215-229.

Felix R (2002) Insights from mouse models of absence epilepsy into Ca2+ channel physiology and disease etiology. Cell Mol Neurobiol 22:103-120.

Fenoglio-Simeone KA, Wilke JC, Milligan HL, Allen CN, Rho JM, and Maganti RK (2009) Ketogenic diet treatment abolishes seizure periodicity and improves diurnal rhythmicity in epileptic Kcna1-null mice. Epilepsia 50:2027-2034

Fisher RS, Cross JH, D'Souza C, French JA, Haut SR, Higurashi N, Hirsch E, Jansen FE, Lagae L, Moshé SL, et al. (2017) Instruction manual for the ILAE 2017 operational classification of seizure types. Epilepsia 58:531-542.

Fletcher CF, Lutz CM, O'Sullivan TN, Shaughnessy JD Jr, Hawkes R, Frankel WN, Copeland NG, and Jenkins NA (1996) Absence epilepsy in tottering mutant mice is associated with calcium channel defects. Cell 87:607-617.

Fletcher CF, Tottene A, Lennon VA, Wilson SM, Dubel SJ, Paylor R, Hosford DA, Tessarollo L, McEnery MW, Pietrobon D, et al. (2001) Dystonia and cerebellar atrophy in Cacna1a null mice lacking $\mathrm{P} / \mathrm{Q}$ calcium channel activity. FASEB $J$ 15: $1288-1290$

Forrest D, Yuzaki M, Soares HD, Ng L, Luk DC, Sheng M, Stewart CL, Morgan JI, Connor JA, and Curran T (1994) Targeted disruption of NMDA receptor 1 gene abolishes NMDA response and results in neonatal death. Neuron 13:325-338.

Foust AJ, Yu Y, Popovic M, Zecevic D, and McCormick DA (2011) Somatic membrane potential and Kv1 channels control spike repolarization in cortical axon collaterals and presynaptic boutons. $J$ Neurosci 31:15490-15498.

Frederiksen K, Lu D, Yang J, Jensen HS, Bastlund JF, Larsen PH, Liu H, Crestey F, Dekermendjian K, Badolo L, et al. (2017) A small molecule activator of Nav 1.1 channels increases fast-spiking interneuron excitability and GABAergic transmission in vitro and has anti-convulsive effects in vivo. Eur $J$ Neurosci 46: 1887-1896.

Fritschy J-M and Panzanelli P (2014) GABAA receptors and plasticity of inhibitory neurotransmission in the central nervous system. Eur J Neurosci 39: $1845-1865$

Fujiwara T, Sugawara T, Mazaki-Miyazaki E, Takahashi Y, Fukushima K, Watanabe M, Hara K, Morikawa T, Yagi K, Yamakawa K, et al. (2003) Mutations of sodium channel alpha subunit type 1 (SCN1A) in intractable childhood epilepsies with frequent generalized tonic-clonic seizures. Brain 126:531-546.

Fukuoka M, Kuki I, Kawawaki H, Okazaki S, Kim K, Hattori Y, Tsuji H, Nukui M, Inoue T, Yoshida Y, et al. (2017) Quinidine therapy for West syndrome with KCNTI mutation: a case report. Brain Dev 39:80-83.

Gallagher MJ, Shen W, Song L, and Macdonald RL (2005) Endoplasmic reticulum retention and associated degradation of a GABAA receptor epilepsy mutation that inserts an aspartate in the M3 transmembrane segment of the alpha1 subunit. $J$ Biol Chem 280:37995-38004.

Gallagher MJ, Song L, Arain F, and Macdonald RL (2004) The juvenile myoclonic epilepsy $\operatorname{GABA}(\mathrm{A})$ receptor alpha1 subunit mutation A322D produces asymmetrical, subunit position-dependent reduction of heterozygous receptor currents and alpha1 subunit protein expression. J Neurosci 24:5570-5578.

Gao K, Tankovic A, Zhang Y, Kusumoto H, Zhang J, Chen W, XiangWei W, Shaulsky GH, Hu C, Traynelis SF, et al. (2017) A de novo loss-of-function GRIN2A mutation associated with childhood focal epilepsy and acquired epileptic aphasia. PLoS One 12 $\mathrm{e} 0170818$

Gardella E, Becker F, Møller RS, Schubert J, Lemke JR, Larsen LHG, Eiberg H, Nothnagel M, Thiele H, Altmüller J, et al. (2016) Benign infantile seizures and paroxysmal dyskinesia caused by an SCN8A mutation. Ann Neurol 79:428-436.

Gasser A, Ho TS-Y, Cheng X, Chang K-J, Waxman SG, Rasband MN, and Dib-Hajj SD (2012) An ankyrinG-binding motif is necessary and sufficient for targeting Nav1.6 sodium channels to axon initial segments and nodes of Ranvier. J Neurosci 32:7232-7243.

Ghasemi M and Hadipour-Niktarash A (2015) Pathologic role of neuronal nicotinic acetylcholine receptors in epileptic disorders: implication for pharmacological interventions. Rev Neurosci 26:199-223.

Giavarini A and de Silva R (2016) The role of ivabradine in the management of angina pectoris. Cardiovasc Drugs Ther 30:407-417.

Glasscock E, Yoo JW, Chen TT, Klassen TL, and Noebels JL (2010) Kv1.1 potassium channel deficiency reveals brain-driven cardiac dysfunction as a candidate mechanism for sudden unexplained death in epilepsy. J Neurosci 30:5167-5175.

Glauser TA, Holland K, O'Brien VP, Keddache M, Martin LJ, Clark PO, Cnaan A, Dlugos D, Hirtz DG, Shinnar S, et al.; Childhood Absence Epilepsy Study Group (2017) Pharmacogenetics of antiepileptic drug efficacy in childhood absence epilepsy. Ann Neurol 81:444-453.

Goldberg EM, Clark BD, Zagha E, Nahmani M, Erisir A, and Rudy B (2008) K+ channels at the axon initial segment dampen near-threshold excitability of neocortical fast-spiking GABAergic interneurons. Neuron 58:387-400.

Gotti C, Fornasari D, and Clementi F (1997) Human neuronal nicotinic receptors. Prog Neurobiol 53:199-237.

Grigorov A, Moskalyuk A, Kravchenko M, Veselovsky N, Verkhratsky A, and Fedulova S (2014) Kv7 potassium channel subunits and M currents in cultured hippocampal interneurons. Pflugers Arch 466:1747-1758.

Guerrini R, Dravet C, Genton P, Belmonte A, Kaminska A, and Dulac O (1998) Lamotrigine and seizure aggravation in severe myoclonic epilepsy. Epilepsia 39: $508-512$. 
Gunthorpe MJ, Large CH, and Sankar R (2012) The mechanism of action of retigabine (ezogabine), a first-in-class $\mathrm{K}+$ channel opener for the treatment of epilepsy. Epilepsia 53:412-424.

Haas M, Qu Z, Kim TH, Vargas E, Campbell K, Petrou S, Tan S-S, Reid CA, and Heng J (2013) Perturbations in cortical development and neuronal network excitability arising from prenatal exposure to benzodiazepines in mice. Eur $J$ Neurosci 37:1584-1593.

Hales TG, Tang H, Bollan KA, Johnson SJ, King DP, McDonald NA, Cheng A, and Connolly CN (2005) The epilepsy mutation, gamma2(R43Q) disrupts a highly conserved inter-subunit contact site, perturbing the biogenesis of GABAA receptors. Mol Cell Neurosci 29:120-127.

Hall BJ, Ripley B, and Ghosh A (2007) NR2B signaling regulates the development of synaptic AMPA receptor current. $J$ Neurosci 27:13446-13456.

Hamdan FF, Gauthier J, Araki Y, Lin D-T, Yoshizawa Y, Higashi K, Park A-R Spiegelman D, Dobrzeniecka S, Piton A, et al.; S2D Group (2011) Excess of de novo deleterious mutations in genes associated with glutamatergic systems in nonsyndromic intellectual disability. Am J Hum Genet 88:306-316.

Hamdan FF, Srour M, Capo-Chichi J-M, Daoud H, Nassif C, Patry L, Massicotte C, Ambalavanan A, Spiegelman D, Diallo O, et al. (2014) De novo mutations in moderate or severe intellectual disability. PLoS Genet 10:e1004772.

Harkin LA, Bowser DN, Dibbens LM, Singh R, Phillips F, Wallace RH, Richards MC, Williams DA, Mulley JC, Berkovic SF, et al. (2002) Truncation of the GABA(A)receptor gamma2 subunit in a family with generalized epilepsy with febrile seizures plus. Am J Hum Genet 70:530-536.

Harkin LA, McMahon JM, Iona X, Dibbens L, Pelekanos JT, Zuberi SM, Sadleir LG, Andermann E, Gill D, Farrell K, et al.; Infantile Epileptic Encephalopathy Referral Consortium (2007) The spectrum of SCN1A-related infantile epileptic encephalopathies. Brain 130:843-852.

Hasan MT, Hernández-González S, Dogbevia G, Treviño M, Bertocchi I, Gruart A and Delgado-García JM (2013) Role of motor cortex NMDA receptors in learningdependent synaptic plasticity of behaving mice. Nat Commun 4:2258.

Hawkins NA, Anderson LL, Gertler TS, Laux L, George AL Jr, and Kearney JA (2017) Screening of conventional anticonvulsants in a genetic mouse model of epilepsy. Ann Clin Transl Neurol 4:326-339.

He C, Chen F, Li B, and Hu Z (2014) Neurophysiology of HCN channels: from cellular functions to multiple regulations. Prog Neurobiol 112:1-23.

Hedrich UBS, Liautard C, Kirschenbaum D, Pofahl M, Lavigne J, Liu Y, Theiss S, Slotta J, Escayg A, Dihné M, et al. (2014) Impaired action potential initiation in GABAergic interneurons causes hyperexcitable networks in an epileptic mouse model carrying a human $\mathrm{Na}(\mathrm{V}) 1.1$ mutation. J Neurosci 34:14874-14889.

Heeroma JH, Henneberger C, Rajakulendran S, Hanna MG, Schorge S, and Kullmann DM (2009) Episodic ataxia type 1 mutations differentially affect neuronal excitability and transmitter release. Dis Model Mech 2:612-619.

Heinzen EL, Depondt C, Cavalleri GL, Ruzzo EK, Walley NM, Need AC, Ge D, He M, Cirulli ET, Zhao Q, et al. (2012) Exome sequencing followed by large-scale genotyping fails to identify single rare variants of large effect in idiopathic generalized epilepsy. Am J Hum Genet 91:293-302.

Helbig I, Hartmann C, and Mefford HC (2013) The unexpected role of copy number variations in juvenile myoclonic epilepsy. Epilepsy Behav 28 (Suppl 1):S66-S68.

Helbig I, Mefford HC, Sharp AJ, Guipponi M, Fichera M, Franke A, Muhle H, de Kovel C, Baker C, von Spiczak S, et al. (2009) 15q13.3 microdeletions increase risk of idiopathic generalized epilepsy. Nat Genet 41:160-162.

Helbig KL, Hedrich UBS, Shinde DN, Krey I, Teichmann A-C, Hentschel J, Schubert J, Chamberlin AC, Huether R, Lu H-M, et al. (2016) A recurrent mutation in KCNA2 as a novel cause of hereditary spastic paraplegia and ataxia. Ann Neurol DOI: 10.1002/ana.24762 [published ahead of print].

Herlenius E, Heron SE, Grinton BE, Keay D, Scheffer IE, Mulley JC, and Berkovic SF (2007) SCN2A mutations and benign familial neonatal-infantile seizures: the phenotypic spectrum. Epilepsia 48:1138-1142.

Hernandez CC, Kong W, Hu N, Zhang Y, Shen W, Jackson L, Liu X, Jiang Y, and Macdonald RL (2017) Altered channel conductance states and gating of GABAA receptors by a pore mutation linked to Dravet syndrome. eNeuro DOI: 10.1523/ENEURO.0251-16.2017 [published ahead of print].

Heron SE, Crossland KM, Andermann E, Phillips HA, Hall AJ, Bleasel A, Shevell M, Mercho S, Seni M-H, Guiot M-C, et al. (2002) Sodium-channel defects in benign familial neonatal-infantile seizures. Lancet 360:851-852.

Heron SE, Khosravani H, Varela D, Bladen C, Williams TC, Newman MR, Scheffer IE, Berkovic SF, Mulley JC, and Zamponi GW (2007) Extended spectrum of idiopathic generalized epilepsies associated with CACNA1H functional variants. Ann Neurol 62 $560-568$.

Heron SE, Smith KR, Bahlo M, Nobili L, Kahana E, Licchetta L, Oliver KL, Mazarib A, Afawi Z, Korczyn A, et al. (2012) Missense mutations in the sodium-gated potassium channel gene KCNT1 cause severe autosomal dominant nocturnal frontal lobe epilepsy. Nat Genet 44:1188-1190.

Herson PS, Virk M, Rustay NR, Bond CT, Crabbe JC, Adelman JP, and Maylie J (2003) A mouse model of episodic ataxia type-1. Nat Neurosci 6:378-383.

Higurashi N, Uchida T, Lossin C, Misumi Y, Okada Y, Akamatsu W, Imaizumi Y, Zhang B, Nabeshima K, Mori MX, et al. (2013) A human Dravet syndrome model from patient induced pluripotent stem cells. Mol Brain 6:19.

Hino-Fukuyo N, Kikuchi A, Arai-Ichinoi N, Niihori T, Sato R, Suzuki T, Kudo H, Sato Y, Nakayama T, Kakisaka Y, et al. (2015) Genomic analysis identifies candidate pathogenic variants in 9 of 18 patients with unexplained West syndrome. Hum Genet 134:649-658

Hirose S, Iwata H, Akiyoshi $\mathrm{H}$, Kobayashi $\mathrm{K}$, Ito M, Wada $\mathrm{K}$, Kaneko S, and Mitsudome A (1999) A novel mutation of CHRNA4 responsible for autosomal dominant nocturnal frontal lobe epilepsy. Neurology 53:1749-1753.

Ho CS, Grange RW, and Joho RH (1997) Pleiotropic effects of a disrupted K+ channel gene: reduced body weight, impaired motor skill and muscle contraction, but no seizures. Proc Natl Acad Sci USA 94:1533-1538.

Hoda J-C, Gu W, Friedli M, Phillips HA, Bertrand S, Antonarakis SE, Goudie D, Roberts R, Scheffer IE, Marini C, et al. (2008) Human nocturnal frontal lobe epilepsy: pharmocogenomic profiles of pathogenic nicotinic acetylcholine receptor beta-subunit mutations outside the ion channel pore. Mol Pharmacol 74 379-391.

Hogg RC, Raggenbass M, and Bertrand D (2003) Nicotinic acetylcholine receptors: from structure to brain function. Rev Physiol Biochem Pharmacol 147:1-46.

Homanics GE, DeLorey TM, Firestone LL, Quinlan JJ, Handforth A, Harrison NL, Krasowski MD, Rick CE, Korpi ER, Mäkelä R, et al. (1997) Mice devoid of gammaaminobutyrate type A receptor beta3 subunit have epilepsy, cleft palate, and hypersensitive behavior. Proc Natl Acad Sci USA 94:4143-4148.

Hörtnagl H, Tasan RO, Wieselthaler A, Kirchmair E, Sieghart W, and Sperk G (2013) Patterns of mRNA and protein expression for 12 GABAA receptor subunits in the mouse brain. Neuroscience 236:345-372.

Howell KB, McMahon JM, Carvill GL, Tambunan D, Mackay MT, Rodriguez-Casero V, Webster R, Clark D, Freeman JL, Calvert S, et al. (2015) SCN2A encephalopathy: a major cause of epilepsy of infancy with migrating focal seizures. Neurology 85: 958-966.

Hsiao J, Yuan TY, Tsai MS, Lu CY, Lin YC, Lee ML, Lin SW, Chang FC, Liu Pimentel H, Olive C, et al. (2016) Upregulation of haploinsufficient gene expression in the brain by targeting a long non-coding RNA improves seizure phenotype in a model of Dravet syndrome. EBioMedicine 9:257-277.

Hu W, Tian C, Li T, Yang M, Hou H, and Shu Y (2009) Distinct contributions of $\mathrm{Na}$ (v)1.6 and $\mathrm{Na}(\mathrm{v}) 1.2$ in action potential initiation and backpropagation. Nat Neurosci 12:996-1002.

Huguenard JR and McCormick DA (1992) Simulation of the currents involved in rhythmic oscillations in thalamic relay neurons. $J$ Neurophysiol 68:1373-1383.

Hundallah K, Alenizi A, AlHashem A, and Tabarki B (2016) Severe early-onset epileptic encephalopathy due to mutations in the KCNA2 gene: expansion of the genotypic and phenotypic spectrum. Eur J Paediatr Neurol 20:657-660.

Hurst R, Rollema H, and Bertrand D (2013) Nicotinic acetylcholine receptors: from basic science to therapeutics. Pharmacol Ther 137:22-54.

Ikeda K, Araki K, Takayama C, Inoue Y, Yagi T, Aizawa S, and Mishina M (1995) Reduced spontaneous activity of mice defective in the epsilon 4 subunit of the NMDA receptor channel. Brain Res Mol Brain Res 33:61-71.

Imbrici P, Jaffe SL, Eunson LH, Davies NP, Herd C, Robertson R, Kullmann DM, and Hanna MG (2004) Dysfunction of the brain calcium channel CaV2.1 in absence epilepsy and episodic ataxia. Brain 127:2682-2692.

International League Against Epilepsy Consortium on Complex Epilepsies (2014) Genetic determinants of common epilepsies: a meta-analysis of genome-wide association studies. Lancet Neurol 13:893-903.

Iossifov I, O'Roak BJ, Sanders SJ, Ronemus M, Krumm N, Levy D, Stessman HA, Witherspoon KT, Vives L, Patterson KE, et al. (2014) The contribution of de novo coding mutations to autism spectrum disorder. Nature 515:216-221.

Ishii A, Kang J-Q, Schornak CC, Hernandez CC, Shen W, Watkins JC, Macdonald RL, and Hirose S (2017) A de novo missense mutation of GABRB2 causes early myoclonic encephalopathy. J Med Genet 54:202-211.

Isom LL (2002) The role of sodium channels in cell adhesion. Front Biosci 7:12-23.

Jan LY and Jan YN (2012) Voltage-gated potassium channels and the diversity of electrical signalling. J Physiol 590:2591-2599.

Janve VS, Hernandez CC, Verdier KM, Hu N, and Macdonald RL (2016) Epileptic encephalopathy de novo GABRB mutations impair GABAA receptor function. Ann Neurol 79:806-825.

Jiang YH, Yuen RKC, Jin X, Wang M, Chen N, Wu X, Ju J, Mei J, Shi Y, He M, et al. (2013) Detection of clinically relevant genetic variants in autism spectrum disorder by whole-genome sequencing. Am J Hum Genet 93:249-263.

Jiao J, Yang Y, Shi Y, Chen J, Gao R, Fan Y, Yao H, Liao W, Sun X-F, and Gao S (2013) Modeling Dravet syndrome using induced pluripotent stem cells (iPSCs) and directly converted neurons. Hum Mol Genet 22:4241-4252.

Jodice C, Mantuano E, Veneziano L, Trettel F, Sabbadini G, Calandriello L, Francia A, Spadaro M, Pierelli F, Salvi F, et al. (1997) Episodic ataxia type 2 (EA2) and spinocerebellar ataxia type 6 (SCA6) due to CAG repeat expansion in the CACNA1A gene on chromosome 19p. Hum Mol Genet 6:1973-1978.

Johannesen K, Marini C, Pfeffer S, Møller RS, Dorn T, Niturad CE, Gardella E, Weber Y, Søndergård M, Hjalgrim H, et al. (2016) Phenotypic spectrum of GABRA1: from generalized epilepsies to severe epileptic encephalopathies. Neurology 87:1140-1151.

Johannessen CU (2000) Mechanisms of action of valproate: a commentatory. Neurochem Int 37:103-110.

Jouvenceau A, Eunson LH, Spauschus A, Ramesh V, Zuberi SM, Kullmann DM, and Hanna MG (2001) Human epilepsy associated with dysfunction of the brain P/Q-type calcium channel Lancet 358:801-807.

Jun K, Piedras-Rentería ES, Smith SM, Wheeler DB, Lee SB, Lee TG, Chin H, Adams ME, Scheller RH, Tsien RW, et al. (1999) Ablation of P/Q-type $\mathrm{Ca}(2+)$ channel currents, altered synaptic transmission, and progressive ataxia in mice lacking the alpha(1A)-subunit. Proc Natl Acad Sci USA 96:15245-15250.

Kahlig KM, Misra SN, and George AL Jr (2006) Impaired inactivation gate stabilization predicts increased persistent current for an epilepsy-associated SCN1A mutation. J Neurosci 26:10958-10966.

Kalume F, Yu FH, Westenbroek RE, Scheuer T, and Catterall WA (2007) Reduced sodium current in Purkinje neurons from Nav1.1 mutant mice: implications for ataxia in severe myoclonic epilepsy in infancy. J Neurosci 27:11065-11074.

Kananura C, Haug K, Sander T, Runge U, Gu W, Hallmann K, Rebstock J, Heils A, and Steinlein OK (2002) A splice-site mutation in GABRG2 associated with childhood absence epilepsy and febrile convulsions. Arch Neurol 59:1137-1141.

Kang J-Q and Macdonald RL (2016) Molecular pathogenic basis for GABRG2 mutations associated with a spectrum of epilepsy syndromes, from generalized absence epilepsy to Dravet syndrome. JAMA Neurol 73:1009-1016.

Kang J-Q, Shen W, and Macdonald RL (2006) Why does fever trigger febrile seizures? GABAA receptor gamma2 subunit mutations associated with idiopathic generalized epilepsies have temperature-dependent trafficking deficiencies. J Neurosci $\mathbf{2 6}$ $2590-2597$. 
Kang J-Q, Shen W, Zhou C, Xu D, and Macdonald RL (2015) The human epilepsy mutation GABRG2(Q390X) causes chronic subunit accumulation and neurodegeneration. Nat Neurosci 18:988-996.

Kearney JA, Plummer NW, Smith MR, Kapur J, Cummins TR, Waxman SG, Goldin AL, and Meisler MH (2001) A gain-of-function mutation in the sodium channel gene Scn2a results in seizures and behavioral abnormalities. Neuroscience 102:307-317.

Kearney JA, Wiste AK, Stephani U, Trudeau MM, Siegel A, RamachandranNair R, Elterman RD, Muhle H, Reinsdorf J, Shields WD, et al. (2006) Recurrent de novo mutations of SCN1A in severe myoclonic epilepsy of infancy. Pediatr Neurol 34 116-120.

Khosravani H, Altier C, Simms B, Hamming KS, Snutch TP, Mezeyova J, McRory JE, and Zamponi GW (2004) Gating effects of mutations in the Cav3.2 T-type calcium channel associated with childhood absence epilepsy. $J$ Biol Chem 279:9681-9684.

Kim TH, Reid CA, and Petrou S (2015) Oxcarbazepine and its active metabolite, (S)-licarbazepine, exacerbate seizures in a mouse model of genetic generalized epilepsy. Epilepsia 56:e6-e9.

Klaassen A, Glykys J, Maguire J, Labarca C, Mody I, and Boulter J (2006) Seizures and enhanced cortical GABAergic inhibition in two mouse models of human autosomal dominant nocturnal frontal lobe epilepsy. Proc Natl Acad Sci USA 103: 19152-19157.

Klassen TL, Bomben VC, Patel A, Drabek J, Chen TT, Gu W, Zhang F, Chapman K, Lupski JR, Noebels JL, et al. (2014) High-resolution molecular genomic autopsy reveals complex sudden unexpected death in epilepsy risk profile. Epilepsia 55: e6-e12

Kodera H, Ohba C, Kato M, Maeda T, Araki K, Tajima D, Matsuo M, Hino-Fukuyo N, Kohashi K, Ishiyama A, et al. (2016) De novo GABRA1 mutations in Ohtahara and West syndromes. Epilepsia 57:566-573.

Kole MHP, Bräuer AU, and Stuart GJ (2007) Inherited cortical HCN1 channel loss amplifies dendritic calcium electrogenesis and burst firing in a rat absence epilepsy model. J Physiol 578:507-525.

Kousi M, Anttila V, Schulz A, Calafato S, Jakkula E, Riesch E, Myllykangas L, Kalimo H, Topcu M, Gökben S, et al. (2012) Novel mutations consolidate KCTD7 as a progressive myoclonus epilepsy gene. J Med Genet 49:391-399.

Krabichler B, Rostasy K, Baumann M, Karall D, Scholl-Bürgi S, Schwarzer C, Gautsch K, Spreiz A, Kotzot D, Zschocke J, et al. (2012) Novel mutation in potassium channel related gene KCTD7 and progressive myoclonic epilepsy. Ann Hum Genet 76:326-331.

Krampfl K, Maljevic S, Cossette P, Ziegler E, Rouleau GA, Lerche H, and Bufler J (2005) Molecular analysis of the A322D mutation in the GABA receptor alphasubunit causing juvenile myoclonic epilepsy. Eur J Neurosci 22:10-20.

Kruger LC, O'Malley HA, Hull JM, Kleeman A, Patino GA, and Isom LL (2016) 31-C121W is down but not out: epilepsy-associated Scn1b-C121W results in a deleterious gain-of-function. J Neurosci 36:6213-6224.

Kutsuwada T, Sakimura K, Manabe T, Takayama C, Katakura N, Kushiya E, Natsume R, Watanabe M, Inoue Y, Yagi T, et al. (1996) Impairment of suckling response, trigeminal neuronal pattern formation, and hippocampal LTD in NMDA receptor epsilon 2 subunit mutant mice. Neuron 16:333-344.

Kwan P, Sills GJ, and Brodie MJ (2001) The mechanisms of action of commonly used antiepileptic drugs. Pharmacol Ther 90:21-34.

Labro AJ and Snyders DJ (2012) Being flexible: the voltage-controllable activation gate of kv channels. Front Pharmacol 3:168.

Lachance-Touchette P, Brown P, Meloche C, Kinirons P, Lapointe L, Lacasse H, Lortie A, Carmant L, Bedford F, Bowie D, et al. (2011) Novel $\alpha 1$ and $\gamma 2$ GABAA receptor subunit mutations in families with idiopathic generalized epilepsy. Eur $J$ Neurosci 34:237-249.

Larsen J, Carvill GL, Gardella E, Kluger G, Schmiedel G, Barisic N, Depienne C, Brilstra E, Mang Y, Nielsen JEK, et al.; EuroEPINOMICS RES Consortium CRP (2015) The phenotypic spectrum of SCN8A encephalopathy. Neurology 84:480-489.

Lawrence JJ, Saraga F, Churchill JF, Statland JM, Travis KE, Skinner FK, and McBain CJ (2006) Somatodendritic Kv7/KCNQ/M channels control interspike interval in hippocampal interneurons. J Neurosci 26:12325-12338.

Lek M, Karczewski KJ, Minikel EV, Samocha KE, Banks E, Fennell T, O’DonnellLuria AH, Ware JS, Hill AJ, Cummings BB, et al.; Exome Aggregation Consortium (2016) Analysis of protein-coding genetic variation in 60,706 humans. Nature $\mathbf{5 3 6}$ $285-291$.

Lemke JR, Geider K, Helbig KL, Heyne HO, Schütz H, Hentschel J, Courage C, Depienne C, Nava C, Heron D, et al. (2016) Delineating the GRIN1 phenotypic spectrum: a distinct genetic NMDA receptor encephalopathy. Neurology 86 2171-2178.

Lemke JR, Hendrickx R, Geider K, Laube B, Schwake M, Harvey RJ, James VM, Pepler A, Steiner I, Hörtnagel K, et al. (2014) GRIN2B mutations in West syndrome and intellectual disability with focal epilepsy. Ann Neurol 75:147-154.

Lemke JR, Lal D, Reinthaler EM, Steiner I, Nothnagel M, Alber M, Geider K, Laube B, Schwake M, Finsterwalder K, et al. (2013) Mutations in GRIN2A cause idiopathic focal epilepsy with rolandic spikes. Nat Genet 45:1067-1072.

Lenzen KP, Heils A, Lorenz S, Hempelmann A, and Sander T (2005) Association analysis of the Arg220His variation of the human gene encoding the GABA delta subunit with idiopathic generalized epilepsy. Epilepsy Res 65:53-57.

Lerche H, Biervert C, Alekov AK, Schleithoff L, Lindner M, Klinger W, Bretschneider F, Mitrovic N, Jurkat-Rott K, Bode H, et al. (1999) A reduced K+ current due to a novel mutation in KCNQ2 causes neonatal convulsions. Ann Neurol 46:305-312.

Lesca G, Rudolf G, Bruneau N, Lozovaya N, Labalme A, Boutry-Kryza N, Salmi M, Tsintsadze T, Addis L, Motte J, et al. (2013) GRIN2A mutations in acquired epileptic aphasia and related childhood focal epilepsies and encephalopathies with speech and language dysfunction. Nat Genet 45:1061-1066.

Li D, Yuan H, Ortiz-Gonzalez XR, Marsh ED, Tian L, McCormick EM, Kosobucki GJ, Chen W, Schulien AJ, Chiavacci R, et al. (2016) GRIN2D recurrent de novo dominant mutation causes a severe epileptic encephalopathy treatable with NMDA receptor channel blockers. Am J Hum Genet 99:802-816.
Lim CX, Ricos MG, Dibbens LM, and Heron SE (2016) KCNT1 mutations in seizure disorders: the phenotypic spectrum and functional effects. J Med Genet $\mathbf{5 3}$ $217-225$.

Liu J, Gao C, Chen W, Ma W, Li X, Shi Y, Zhang H, Zhang L, Long Y, Xu H, et al. (2016) CRISPR/Cas9 facilitates investigation of neural circuit disease using human iPSCs: mechanism of epilepsy caused by an SCN1A loss-of-function mutation. Transl Psychiatry 6:e703.

Liu Y, Lopez-Santiago LF, Yuan Y, Jones JM, Zhang H, O’Malley HA, Patino GA, O'Brien JE, Rusconi R, Gupta A, et al. (2013a) Dravet syndrome patient-derived neurons suggest a novel epilepsy mechanism. Ann Neurol 74:128-139.

Liu Z, Xiang Y, and Sun G (2013b) The KCTD family of proteins: structure, function, disease relevance. Cell Biosci 3:45.

Lopantsev V, Tempel BL, and Schwartzkroin PA (2003) Hyperexcitability of CA3 pyramidal cells in mice lacking the potassium channel subunit Kv1.1. Epilepsia 44: 1506-1512.

Lopez-Santiago LF, Yuan Y, Wagnon JL, Hull JM, Frasier CR, O’Malley HA, Meisler MH, and Isom LL (2017) Neuronal hyperexcitability in a mouse model of SCN8A epileptic encephalopathy. Proc Natl Acad Sci USA 114:2383-2388.

Lorincz A and Nusser Z (2008) Cell-type-dependent molecular composition of the axon initial segment. $J$ Neurosci 28:14329-14340.

Lüscher C and Malenka RC (2012) NMDA receptor-dependent long-term potentiation and long-term depression (LTP/LTD). Cold Spring Harb Perspect Biol DOI: 10.1101/cshperspect.a005710 [published ahead of print]

Lyashchenko AK, Redd KJ, Yang J, and Tibbs GR (2007) Propofol inhibits HCN1 pacemaker channels by selective association with the closed states of the membrane embedded channel core. J Physiol 583:37-56.

Macdonald RL and Olsen RW (1994) GABAA receptor channels. Annu Rev Neurosci 17:569-602.

Madia F, Striano P, Gennaro E, Malacarne M, Paravidino R, Biancheri R, Budetta M, Cilio MR, Gaggero R, Pierluigi M, et al. (2006) Cryptic chromosome deletions involving SCN1A in severe myoclonic epilepsy of infancy. Neurology 67:1230-1235.

Makinson CD, Tanaka BS, Sorokin JM, Wong JC, Christian CA, Goldin AL, Escayg A, and Huguenard JR (2017) Regulation of thalamic and cortical network synchrony by scn8a. Neuron 93:1165-1179.e6.

Maljevic S, Krampfl K, Cobilanschi J, Tilgen N, Beyer S, Weber YG, Schlesinger F, Ursu D, Melzer W, Cossette P, et al. (2006) A mutation in the GABA(A) receptor alpha(1)-subunit is associated with absence epilepsy. Ann Neurol 59:983-987.

Maljevic S and Lerche H (2013) Potassium channels: a review of broadening therapeutic possibilities for neurological diseases. J Neurol 260:2201-2211.

Maljevic S and Lerche H (2014) Potassium channel genes and benign familial neonatal epilepsy. Prog Brain Res 213:17-53.

Maljevic S, Reid CA, and Petrou S (2017) Models for discovery of targeted therapy in genetic epileptic encephalopathies. $J$ Neurochem 143:30-48.

Manfredi I, Zani AD, Rampoldi L, Pegorini S, Bernascone I, Moretti M, Gotti C, Croci L, Consalez GG, Ferini-Strambi L, et al. (2009) Expression of mutant beta2 nicotinic receptors during development is crucial for epileptogenesis. Hum Mol Genet 18:1075-1088

Mann EO and Mody I (2008) The multifaceted role of inhibition in epilepsy: seizuregenesis through excessive GABAergic inhibition in autosomal dominant nocturnal frontal lobe epilepsy. Curr Opin Neurol 21:155-160.

Manole A, Männikkö R, Hanna MG, Kullmann DM, and Houlden H; SYNAPS Study Group (2017) De novo KCNA2 mutations cause hereditary spastic paraplegia. Ann Neurol 81:326-328.

Marini C, Scheffer IE, Nabbout R, Suls A, De Jonghe P, Zara F, and Guerrini R (2011) The genetics of Dravet syndrome. Epilepsia 52 (Suppl 2):24-29.

Martin MS, Dutt K, Papale LA, Dubé CM, Dutton SB, de Haan G, Shankar A Tufik S, Meisler MH, Baram TZ, et al. (2010) Altered function of the SCN1A voltage-gated sodium channel leads to gamma-aminobutyric acid-ergic (GABAergic) interneuron abnormalities. J Biol Chem 285:9823-9834.

Martin MS, Tang B, Papale LA, Yu FH, Catterall WA, and Escayg A (2007) The voltage-gated sodium channel Scn8a is a genetic modifier of severe myoclonic epilepsy of infancy. Hum Mol Genet 16:2892-2899.

Matsukawa H, Wolf AM, Matsushita S, Joho RH, and Knöpfel T (2003) Motor dysfunction and altered synaptic transmission at the parallel fiber-Purkinje cell synapse in mice lacking potassium channels Kv3.1 and Kv3.3. $J$ Neurosci 23: $7677-7684$

Mayer ML and Westbrook GL (1987) Permeation and block of N-methyl-D-aspartic acid receptor channels by divalent cations in mouse cultured central neurones. J Physiol 394:501-527.

McTague A, Howell KB, Cross JH, Kurian MA, and Scheffer IE (2016) The genetic landscape of the epileptic encephalopathies of infancy and childhood. Lancet Neurol 15:304-316.

Meadows LS, Malhotra J, Loukas A, Thyagarajan V, Kazen-Gillespie KA, Koopman MC, Kriegler S, Isom LL, and Ragsdale DS (2002) Functional and biochemical analysis of a sodium channel beta1 subunit mutation responsible for generalized epilepsy with febrile seizures plus type 1. J Neurosci 22:10699-10709.

Melé M, Ferreira PG, Reverter F, DeLuca DS, Monlong J, Sammeth M, Young TR Goldmann JM, Pervouchine DD, Sullivan TJ, et al.; GTEx Consortium (2015) Human genomics: the human transcriptome across tissues and individuals. Science 348:660-665.

Meyerson JR, Kumar J, Chittori S, Rao P, Pierson J, Bartesaghi A, Mayer ML, and Subramaniam S (2014) Structural mechanism of glutamate receptor activation and desensitization. Nature 514:328-334.

Miceli F, Soldovieri MV, Ambrosino P, De Maria M, Migliore M, Migliore R, and Taglialatela M (2015a) Early-onset epileptic encephalopathy caused by gainof-function mutations in the voltage sensor of Kv7.2 and Kv7.3 potassium channe subunits. J Neurosci 35:3782-3793.

Miceli F, Striano P, Soldovieri MV, Fontana A, Nardello R, Robbiano A, Bellini G, Elia M, Zara F, Taglialatela M, et al. (2015b) A novel KCNQ3 mutation in familial epilepsy with focal seizures and intellectual disability. Epilepsia 56:e15-e20. 
Mikati MA, Jiang Y-H, Carboni M, Shashi V, Petrovski S, Spillmann R, Milligan CJ, Li M, Grefe A, McConkie A, et al. (2015) Quinidine in the treatment of KCNT1positive epilepsies. Ann Neurol 78:995-999.

Millichap JJ, Park KL, Tsuchida T, Ben-Zeev B, Carmant L, Flamini R, Joshi N, Levisohn PM, Marsh E, Nangia S, et al. (2016) KCNQ2 encephalopathy: features, mutational hot spots, and ezogabine treatment of 11 patients. Neurol Genet 2:e96.

Milligan CJ, Li M, Gazina EV, Heron SE, Nair U, Trager C, Reid CA, Venkat A Younkin DP, Dlugos DJ, et al. (2014) KCNT1 gain of function in 2 epilepsy phenotypes is reversed by quinidine. Ann Neurol 75:581-590.

Mishra V, Karumuri BK, Gautier NM, Liu R, Hutson TN, Vanhoof-Villalba SL Vlachos I, Iasemidis L, and Glasscock E (2017) Scn2a deletion improves survival and brain-heart dynamics in the Kcna1-null mouse model of sudden unexpected death in epilepsy (SUDEP). Hum Mol Genet 26:2091-2103.

Moen MN, Fjær R, Hamdani EH, Laerdahl JK, Menchini RJ, Vigeland MD, Sheng Y, Undlien DE, Hassel B, Salih MA, et al. (2016) Pathogenic variants in KCTD7 perturb neuronal K+ fluxes and glutamine transport. Brain 139:3109-3120.

Mohapatra DP, Park K-S, and Trimmer JS (2007) Dynamic regulation of the voltagegated Kv2.1 potassium channel by multisite phosphorylation. Biochem Soc Trans 35:1064-1068.

Møller RS, Heron SE, Larsen LHG, Lim CX, Ricos MG, Bayly MA, van Kempen MJA, Klinkenberg S, Andrews I, Kelley K, et al. (2015) Mutations in KCNT1 cause a spectrum of focal epilepsies. Epilepsia 56:e114-e120.

Møller RS, Wuttke TV, Helbig I, Marini C, Johannesen KM, Brilstra EH, Vaher U, Borggraefe I, Talvik I, Talvik T, et al. (2017) Mutations in GABRB3: from febrile seizures to epileptic encephalopathies. Neurology 88:483-492.

Monaghan MM, Trimmer JS, and Rhodes KJ (2001) Experimental localization of Kv1 family voltage-gated $\mathrm{K}+$ channel alpha and beta subunits in rat hippocampal formation. J Neurosci 21:5973-5983.

Monyer H, Burnashev N, Laurie DJ, Sakmann B, and Seeburg PH (1994) Developmental and regional expression in the rat brain and functional properties of four NMDA receptors. Neuron 12:529-540.

Mullen SA, Carney PW, Roten A, Ching M, Lightfoot PA, Churilov L, Nair U, Li M, Berkovic SF, Petrou S, et al. (2017) Precision therapy for epilepsy due to KCNT1 mutations: a randomised trial of oral quinidine. Neurology.

Mulley JC, Nelson P, Guerrero S, Dibbens L, Iona X, McMahon JM, Harkin L, Schouten J, Yu S, Berkovic SF, et al. (2006) A new molecular mechanism for severe myoclonic epilepsy of infancy: exonic deletions in SCN1A. Neurology 67:1094-1095.

Muona M, Berkovic SF, Dibbens LM, Oliver KL, Maljevic S, Bayly MA, Joensuu T, Canafoglia L, Franceschetti S, Michelucci R, et al. (2015) A recurrent de novo mutation in KCNC1 causes progressive myoclonus epilepsy. Nat Genet 47:39-46.

Myers KA and Scheffer IE (2016) GRIN2A-related speech disorders and epilepsy, in GeneReviews (Pagon RA, Adam MP, Ardinger HH, Wallace SE, Amemiya A, Bean LJ, Bird TD, Ledbetter N, Mefford HC, Smith RJ, et al. eds) University of Washington, Seattle, WA.

Nabbout R, Gennaro E, Dalla Bernardina B, Dulac O, Madia F, Bertini E, Capovilla G, Chiron C, Cristofori G, Elia M, et al. (2003) Spectrum of SCN1A mutations in severe myoclonic epilepsy of infancy. Neurology 60:1961-1967.

Nakamura Y, Shi X, Numata T, Mori Y, Inoue R, Lossin C, Baram TZ, and Hirose S (2013) Novel HCN2 mutation contributes to febrile seizures by shifting the channel's kinetics in a temperature-dependent manner. PLoS One 8:e80376.

Nakazawa K, Quirk MC, Chitwood RA, Watanabe M, Yeckel MF, Sun LD, Kato A, Carr CA, Johnston D, Wilson MA, et al. (2002) Requirement for hippocampal CA3 NMDA receptors in associative memory recall. Science 297:211-218.

Nava C, Dalle C, Rastetter A, Striano P, de Kovel CGF, Nabbout R, Cancès C, Ville D, Brilstra EH, Gobbi G, et al.; EuroEPINOMICS RES Consortium (2014) De novo mutations in HCN1 cause early infantile epileptic encephalopathy. Nat Genet $\mathbf{4 6}$ : 640-645.

Nieto-Gonzalez JL and Jensen K (2013) BDNF depresses excitability of parvalbuminpositive interneurons through an M-like current in rat dentate gyrus. PLoS One 8 e67318.

Niturad CE, Lev D, Kalscheuer V, Charzewska A, Schubert J, Lerman-Sagie T, Kroes HY, Oegema R, Traverso M, Specchio N, et al. (2017) Mutations in GABRA3 are associated with epileptic seizures, encephalopathy and dysmorphic features. Brain 140:2879-2894

Noebels JL, Avoli M, Rogawski MA, Olsen RW, and Delgado-Escueta AV (2012) Jasper's Basic Mechanisms of the Epilepsies, Oxford University Press, New York.

Oakley JC, Cho AR, Cheah CS, Scheuer T, and Catterall WA (2013) Synergistic GABA-enhancing therapy against seizures in a mouse model of Dravet syndrome $J$ Pharmacol Exp Ther 345:215-224.

Oakley JC, Kalume F, Yu FH, Scheuer T, and Catterall WA (2009) Temperature- and age-dependent seizures in a mouse model of severe myoclonic epilepsy in infancy. Proc Natl Acad Sci USA 106:3994-3999.

Ogiwara I, Miyamoto H, Morita N, Atapour N, Mazaki E, Inoue I, Takeuchi T, Itohara S, Yanagawa Y, Obata K, et al. (2007) Nav1.1 localizes to axons of parvalbumin-positive inhibitory interneurons: a circuit basis for epileptic seizures in mice carrying an Scn1a gene mutation. J Neurosci 27:5903-5914.

Ohba C, Shiina M, Tohyama J, Haginoya K, Lerman-Sagie T, Okamoto N, Blumkin L, Lev D, Mukaida S, Nozaki F, et al. (2015) GRIN1 mutations cause encephalopathy with infantile-onset epilepsy, and hyperkinetic and stereotyped movement disorders. Epilepsia 56:841-848.

Ohmori I, Kahlig KM, Rhodes TH, Wang DW, and George AL Jr (2006) Nonfunctional SCN1A is common in severe myoclonic epilepsy of infancy. Epilepsia 47: $1636-1642$

Ohmori I, Ouchida M, Ohtsuka Y, Oka E, and Shimizu K (2002) Significant correlation of the SCN1A mutations and severe myoclonic epilepsy in infancy. Biochem Biophys Res Commun 295:17-23.

Oliva M, Berkovic SF, and Petrou S (2012) Sodium channels and the neurobiology of epilepsy. Epilepsia 53:1849-1859.

Oliver KL, Franceschetti S, Milligan CJ, Muona M, Mandelstam SA, Canafoglia L, Boguszewska-Chachulska AM, Korczyn AD, Bisulli F, Di Bonaventura C, et al.
(2017) Myoclonus epilepsy and ataxia due to KCNC1 mutation: analysis of 20 cases and $\mathrm{K}(+)$ channel properties. Ann Neurol 81:677-689.

O'Malley HA and Isom LL (2015) Sodium channel $\beta$ subunits: emerging targets in channelopathies. Annu Rev Physiol 77:481-504.

O’Neill HC, Laverty DC, Patzlaff NE, Cohen BN, Fonck C, McKinney S, McIntosh JM, Lindstrom JM, Lester HA, Grady SR, et al. (2013) Mice expressing the ADNFLE valine 287 leucine mutation of the B2 nicotinic acetylcholine receptor subunit display increased sensitivity to acute nicotine administration and altered presynaptic nicotinic receptor function. Pharmacol Biochem Behav 103:603-621.

Orhan G, Bock M, Schepers D, Ilina EI, Reichel SN, Löffler H, Jezutkovic N, Weckhuysen S, Mandelstam S, Suls A, et al. (2014) Dominant-negative effects of KCNQ2 mutations are associated with epileptic encephalopathy. Ann Neurol $\mathbf{7 5}$ : $382-394$.

Osteen JD, Herzig V, Gilchrist J, Emrick JJ, Zhang C, Wang X, Castro J, GarciaCaraballo S, Grundy L, Rychkov GY, et al. (2016) Selective spider toxins reveal a role for the Nav1.1 channel in mechanical pain. Nature 534:494-499.

Otto JF, Singh NA, Dahle EJ, Leppert MF, Pappas CM, Pruess TH, Wilcox KS, and White HS (2009) Electroconvulsive seizure thresholds and kindling acquisition rates are altered in mouse models of human KCNQ2 and KCNQ3 mutations for benign familial neonatal convulsions. Epilepsia 50:1752-1759.

Otto JF, Yang Y, Frankel WN, White HS, and Wilcox KS (2006) A spontaneous mutation involving Kenq2 (Kv7.2) reduces M-current density and spike frequency adaptation in mouse CA1 neurons. J Neurosci 26:2053-2059.

Palmer L, Murayama M, and Larkum M (2012) Inhibitory regulation of dendritic activity in vivo. Front Neural Circuits 6:26.

Paoletti P (2011) Molecular basis of NMDA receptor functional diversity. Eur $J$ Neurosci 33:1351-1365.

Paoletti P, Bellone C, and Zhou Q (2013) NMDA receptor subunit diversity: impact on receptor properties, synaptic plasticity and disease. Nat Rev Neurosci 14: 383-400.

Papale LA, Beyer B, Jones JM, Sharkey LM, Tufik S, Epstein M, Letts VA, Meisler MH, Frankel WN, and Escayg A (2009) Heterozygous mutations of the voltagegated sodium channel SCN8A are associated with spike-wave discharges and absence epilepsy in mice. Hum Mol Genet 18:1633-1641.

Papandreou A, McTague A, Trump N, Ambegaonkar G, Ngoh A, Meyer E, Scott RH and Kurian MA (2016) GABRB3 mutations: a new and emerging cause of early infantile epileptic encephalopathy. Dev Med Child Neurol 58:416-420.

Parent JM and Anderson SA (2015) Reprogramming patient-derived cells to study the epilepsies. Nat Neurosci 18:360-366.

Patel RR, Barbosa C, Brustovetsky T, Brustovetsky N, and Cummins TR (2016) Aberrant epilepsy-associated mutant Nav1.6 sodium channel activity can be targeted with cannabidiol. Brain 139:2164-2181.

Patino GA, Claes LRF, Lopez-Santiago LF, Slat EA, Dondeti RSR, Chen C, O'Malley HA, Gray CBB, Miyazaki H, Nukina N, et al. (2009) A functional null mutation of SCN1B in a patient with Dravet syndrome. J Neurosci 29:10764-10778.

Pena SDJ and Coimbra RLM (2015) Ataxia and myoclonic epilepsy due to a heterozygous new mutation in KCNA2: proposal for a new channelopathy. Clin Genet 87:e1-e3.

Perszyk RE, DiRaddo JO, Strong KL, Low C-M, Ogden KK, Khatri A, Vargish GA, Pelkey KA, Tricoire L, Liotta DC, et al. (2016) GluN2D-containing N-methyl-daspartate receptors mediate synaptic transmission in hippocampal interneurons and regulate interneuron activity. Mol Pharmacol 90:689-702.

Peters HC, Hu H, Pongs O, Storm JF, and Isbrandt D (2005) Conditional transgenic suppression of $\mathrm{M}$ channels in mouse brain reveals functions in neuronal excitability, resonance and behavior. Nat Neurosci 8:51-60.

Phillips HA, Favre I, Kirkpatrick M, Zuberi SM, Goudie D, Heron SE, Scheffer IE, Sutherland GR, Berkovic SF, Bertrand D, et al. (2001) CHRNB2 is the second acetylcholine receptor subunit associated with autosomal dominant nocturnal frontal lobe epilepsy. Am J Hum Genet 68:225-231.

Pierson TM, Yuan H, Marsh ED, Fuentes-Fajardo K, Adams DR, Markello T, Golas G, Simeonov DR, Holloman C, Tankovic A, et al.; PhD for the NISC Comparative Sequencing Program (2014) GRIN2A mutation and early-onset epileptic encephalopathy: personalized therapy with memantine. Ann Clin Transl Neurol 1 190-198.

Pietrobon D (2005) Function and dysfunction of synaptic calcium channels: insights from mouse models. Curr Opin Neurobiol 15:257-265.

Pirker S, Schwarzer C, Wieselthaler A, Sieghart W, and Sperk G (2000) GABA(A) receptors: immunocytochemical distribution of 13 subunits in the adult rat brain. Neuroscience 101:815-850.

Planells-Cases R, Caprini M, Zhang J, Rockenstein EM, Rivera RR, Murre C, Masliah E, and Montal M (2000) Neuronal death and perinatal lethality in voltage-gated sodium channel alpha(II)-deficient mice. Biophys $J$ 78:2878-2891. Platzer K, Yuan H, Schütz H, Winschel A, Chen W, Hu C, Kusumoto H, Heyne HO, Helbig KL, Tang S, et al. (2017) GRIN2B encephalopathy: novel findings on phenotype, variant clustering, functional consequences and treatment aspects. $J \mathrm{Med}$ Genet 54:460-470

Poduri A, Evrony GD, Cai X, and Walsh CA (2013) Somatic mutation, genomic variation, and neurological disease. Science 341:1237758.

Poirier K, Viot G, Lombardi L, Jauny C, Billuart P, and Bienvenu T (2017) Loss of function of KCNC1 is associated with intellectual disability without seizures. Eur $J$ Hum Genet 25:560-564.

Poolos NP, Migliore M, and Johnston D (2002) Pharmacological upregulation of h-channels reduces the excitability of pyramidal neuron dendrites. Nat Neurosci $\mathbf{5}$ : $767-774$

Powell KL, Cain SM, Ng C, Sirdesai S, David LS, Kyi M, Garcia E, Tyson JR, Reid CA, Bahlo M, et al. (2009) A Cav3.2 T-type calcium channel point mutation has splice-variant-specific effects on function and segregates with seizure expression in a polygenic rat model of absence epilepsy. J Neurosci 29:371-380.

Rajakulendran S, Schorge S, Kullmann DM, and Hanna MG (2007) Episodic ataxia type 1: a neuronal potassium channelopathy. Neurotherapeutics 4:258-266. 
Ramadan W, Patel N, Anazi S, Kentab AY, Bashiri FA, Hamad MH, Jad L, Salih MA, Alsaif H, Hashem M, et al. (2017) Confirming the recessive inheritance of SCN1B mutations in developmental epileptic encephalopathy. Clin Genet 92:327-331.

Redin C, Gérard B, Lauer J, Herenger Y, Muller J, Quartier A, Masurel-Paulet A, Willems M, Lesca G, El-Chehadeh S, et al. (2014) Efficient strategy for the molecular diagnosis of intellectual disability using targeted high-throughput sequencing. J Med Genet 51:724-736.

Reid CA, Berkovic SF, and Petrou S (2009) Mechanisms of human inherited epilepsies. Prog Neurobiol 87:41-57.

Reid CA, Kim T, Phillips AM, Low J, Berkovic SF, Luscher B, and Petrou S (2013) Multiple molecular mechanisms for a single GABAA mutation in epilepsy. Neurology 80:1003-1008.

Reid CA, Leaw B, Richards KL, Richardson R, Wimmer V, Yu C, Hill-Yardin EL, Lerche H, Scheffer IE, Berkovic SF, et al. (2014) Reduced dendritic arborization and hyperexcitability of pyramidal neurons in a Scn1b-based model of Dravet syndrome. Brain 137:1701-1715.

Reid CA, Phillips AM, and Petrou S (2012) HCN channelopathies: pathophysiology in genetic epilepsy and therapeutic implications. $B r$ J Pharmacol 165:49-56.

Reinson K, Õiglane-Shlik E, Talvik I, Vaher U, Õunapuu A, Ennok M, Teek R, Pajusalu S, Murumets Ü, Tomberg T, et al. (2016) Biallelic CACNA1A mutations cause early onset epileptic encephalopathy with progressive cerebral, cerebellar, and optic nerve atrophy. Am J Med Genet A 170:2173-2176.

Reutlinger C, Helbig I, Gawelczyk B, Subero JIM, Tönnies H, Muhle H, Finsterwalder K Vermeer S, Pfundt R, Sperner J, et al. (2010) Deletions in 16p13 including GRIN2A in patients with intellectual disability, various dysmorphic features, and seizure disorders of the rolandic region. Epilepsia 51:1870-1873.

Rivera C, Voipio J, Payne JA, Ruusuvuori E, Lahtinen H, Lamsa K, Pirvola U, Saarma M, and Kaila K (1999) The K+/Cl- co-transporter KCC2 renders GABA hyperpolarizing during neuronal maturation. Nature 397:251-255.

Roundtree HM, Simeone TA, Johnson C, Matthews SA, Samson KK, and Simeone KA (2016) Orexin receptor antagonism improves sleep and reduces seizures in Kcna1null mice. Sleep 39:357-368.

Rudy B and McBain CJ (2001) Kv3 channels: voltage-gated K+ channels designed for high-frequency repetitive firing. Trends Neurosci 24:517-526.

Rundfeldt C and Netzer R (2000) The novel anticonvulsant retigabine activates M-currents in Chinese hamster ovary-cells tranfected with human KCNQ2/3 subunits. Neurosci Lett 282:73-76.

Saitsu H, Akita T, Tohyama J, Goldberg-Stern H, Kobayashi Y, Cohen R, Kato M, Ohba C, Miyatake S, Tsurusaki Y, et al. (2015) De novo KCNB1 mutations in infantile epilepsy inhibit repetitive neuronal firing. Sci Rep 5:15199.

Sancar F and Czajkowski C (2004) A GABAA receptor mutation linked to human epilepsy (gamma2R43Q) impairs cell surface expression of alphabetagamma receptors. J Biol Chem 279:47034-47039.

Sanders SJ, He X, Willsey AJ, Ercan-Sencicek AG, Samocha KE, Cicek AE, Murtha MT, Bal VH, Bishop SL, Dong S, et al.; Autism Sequencing Consortium (2015) Insights into autism spectrum disorder genomic architecture and biology from 71 risk loci. Neuron 87:1215-1233.

Santi CM, Ferreira G, Yang B, Gazula V-R, Butler A, Wei A, Kaczmarek LK, and Salkoff L (2006) Opposite regulation of slick and slack K+ channels by neuromodulators. J Neurosci 26:5059-5068.

Sausbier M, Hu H, Arntz C, Feil S, Kamm S, Adelsberger H, Sausbier U, Sailer CA, Feil R Hofmann F, et al. (2004) Cerebellar ataxia and Purkinje cell dysfunction caused by Ca2 +-activated K+ channel deficiency. Proc Natl Acad Sci USA 101:9474-9478.

Savelieva I and Camm AJ (2006) Novel If current inhibitor ivabradine: safety considerations. Adv Cardiol 43:79-96.

Schattling B, Fazeli W, Engeland B, Liu Y, Lerche H, Isbrandt D, and Friese MA (2016) Activity of NaV1.2 promotes neurodegeneration in an animal model of multiple sclerosis. JCI Insight 1:e89810.

Scheffer IE (2012) Diagnosis and long-term course of Dravet syndrome. Eur J Paediatr Neurol 16 (Suppl 1):S5-S8.

Scheffer IE, Berkovic S, Capovilla G, Connolly MB, French J, Guilhoto L, Hirsch E, Jain S, Mathern GW, Moshé SL, et al. (2017) ILAE classification of the epilepsies: position paper of the ILAE commission for classification and terminology. Epilepsia 58:512-521.

Scheffer IE and Berkovic SF (1997) Generalized epilepsy with febrile seizures plus: a genetic disorder with heterogeneous clinical phenotypes. Brain 120:479-490.

Scheffer IE, Bhatia KP, Lopes-Cendes I, Fish DR, Marsden CD, Andermann F, Andermann E, Desbiens R, Cendes F, Manson JI, et al. (1994) Autosomal dominant frontal epilepsy misdiagnosed as sleep disorder. Lancet 343:515-517.

Scheffer IE, Harkin LA, Grinton BE, Dibbens LM, Turner SJ, Zielinski MA, Xu R, Jackson G, Adams J, Connellan M, et al. (2007) Temporal lobe epilepsy and GEFS+ phenotypes associated with SCN1B mutations. Brain 130:100-109.

Scheffer IE, Phillips HA, O’Brien CE, Saling MM, Wrennall JA, Wallace RH, Mulley JC, and Berkovic SF (1998) Familial partial epilepsy with variable foci: a new partial epilepsy syndrome with suggestion of linkage to chromosome 2. Ann Neurol 44:890-899.

Scheffer IE, Zhang Y-H, Jansen FE, and Dibbens L (2009) Dravet syndrome or genetic (generalized) epilepsy with febrile seizures plus? Brain Dev 31:394-400.

Schneggenburger R (1996) Simultaneous measurement of Ca2+ influx and reversal potentials in recombinant N-methyl-D-aspartate receptor channels. Biophys $J$ 70: $2165-2174$

Schoonjans A, Paelinck BP, Marchau F, Gunning B, Gammaitoni A, Galer BS, Lagae L, and Ceulemans B (2017) Low-dose fenfluramine significantly reduces seizure frequency in Dravet syndrome: a prospective study of a new cohort of patients. Eur J Neurol 24:309-314.

Schroeder BC, Kubisch C, Stein V, and Jentsch TJ (1998) Moderate loss of function of cyclicAMP-modulated KCNQ2/KCNQ3 K+ channels causes epilepsy. Nature 396:687-690.

Schwarz JR, Glassmeier G, Cooper EC, Kao T-C, Nodera H, Tabuena D, Kaji R, and Bostock H (2006) KCNQ channels mediate IKs, a slow K+ current regulating excitability in the rat node of Ranvier. $J$ Physiol 573:17-34.
Serraz B, Grand T, and Paoletti P (2016) Altered zinc sensitivity of NMDA receptors harboring clinically-relevant mutations. Neuropharmacology 109:196-204.

Shen D, Hernandez CC, Shen W, Hu N, Poduri A, Shiedley B, Rotenberg A Datta AN, Leiz S, Patzer S, et al. (2017) De novo GABRG2 mutations associated with epileptic encephalopathies. Brain 140:49-67.

Shiba Y, Mori F, Yamada J, Migita K, Nikaido Y, Wakabayashi K, Kaneko S, Okada M, Hirose S, and Ueno S (2015) Spontaneous epileptic seizures in transgenic rats harboring a human ADNFLE missense mutation in the $\beta 2$-subunit of the nicotinic acetylcholine receptor. Neurosci Res 100:46-54.

Shieh CC, Coghlan M, Sullivan JP, and Gopalakrishnan M (2000) Potassium channels: molecular defects, diseases, and therapeutic opportunities. Pharmacol Rev 52:557-594.

Shu Y, Hasenstaub A, Duque A, Yu Y, and McCormick DA (2006) Modulation of intracortical synaptic potentials by presynaptic somatic membrane potential. $\mathrm{Na}$ ture 441:761-765.

Simeone KA, Matthews SA, Rho JM, and Simeone TA (2016) Ketogenic diet treatment increases longevity in Kcna1-null mice, a model of sudden unexpected death in epilepsy. Epilepsia 57:e178-e182.

Simeone TA, Simeone KA, Samson KK, Kim DY, and Rho JM (2013) Loss of the Kv1.1 potassium channel promotes pathologic sharp waves and high frequency oscillations in in vitro hippocampal slices. Neurobiol Dis 54:68-81.

Simms BA and Zamponi GW (2014) Neuronal voltage-gated calcium channels: structure, function, and dysfunction. Neuron 82:24-45.

Singh NA, Charlier C, Stauffer D, DuPont BR, Leach RJ, Melis R, Ronen GM, Bjerre I, Quattlebaum T, Murphy JV, et al. (1998) A novel potassium channel gene, KCNQ2, is mutated in an inherited epilepsy of newborns. Nat Genet 18:25-29.

Singh NA, Otto JF, Dahle EJ, Pappas C, Leslie JD, Vilaythong A, Noebels JL, White HS, Wilcox KS, and Leppert MF (2008) Mouse models of human KCNQ2 and KCNQ3 mutations for benign familial neonatal convulsions show seizures and neuronal plasticity without synaptic reorganization. J Physiol 586:3405-3423.

Singh R, Scheffer IE, Crossland K, and Berkovic SF (1999) Generalized epilepsy with febrile seizures plus: a common childhood-onset genetic epilepsy syndrome. Ann Neurol 45:75-81.

Smart SL, Lopantsev V, Zhang CL, Robbins CA, Wang H, Chiu SY, Schwartzkroin PA, Messing A, and Tempel BL (1998) Deletion of the K(V)1.1 potassium channel causes epilepsy in mice. Neuron 20:809-819.

Smart TG and Paoletti P (2012) Synaptic neurotransmitter-gated receptors. Cold Spring Harb Perspect Biol DOI: 10.1101/cshperspect.a009662 [published ahead of print].

Smigiel R, Kostrzewa G, Kosinska J, Pollak A, Stawinski P, Szmida E, Bloch M, Szymanska K, Karpinski P, Sasiadek MM, et al. (2016) Further evidence for GRIN2B mutation as the cause of severe epileptic encephalopathy. Am J Med Genet A 170:3265-3270.

Sobolevsky AI, Rosconi MP, and Gouaux E (2009) X-ray structure, symmetry and mechanism of an AMPA-subtype glutamate receptor. Nature 462:745-756.

Son J-H and Winzer-Serhan UH (2006) Postnatal expression of alpha2 nicotinic acetylcholine receptor subunit mRNA in developing cortex and hippocampus. $J$ Chem Neuroanat 32:179-190.

Song I, Kim D, Choi S, Sun M, Kim Y, and Shin H-S (2004) Role of the alpha1G T-type calcium channel in spontaneous absence seizures in mutant mice. J Neurosci 24:5249-5257.

Spampanato J, Aradi I, Soltesz I, and Goldin AL (2004a) Increased neuronal firing in computer simulations of sodium channel mutations that cause generalized epilepsy with febrile seizures plus. $J$ Neurophysiol 91:2040-2050.

Spampanato J, Escayg A, Meisler MH, and Goldin AL (2001) Functional effects of two voltage-gated sodium channel mutations that cause generalized epilepsy with febrile seizures plus type 2. J Neurosci 21:7481-7490.

Spampanato J, Kearney JA, de Haan G, McEwen DP, Escayg A, Aradi I, MacDonald BT, Levin SI, Soltesz I, Benna P, et al. (2004b) A novel epilepsy mutation in the sodium channel SCN1A identifies a cytoplasmic domain for beta subunit in teraction. $J$ Neurosci 24:10022-10034.

Speca DJ, Ogata G, Mandikian D, Bishop HI, Wiler SW, Eum K, Wenzel HJ, Doisy ET, Matt L, Campi KL, et al. (2014) Deletion of the Kv2.1 delayed rectifier potassium channel leads to neuronal and behavioral hyperexcitability. Genes Brain Behav 13:394-408.

Sprissler RS, Wagnon JL, Bunton-Stasyshyn RK, Meisler MH, and Hammer MF (2017) Altered gene expression profile in a mouse model of SCN8A encephalopathy. Exp Neurol 288:134-141.

Srivastava S, Cohen J, Pevsner J, Aradhya S, McKnight D, Butler E, Johnston M, and Fatemi A (2014) A novel variant in GABRB2 associated with intellectual disability and epilepsy. Am J Med Genet A 164A:2914-2921.

Stafstrom CE (2007) Persistent sodium current and its role in epilepsy. Epilepsy Curr 7:15-22.

Standaert DG, Landwehrmeyer GB, Kerner JA, Penney JB Jr, and Young AB (1996) Expression of NMDAR2D glutamate receptor subunit mRNA in neurochemically identified interneurons in the rat neostriatum, neocortex and hippocampus. Brain Res Mol Brain Res 42:89-102.

Staropoli JF, Karaa A, Lim ET, Kirby A, Elbalalesy N, Romansky SG, Leydiker KB Coppel SH, Barone R, Xin W, et al. (2012) A homozygous mutation in KCTD7 links neuronal ceroid lipofuscinosis to the ubiquitin-proteasome system. Am J Hum Genet 91:202-208.

Steffens M, Leu C, Ruppert AK, Zara F, Striano P, Robbiano A, Capovilla G, Tinuper P, Gambardella A, Bianchi A, et al.; EPICURE Consortium; ; EMINet Consortium (2012) Genome-wide association analysis of genetic generalized epilepsies implicates susceptibility loci at 1q43, 2p16.1, 2q22.3 and 17q21.32. Hum Mol Genet 21: $5359-5372$

Steinlein OK, Magnusson A, Stoodt J, Bertrand S, Weiland S, Berkovic SF, Nakken KO, Propping P, and Bertrand D (1997) An insertion mutation of the CHRNA4 gene in a family with autosomal dominant nocturnal frontal lobe epilepsy. Hum Mol Genet 6:943-947. 
Steinlein OK, Mulley JC, Propping P, Wallace RH, Phillips HA, Sutherland GR, Scheffer IE, and Berkovic SF (1995) A missense mutation in the neuronal nicotinic acetylcholine receptor alpha 4 subunit is associated with autosomal dominant nocturnal frontal lobe epilepsy. Nat Genet 11:201-203.

Strauss U, Kole MHP, Bräuer AU, Pahnke J, Bajorat R, Rolfs A, Nitsch R, and Deisz RA (2004) An impaired neocortical Ih is associated with enhanced excitability and absence epilepsy. Eur J Neurosci 19:3048-3058.

Strehlow V, Heyne H, and Lemke J (2015) The spectrum of GRIN2A-associated disorders. Epileptologie 32:147-151.

Suls A, Claeys KG, Goossens D, Harding B, Van Luijk R, Scheers S, Deprez L, Audenaert D, Van Dyck T, Beeckmans S, et al. (2006) Microdeletions involving the SCN1A gene may be common in SCN1A-mutation-negative SMEI patients. Hum Mutat 27:914-920.

Sun Y, Paşca SP, Portmann T, Goold C, Worringer KA, Guan W, Chan KC, Gai H, Vogt D, Chen Y-JJ, et al. (2016) A deleterious Nav1.1 mutation selectively impairs telencephalic inhibitory neurons derived from Dravet syndrome patients. eLife DOI: 10.7554/eLife.13073 [published ahead of print].

Surges R, Freiman TM, and Feuerstein TJ (2003) Gabapentin increases the hyperpolarization-activated cation current Ih in rat CA1 pyramidal cells. Epilepsia 44:150-156.

Sutor B and Zolles G (2001) Neuronal nicotinic acetylcholine receptors and autosomal dominant nocturnal frontal lobe epilepsy: a critical review. Pflugers Arch 442: 642-651.

Syrbe S, Hedrich UBS, Riesch E, Djémié T, Müller S, Møller RS, Maher B, Hernandez-Hernandez L, Synofzik M, Caglayan HS, et al.; EuroEPINOMICS RES Consortium (2015) De novo loss- or gain-of-function mutations in KCNA2 cause epileptic encephalopathy. Nat Genet 47:393-399.

Takahashi S, Yamamoto S, Okayama A, Araki A, Saitsu H, Matsumoto N, and Azuma H (2015) Electroclinical features of epileptic encephalopathy caused by SCN8A mutation. Pediatr Int 57:758-762.

Tan HO, Reid CA, Single FN, Davies PJ, Chiu C, Murphy S, Clarke AL, Dibbens L, Krestel H, Mulley JC, et al. (2007) Reduced cortical inhibition in a mouse model of familial childhood absence epilepsy. Proc Natl Acad Sci USA 104:17536-17541.

Tanaka M, Delorey TM, Delgado-Escueta A, and Olsen RW (2012) GABRB3, epilepsy, and neurodevelopment, in Jasper's Basic Mechanisms of the Epilepsies (Noebels JL, Avoli M, Rogawski MA, Olsen RW, Delgado-Escueta AV eds) pp 1-18, National Center for Biotechnology Information, Bethesda, MD.

Teper Y, Whyte D, Cahir E, Lester HA, Grady SR, Marks MJ, Cohen BN, Fonck C, McClure-Begley T, McIntosh JM, et al. (2007) Nicotine-induced dystonic arousa complex in a mouse line harboring a human autosomal-dominant nocturnal frontal lobe epilepsy mutation. J Neurosci 27:10128-10142.

Thelin J, Halje P, Nielsen J, Didriksen M, Petersson P, and Bastlund JF (2017) The translationally relevant mouse model of the $15 \mathrm{q} 13.3$ microdeletion syndrome reveals deficits in neuronal spike firing matching clinical neurophysiological biomarkers seen in schizophrenia. Acta Physiol (Oxf) 220:124-136.

Thiffault I, Speca DJ, Austin DC, Cobb MM, Eum KS, Safina NP, Grote L, Farrow EG, Miller N, Soden S, et al. (2015) A novel epileptic encephalopathy mutation in KCNB1 disrupts Kv2.1 ion selectivity, expression, and localization. J Gen Physiol 146:399-410

Thomas EA, Xu R, and Petrou S (2007) Computational analysis of the R85C and $\mathrm{R} 85 \mathrm{H}$ epilepsy mutations in $\mathrm{Na}+$ channel beta1 subunits. Neuroscience 147: 1034-1046.

Thomas RH and Berkovic SF (2014) The hidden genetics of epilepsy: a clinically important new paradigm. Nat Rev Neurol 10:283-292.

Tompson DJ, Buraglio M, Andrews SM, and Wheless JW (2016) Adolescent clinical development of ezogabine/retigabine as adjunctive therapy for partial-onset seizures: pharmacokinetics and tolerability. J Pediatr Pharmacol Ther 21:404-412.

Torkamani A, Bersell K, Jorge BS, Bjork RL Jr, Friedman JR, Bloss CS, Cohen J, Gupta S, Naidu S, Vanoye CG, et al. (2014) De novo KCNB1 mutations in epileptic encephalopathy. Ann Neurol 76:529-540.

Traynelis SF, Wollmuth LP, McBain CJ, Menniti FS, Vance KM, Ogden KK, Hansen KB, Yuan H, Myers SJ, and Dingledine R (2010) Glutamate receptor ion channels: structure, regulation, and function. Pharmacol Rev 62:405-496.

Trimmer JS (2015) Subcellular localization of K+ channels in mammalian brain neurons: remarkable precision in the midst of extraordinary complexity. Neuron 85:238-256.

Trivisano M, Terracciano A, Milano T, Cappelletti S, Pietrafusa N, Bertini ES, Vigevano F, and Specchio N (2015) Mutation of CHRNA2 in a family with benign familial infantile seizures: potential role of nicotinic acetylcholine receptor in various phenotypes of epilepsy. Epilepsia 56:e53-e57.

Turner SJ, Mayes AK, Verhoeven A, Mandelstam SA, Morgan AT, and Scheffer IE (2015) GRIN2A: an aptly named gene for speech dysfunction. Neurology $\mathbf{8 4}$ 586-593.

Vaher U, Nõukas M, Nikopensius T, Kals M, Annilo T, Nelis M, Ounap K, Reimand T, Talvik I, Ilves P, et al. (2014) De novo SCN8A mutation identified by wholeexome sequencing in a boy with neonatal epileptic encephalopathy, multiple congenital anomalies, and movement disorders. J Child Neurol 29:NP202-NP206.

Van Bogaert P, Azizieh R, Désir J, Aeby A, De Meirleir L, Laes J-F, Christiaens F, and Abramowicz MJ (2007) Mutation of a potassium channel-related gene in progressive myoclonic epilepsy. Ann Neurol 61:579-586.

van Brederode JF, Rho JM, Cerne R, Tempel BL, and Spain WJ (2001) Evidence of altered inhibition in layer $\mathrm{V}$ pyramidal neurons from neocortex of Kcna1-null mice. Neuroscience 103:921-929.

Van Wart A, Trimmer JS, and Matthews G (2007) Polarized distribution of ion channels within microdomains of the axon initial segment. J Comp Neurol 500: 339-352.

Veeramah KR, O’Brien JE, Meisler MH, Cheng X, Dib-Hajj SD, Waxman SG, Talwar D, Girirajan S, Eichler EE, Restifo LL, et al. (2012) De novo pathogenic SCN8A mutation identified by whole-genome sequencing of a family quartet affected by infantile epileptic encephalopathy and SUDEP. Am J Hum Genet 90:502-510.
Verma-Ahuja S, Evans MS, and Pencek TL (1995) Evidence for decreased calcium dependent potassium conductance in hippocampal CA3 neurons of genetically epilepsy-prone rats. Epilepsy Res 22:137-144.

Vitko I, Chen Y, Arias JM, Shen Y, Wu X-R, and Perez-Reyes E (2005) Functional characterization and neuronal modeling of the effects of childhood absence epilepsy variants of CACNA1H, a T-type calcium channel. J Neurosci 25: 4844-4855.

von Engelhardt J, Bocklisch C, Tönges L, Herb A, Mishina M, and Monyer H (2015) GluN2D-containing NMDA receptors-mediate synaptic currents in hippocampal interneurons and pyramidal cells in juvenile mice. Front Cell Neurosci 9:95.

Wagnon JL, Barker BS, Hounshell JA, Haaxma CA, Shealy A, Moss T, Parikh S, Messer RD, Patel MK, and Meisler MH (2015a) Pathogenic mechanism of recurrent mutations of SCN8A in epileptic encephalopathy. Ann Clin Transl Neurol 3:114-123

Wagnon JL, Korn MJ, Parent R, Tarpey TA, Jones JM, Hammer MF, Murphy GG, Parent JM, and Meisler MH (2015b) Convulsive seizures and SUDEP in a mouse model of SCN8A epileptic encephalopathy. Hum Mol Genet 24:506-515.

Wallace RH, Marini C, Petrou S, Harkin LA, Bowser DN, Panchal RG, Williams DA, Sutherland GR, Mulley JC, Scheffer IE, et al. (2001) Mutant GABA(A) receptor gamma2-subunit in childhood absence epilepsy and febrile seizures. Nat Genet 28: $49-52$.

Wallace RH, Wang DW, Singh R, Scheffer IE, George AL Jr, Phillips HA, Saar K, Reis A, Johnson EW, Sutherland GR, et al. (1998) Febrile seizures and generalized epilepsy associated with a mutation in the Na+-channel beta1 subunit gene SCN1B. Nat Genet 19:366-370.

Wang H, Kunkel DD, Schwartzkroin PA, and Tempel BL (1994) Localization of Kv1.1 and $\mathrm{Kv} 1.2$, two $\mathrm{K}$ channel proteins, to synaptic terminals, somata, and dendrites in the mouse brain. $J$ Neurosci 14:4588-4599.

Wang T, Guo H, Xiong B, Stessman HAF, Wu H, Coe BP, Turner TN, Liu Y, Zhao W, Hoekzema K, et al. (2016) De novo genic mutations among a Chinese autism spectrum disorder cohort. Nat Commun 7:13316.

Warner TA, Shen W, Huang X, Liu Z, Macdonald RL, and Kang J-Q (2016) Differential molecular and behavioural alterations in mouse models of GABRG2 haploinsufficiency versus dominant negative mutations associated with human epilepsy. Hum Mol Genet 25:3192-3207.

Watanabe Y, Iwamoto T, Shigekawa M, and Kimura J (2002) Inhibitory effect of aprindine on $\mathrm{Na}+/ \mathrm{Ca} 2+$ exchange current in guinea-pig cardiac ventricular myocytes. Br J Pharmacol 136:361-366.

Watanabe $\mathrm{Y}$ and Kimura $\mathrm{J}(2000)$ Inhibitory effect of amiodarone on $\mathrm{Na}(+) / \mathrm{Ca}(2+)$ exchange current in guinea-pig cardiac myocytes. $\mathrm{Br} J$ Pharmacol 131:80-84.

Watanabe Y and Kimura J (2001) Blocking effect of bepridil on $\mathrm{Na}+\mathrm{Ca} 2+$ exchange current in guinea pig cardiac ventricular myocytes. Jpn $J$ Pharmacol 85:370-375.

Weber YG, Geiger J, Kämpchen K, Landwehrmeyer B, Sommer C, and Lerche H (2006) Immunohistochemical analysis of KCNQ2 potassium channels in adult and developing mouse brain. Brain Res 1077:1-6.

Weckhuysen S, Ivanovic V, Hendrickx R, Van Coster R, Hjalgrim H, Møller RS, Grønborg S, Schoonjans A-S, Ceulemans B, Heavin SB, et al.; KCNQ2 Study Group (2013) Extending the KCNQ2 encephalopathy spectrum: clinical and neuroimaging findings in 17 patients. Neurology 81:1697-1703.

Weckhuysen S, Mandelstam S, Suls A, Audenaert D, Deconinck T, Claes LRF, Deprez L, Smets K, Hristova D, Yordanova I, et al. (2012) KCNQ2 encephalopathy: emerging phenotype of a neonatal epileptic encephalopathy. Ann Neurol 71:15-25.

Wenzel HJ, Vacher H, Clark E, Trimmer JS, Lee AL, Sapolsky RM, Tempel BL, and Schwartzkroin PA (2007) Structural consequences of Kcna1 gene deletion and transfer in the mouse hippocampus. Epilepsia 48:2023-2046.

Westenbroek RE, Merrick DK, and Catterall WA (1989) Differential subcellular localization of the RI and RII Na+ channel subtypes in central neurons. Neuron 3: 695-704

Wilmshurst JM, Appleton DB, and Grattan-Smith PJ (2000) Migrating partial seizures in infancy: two new cases. $J$ Child Neurol 15:717-722.

Wimmer VC, Harty RC, Richards KL, Phillips AM, Miyazaki H, Nukina N, and Petrou S (2015) Sodium channel $\beta 1$ subunit localizes to axon initial segments of excitatory and inhibitory neurons and shows regional heterogeneity in mouse brain. J Comp Neurol 523:814-830.

Wimmer VC, Reid CA, Mitchell S, Richards KL, Scaf BB, Leaw BT, Hill EL, Royeck M, Horstmann M-T, Cromer BA, et al. (2010) Axon initial segment dysfunction in a mouse model of genetic epilepsy with febrile seizures plus. J Clin Invest 120:2661-2671.

Wolff M, Johannesen KM, Hedrich UBS, Masnada S, Rubboli G, Gardella E, Lesca G, Ville D, Milh M, Villard L, et al. (2017) Genetic and phenotypic heterogeneity suggest therapeutic implications in SCN2A-related disorders. Brain [published ahead of print].

Wright S, Wallace E, Hwang Y, and Maganti R (2016) Seizure phenotypes, periodicity, and sleep-wake pattern of seizures in Kcna-1 null mice. Epilepsy Behav 55: 24-29.

Xie G, Harrison J, Clapcote SJ, Huang Y, Zhang J-Y, Wang L-Y, and Roder JC (2010) A new Kv1.2 channelopathy underlying cerebellar ataxia. J Biol Chem 285:32160-32173.

Xu R, Thomas EA, Gazina EV, Richards KL, Quick M, Wallace RH, Harkin LA, Heron SE, Berkovic SF, Scheffer IE, et al. (2007) Generalized epilepsy with febrile seizures plus-associated sodium channel beta1 subunit mutations severely reduce beta subunit-mediated modulation of sodium channel function. Neuroscience 148:164-174.

Yamakawa T, Watanabe Y, Watanabe H, and Kimura J (2012) Inhibitory effect of cibenzoline on $\mathrm{Na}+\mathrm{Ca} 2+$ exchange current in guinea-pig cardiac ventricular myocytes. J Pharmacol Sci 120:59-62.

Yang B, Gribkoff VK, Pan J, Damagnez V, Dworetzky SI, Boissard CG, Bhattacharjee A, Yan Y, Sigworth FJ, and Kaczmarek LK (2006) Pharmacological activation and inhibition of Slack (Slo2.2) channels. Neuropharmacology 51:896-906.

Yu FH, Mantegazza M, Westenbroek RE, Robbins CA, Kalume F, Burton KA, Spain WJ, McKnight GS, Scheuer T, and Catterall WA (2006) Reduced sodium current in 
GABAergic interneurons in a mouse model of severe myoclonic epilepsy in infancy. Nat Neurosci 9:1142-1149.

Yu J, Wu G, Yuen P-W, Villemure E, Schwarz J, Ly C, Sellers B, and Volgraf M (2015) inventors. Thiazolopyrimidinones as Modulators of NMDA Receptor Activity. U.S. patent WO2015052226 A1. 2015 Apr 16.

Yu M, Liu SL, Sun PB, Pan H, Tian CL, and Zhang LH (2016) Peptide toxin and small-molecule blockers of BK channels. Acta Pharmacol Sin 37: $56-66$.

Zamponi GW (2016) Targeting voltage-gated calcium channels in neurological and psychiatric diseases. Nat Rev Drug Discov 15:19-34.

Zehavi Y, Mandel H, Zehavi A, Rashid MA, Straussberg R, Jabur B, Shaag A, Elpeleg O, and Spiegel R (2017) De novo GRIN1 mutations: an emerging cause of severe early infantile encephalopathy. Eur J Med Genet 60:317-320.
Zhang Y, Kong W, Gao Y, Liu X, Gao K, Xie H, Wu Y, Zhang Y, Wang J, Gao F, et al. (2015a) Gene mutation analysis in 253 Chinese children with unexplained epilepsy and intellectual/developmental disabilities. PLoS One 10:e0141782.

Zhang Z-B, Tian M-Q, Gao K, Jiang Y-W, and Wu Y (2015b) De novo KCNMA1 mutations in children with early-onset paroxysmal dyskinesia and developmental delay. Mov Disord 30:1290-1292

Zhu X, Petrovski S, Xie P, Ruzzo EK, Lu Y-F, McSweeney KM, Ben-Zeev B, Nissenkorn A, Anikster Y, Oz-Levi D, et al. (2015) Whole-exome sequencing in undiagnosed genetic diseases: interpreting 119 trios. Genet Med 17:774-781.

Zuberi SM, Eunson LH, Spauschus A, De Silva R, Tolmie J, Wood NW, McWilliam RC, Stephenson JB, Kullmann DM, and Hanna MG (1999) A novel mutation in the human voltage-gated potassium channel gene (Kv1.1) associates with episodic ataxia type 1 and sometimes with partial epilepsy. Brain 122:817-825. 